\title{
IN VITRO SCREENING OF CRUDE EXTRACTS AND PURE METABOLITES OBTAINED FROM MARINE INVERTEBRATES FOR THE TREATMENT OF BREAST CANCER
}

$$
\text { by }
$$

JOHN STINGL

B.Sc. (Biochemistry), University of British Columbia

A THESIS SUBMITTED IN PARTIAL FULFILLMENT OF THE REQUIREMENTS FOR THE DEGREE OF MASTER OF SCIENCE in

THE FACULTY OF GRADUATE STUDIES (DEPARTMENT OF ANATOMY)

We accept this thesis as conforming to the required standard

THE UNIVERSITY OF BRITISH COLUMBIA NOVEMBER， 1992

C)John stingl, 1992 
In presenting this thesis in partial fulfilment of the requirements for an advanced degree at the University of British Columbia, I agree that the Library shall make it freely available for reference and study. I further agree that permission for extensive copying of this thesis for scholarly purposes may be granted by the head of my department or by his or her representatives. It is understood that copying or publication of this thesis for financial gain shall not be allowed without my written permission.

(Signature)

Department of ANATOMY

The University of British Columbia Vancouver, Canada

Date JANVARY 11,1993 


\section{THESIS ABSTRACT}

Fifteen samples of crude extracts and pure metabolites obtained from marine invertebrates collected from the offshore waters of British Columbia, Papua New Guinea and Sri Lanka had previously been shown to exert cytotoxic activity in the in vitro $\mathrm{L} 1210$ leukemic bioassay. For this thesis, these samples were screened for in vitro cytotoxic activity against the drug-sensitive breast tumor cell lines MCF-7, T-47D, 2R-75-1 and MDA-MB-231; the multidrugresistant and P-glycoprotein (Pgp)-positive breast tumor cell lines MCF-7 $\mathrm{Ad}^{\mathrm{r}}$ and $\mathrm{MDA}-\mathrm{A1}{ }^{\mathrm{r}}$; and normal and malignant human breast epithelial cells (HBEC) in primary culture. Eight samples exhibited significant [drug concentration resulting in a 50\% decrease in cell growth as compared with controls $\left.\left(E D_{50}\right),<25 \mu \mathrm{g} / \mathrm{ml}\right]$ dose-dependent cytotoxicity against the drug-sensitive cell lines; the $\mathrm{ED}_{50}$ values were as low as $0.004 \mu \mathrm{g} / \mathrm{ml}$. Five of the 8 samples exhibited significant cytotoxicity against the multidrug-resistant cell lines; the $\mathrm{ED}_{50}$ values were as low as $0.0006 \mu \mathrm{g} / \mathrm{ml}$. Incubation of the MCF-7 $\mathrm{Ad}^{\mathrm{r}}$ cells with varying concentrations of compounds in the presence of Adriamycin demonstrated that none of the compounds tested appeared to interfere with Pgp function. Results obtained using HBEC in primary culture showed a wide range of chemosensitivities for a given drug against tissue taken from different patients, demonstrating the uniqueness of the response of different individuals to chemotherapy. 
THESIS ABSTRACT $\ldots \ldots \ldots \ldots \ldots \ldots \ldots \ldots \ldots \ldots \ldots \ldots \ldots \ldots \ldots \ldots \ldots \ldots$

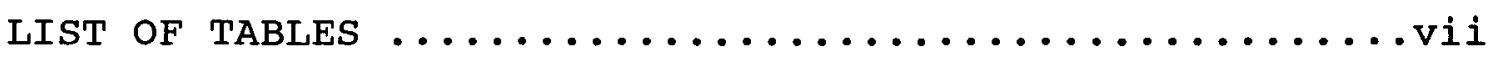

LIST OF ILLUSTRATIONS $\ldots \ldots \ldots \ldots \ldots \ldots \ldots \ldots \ldots \ldots \ldots \ldots \ldots \ldots$

LIST OF ABBREVIATIONS $\ldots \ldots \ldots \ldots \ldots \ldots \ldots \ldots \ldots \ldots \ldots \ldots \ldots \ldots \ldots$

ACKNOWLEDGMENTS $\ldots \ldots \ldots \ldots \ldots \ldots \ldots \ldots \ldots \ldots \ldots \ldots \ldots \ldots \ldots \ldots \ldots \ldots$

CHAPTER 1. INTRODUCTION $\ldots \ldots \ldots \ldots \ldots \ldots \ldots \ldots \ldots \ldots \ldots$

1. Treatment of Cancer with Chemotherapy $\ldots \ldots \ldots \ldots \ldots 1$

1a. Treatment of Breast Cancer with Chemotherapy $\ldots \ldots \ldots \ldots \ldots \ldots \ldots \ldots \ldots \ldots \ldots$

2. The Basis of Chemotherapy $\ldots \ldots \ldots \ldots \ldots \ldots \ldots \ldots$

3. The Kinetics of Tumor Growth $\ldots \ldots \ldots \ldots \ldots \ldots \ldots$

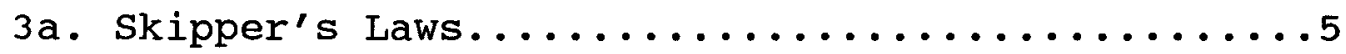

3b. The Goldie-Coldman Model $\ldots \ldots \ldots \ldots \ldots \ldots \ldots$

3c. Gompertzian Growth and the Norton-Simon

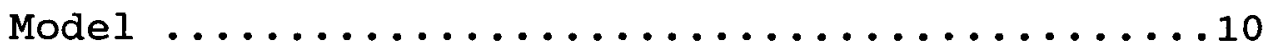

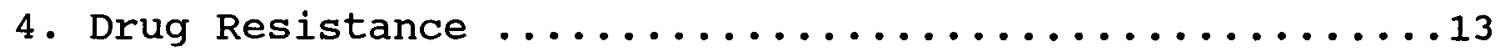

4a. P-Glycoprotein and Multidrug Resistance ......14

5. Historical Background of Anticancer Drug

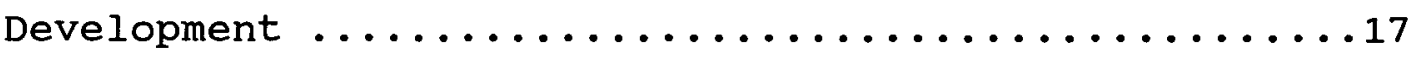

5a. Preclinical Drug Discovery and Development ....17

5b. Clinical Evaluation of New Anticancer Drugs ...21

5c. Evaluation of the National Cancer Institute's Drug Discovery and Development Program .......23

6. Current Status of the National Cancer Institute's 
Drug Discovery and Development Program ..........27

7. Methods to Assess Chemosensitivity $\ldots \ldots \ldots \ldots \ldots \ldots 32$

8. Predictive Value of Chemosensitivity Assays .......37

9. Natural Products as a Source of New Anticancer

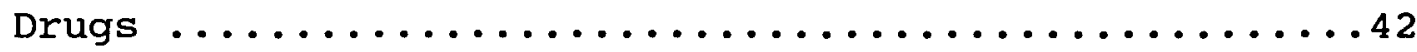

10. Thesis Objectives $\ldots \ldots \ldots \ldots \ldots \ldots \ldots \ldots \ldots \ldots \ldots \ldots$

CHAPTER 2. MATERIALS AND METHODS

1. Isolation and Purification of Compounds ..........49

2. Cell Line Culture ........................

3. Human Breast Epithelial Cells in Primary

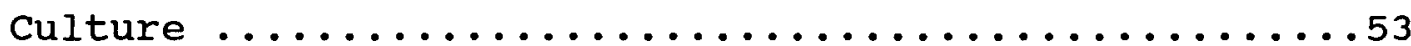

4. Compound-Testing Protocol ..................56

5. Preparation of Standard Curves for each Cell Line ...57

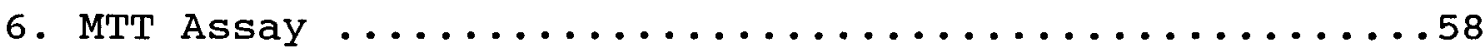

6a. Preparation of MTT $\ldots \ldots \ldots \ldots \ldots \ldots \ldots \ldots \ldots$

6b. MTT Assay Protocol $\ldots \ldots \ldots \ldots \ldots \ldots \ldots \ldots \ldots$

6c. Selection of Solvent for the MTT Assay:

i. With No Removal of MTT Supernatant Prior to Solvent Addition ............61

ii. With Removal of MTT Supernatant

Prior to Solvent Addition ............62

6d. Selection of Optimal MTT Concentration ......663

6e. Selection of Optimal MTT Incubation Time .....63

$6 \mathrm{f}$. Removal of MTT Supernatant .............64

$6 \mathrm{~g}$. Absorbance Limit of the MTT Assay ..........65

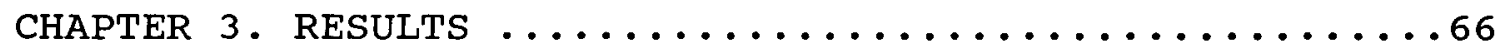

1. Optimization of MTT Assay Parameters $\ldots \ldots \ldots \ldots \ldots 66$ 
1a. Selection of Solvent for the MTT Assay ......66 1b. Selection of optimal MTT concentration .......70 1c. Selection of optimal MTT Incubation Time .....72 1d. Removal of MTT Supernatant ...............75

1e. Absorbance Limit of the MTT Assay ............75

2. Compounds Screened Against Drug-Sensitive

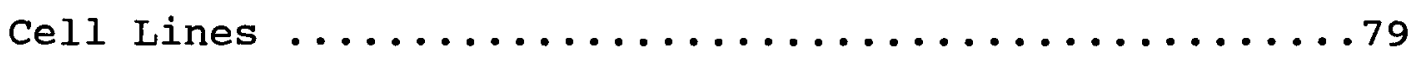

3. Compounds Screened Against Drug-Resistant Cell Lines $\ldots \ldots \ldots \ldots \ldots \ldots \ldots \ldots \ldots \ldots \ldots \ldots \ldots \ldots \ldots . \ldots \ldots \ldots$

4. Compounds Screened Against $\mathrm{MCF}-7 \mathrm{Ad}^{\mathrm{r}}$ Cells in the Presence of Adriamycin ................. 86

5. Compounds Screened Against Normal and Malignant

Human Breast Epithelial Cells in Primary Culture ....88 CHAPTER 4. DISCUSSION $\ldots \ldots \ldots \ldots \ldots \ldots \ldots \ldots \ldots \ldots \ldots \ldots \ldots \ldots . \ldots \ldots$

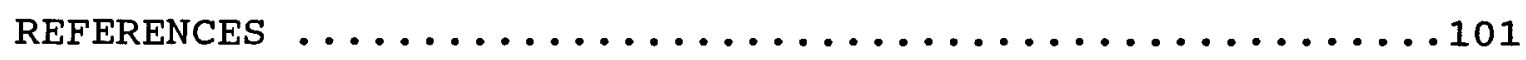
APPENDIX 1: Growth Medium for the MCF-7, T-47D and ZR-75-1 Cell Lines for Routine Passaging ...116 APPENDIX 2: Growth Medium for the MDA-MB-231 cell Line for Routine Passaging .............116 APPENDIX 3: Growth Medium for the MCF-7 $\mathrm{Ad}^{\mathrm{r}} \mathrm{Cell}$ Line for Routine Passaging .............116 APPENDIX 4: Growth Medium for the MDA-A1 ${ }^{\mathrm{r}}$ Cell Line for Routine Passaging .................116

APPENDIX 5: Preparation of Saline-Trypsin-Versene .....116 APPENDIX 6: Preparation of Calcium and Magnesium-Free Phosphate-Buffered Saline ...............117 
APPENDIX 7: Growth Medium for the MCF-7, MCF-7 $\mathrm{Ad}^{\mathrm{r}}$, T-47D and ZR-75-1 Cell Lines for Drug Testing .....................117

APPENDIX 8: Growth Medium for the MDA-MB-231 and MDA-A1 ${ }^{\mathrm{r}}$ Cell Lines for Drug Testing ....117 APPENDIX 9: Transport Medium $\ldots \ldots \ldots \ldots \ldots \ldots \ldots \ldots \ldots \ldots \ldots$ APPENDIX 10: Freezing Medium ................... 118 APPENDIX 11: Dissociation Medium ...............118 APPENDIX 12: Growth Medium for Human Breast Epithelial Cells (Normal and Malignant) in Primary Culture ..................118 APPENDIX 13: Preparation of Human Serum Samples .......118 APPENDIX 14: Preparation of Rat Tail Collagen ........118 


\section{LIST OF TABLES}

Table 1: Curability of disseminated cancer

with treatment involving chemotherapy .......2

Table 2: Known mechanisms of action of chemotherapeutic agents ...............

Table 3: Pathways to the discovery of current anticancer drugs ..................18

Table 4: Historical evolution of in vivo screens

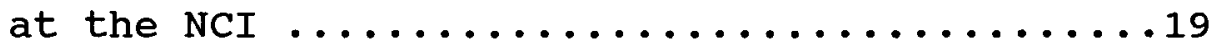

Table 5: Sources and number of samples collected by the NCI $(1986-1991) \ldots \ldots \ldots \ldots \ldots \ldots \ldots$

Table 6: Coefficient of variation associated with different methods of MTT supernatant

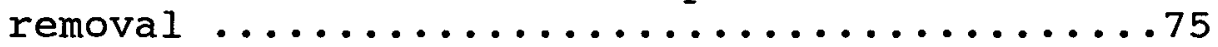

Table 7: ED50 values obtained for compounds screened against the drug-sensitive breast cancer cell Iines MCF-7, T-47D, ZR-75-1

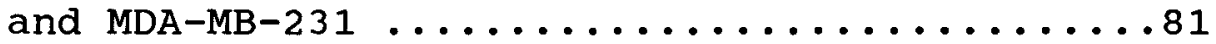

Table 8: $\mathrm{ED}_{50}$ values obtained for compounds screened against the multidrug-resistant breast cancer cell lines $\mathrm{MCF}-7 \mathrm{Ad}^{\mathrm{r}}$ and $\mathrm{MDA}-\mathrm{Al}{ }^{\mathrm{r}} \ldots \ldots .83$

Table 9: $\mathrm{ED}_{50}$ values obtained for the geodiamolides and jaspamide tested against normal and malignant breast epithelial cells in primary culture ................88 


\section{LIST OF ILLUSTRATIONS}

Figure 1: Total survival of premenopausal patients with advanced breast cancer after CMF

chemotherapy .....................

Figure 2: Skipper-Shabel curve for tumor growth $\ldots \ldots \ldots 6$

Figure 3: Gompertzian curve for tumor growth ........11

Figure 4: NCI preclinical drug development

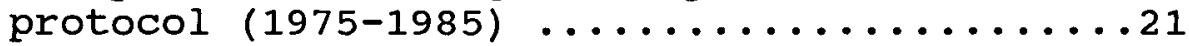

Figure 5: NCI preclinical drug development protocol (1985-present) ....................

Figure 6: Human tumor colony forming assay ..........34

Figure $7:$ NCI MTT assay protocol .................... 35

Figure 8: NCI SRB assay protocol ...................

Figure 9: Molecular structure of Didemnin B ........44

Figure 10: Molecular structure of palytoxin ........45

Figure 11: MTT assay protocol ................60

Figure 12: Wavelength scans of cell generated formazan dissolved in DMSO, isopropanol and ethanol

in the presence of the MTT supernatant ....68A

Figure 13: Wavelength scans of cell generated formazan dissolved in DMSO, isopropanol and ethanol .........................69A

Figure 14: Formazan production as a function of MTT incubation concentration ..............

Figure 15: Formazan production as a function of MTT

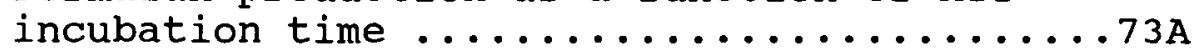

Figure 16: Coefficient of variation as a function of MTT incubation time .....................

Figure 17: Absorbance limit of the MTT assay .......77A

Figure 18: Wavelength scans of pure formazan and cell generated formazan dissolved in

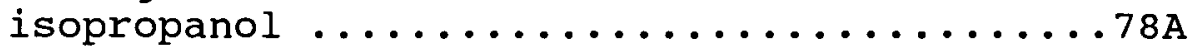


Figure 19: Structures of pure metabolites isolated

from marine organisms ..................

Figure 20: Standard absorbance curve for the MCF-7

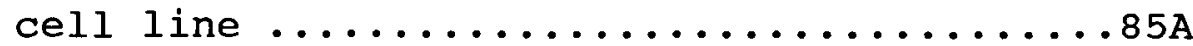

Figure 21: Standard absorbance curve for the T-47D

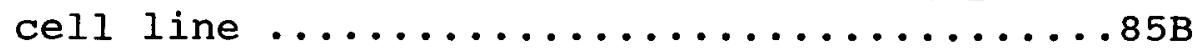

Figure 22: Standard absorbance curve for the ZR-75-1

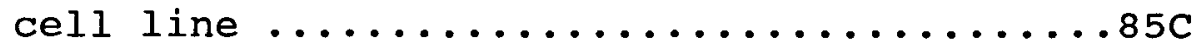

Figure 23: Standard absorbance curve for the

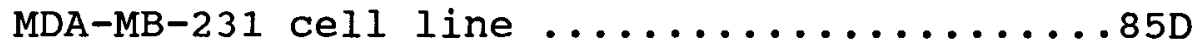

Figure 24: standard absorbance curve for the MCF-7Ad

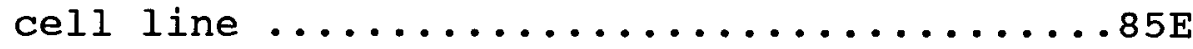

Figure 25: Standard absorbance curve for the $M D A-A{ }^{r}$

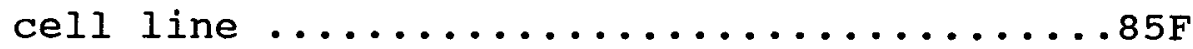

Figure 26: Dose response curve of $\mathrm{MCF}-7 \mathrm{Ad}^{\mathrm{r}}$ cells to varying concentrations of the geodiamolides in the presence of the $\mathrm{ED}_{50}$ concentration

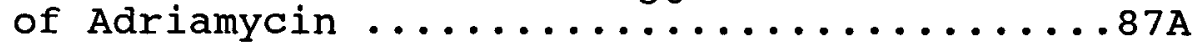

Figure 27: Dose response curve of $\mathrm{MCF}-7 \mathrm{Ad}^{\mathrm{r}}$ cells to varying concentrations of the Garvea extract in the presence of the $\mathrm{ED}_{50}$ concentration of Adriamycin ............87B

Figure 28: Dose response curve of $\mathrm{MCF}-7 \mathrm{Ad}^{\mathrm{r}}$ cells to varying concentrations of the PNG-137A extract in the presence of the $\mathrm{ED}_{50}$ concentration of Adriamycin ............87C

Figure 29: Dose response curve of $\mathrm{MCF}-7 \mathrm{Ad}^{\mathrm{r}}$ cells to varying concentrations of glaciasterol in the presence of the $\mathrm{ED}_{50}$ concentration of Adriamycin .....................

Figure 30: Dose response curve of $\mathrm{MCF}-7 \mathrm{Ad}^{\mathrm{r}}$ cells to varying concentrations of jaspamide in the presence of the $\mathrm{ED}_{50}$ concentration of Adriamycin 


\section{LIST OF ABBREVIATIONS}

\begin{tabular}{|c|c|}
\hline$A_{540}$ & Absorbance at $540 \mathrm{~nm}$ \\
\hline BSA & Bovine serum albumin \\
\hline DMSO & Dimethyl sulfoxide \\
\hline $\mathrm{ED}_{50}$ & $\begin{array}{l}\text { Effective dose which results in a } 50 \% \text { decrease in } \\
\text { cell viability }\end{array}$ \\
\hline FBS & Fetal bovine serum \\
\hline HBEC & Human breast epithelial cells \\
\hline HTCFA & Human tumor colony forming assay \\
\hline ILS & Increase in life span \\
\hline MDR & Multidrug resistance \\
\hline MTT & $\begin{array}{l}3-[4,5 \text {-dimethyl (thialzol-2-yl)-3,5-depheryl] } \\
\text { tetradium bromide }\end{array}$ \\
\hline NCI & National Cancer Institute (USA) \\
\hline PALA & $\mathrm{N}-($ phohonacety 1$)-L$-aspartate \\
\hline Pgp & P-glycoprotein \\
\hline SRB & Sulforhodamine B \\
\hline
\end{tabular}




\section{ACRNOWLEDGEMENTS}

There are many people I wish to thank for the completion of this thesis. The first and foremost is my supervisor Dr. Joanne Emerman, whose patience, guidance and support was invaluable during my studies. I look forward to continuing my PhD studies in her laboratory. I also thank Dr. Raymond Andersen for giving me the opportunity to collaborate with him in this field of research and for participating on my committe. I would also like to thank Dr. Wayne Vogl for taking the time to be on my committee.

I would also like to thank Darcy Wilkinson for teaching me tissue culture methods and for her assistance in laboratory procedures, Dr. Mark Elliot for his useful technical discussions regarding the MTT assay and Dr. Nelly Auersperg for the use of her MacIntosh computer and ELIZA reader.

Finally, I would like to thank my mother and my girlfriend Janet for tolerating my seclusion during my thesis writing.

This research was supported by grants to Dr. Joanne Emerman and Dr. Raymond Andersen from the National Cancer Institute of Canada. 
CHAPTER 1

INTRODUCTION

\section{Treatment of Cancer with Chemotherapy}

over the last half century, approximately forty drugs suitable for the treatment of cancer have been developed (148). As a result, great strides have been made with the use of chemotherapy in the treatment of cancer. The cure rates of different types of disseminated malignancies with chemotherapy, alone or in combination with surgery and/or radiotherapy, is summarized in Table 1. Moderate to high cure rates are seen in the treatment of malignancies such as testicular carcinoma, wilms tumor, childhood sarcomas and many of the leukemias and lymphomas. Unfortunately many common solid tumors, especially the epithelial neoplasms of adulthood still have a poor response rate to chemotherapy, thereby indicating that there is still a dire need for new and more effective chemotherapeutic agents and regimes (21, $62,73,138)$ 
Table 1. Curability of disseminated cancer with treatment involving chemotherapy.

DISEASE

PROBABLE CURE RATE

ADULTS

Diffuse histiocytic lymphoma (III \& IV) $50 \%$

Hodgkin's disease (III \& IV) $50 \%$

Testicular cancer (III) 75\%

Gestational choriocarcinoma $90 \%$

Acute myelocytic leukemia $20 \%$

CHILDREN

Acute lymphocytic leukemia $50 \%$

Non Hodgkin's lymphoma $50 \%$

Burkitt lymphoma $50 \%$

Wilm's tumor $50 \%$

Childhood sarcomas $50 \%$

*Adapted from: Chabner B.A. (1990) Clinical strategies for cancer treatment: The role of drugs. In: Cancer

Chemotherapy, Principles and Practice. (Chabner B. and

Collins J., eds.), JB Lippincot Co, New York. pp 3.

\section{1a. Treatment of Breast Cancer with Chemotherapy}

Breast cancer afflicts one in 9 women in North America. It arises from the epithelial lining of the ducts and lobules of the glandular portion of the breast. Usually at the time of clinical presentation, the cancer has metastasized to distant sites in the body, thereby making treatment of breast cancer a systemic problem. Currently the best form of treatment of advanced breast cancer is treatment of the primary tumor with either surgery or radiation followed by a short course of high-dose adjuvant chemotherapy. This chemotherapy is given to kill any residual cancer cells. Metastatic breast cancer is responsive to all major classes of chemotherapeutic agents, with response rates falling in the $20 \%-40 \%$ range $(77,155)$. 
Response rates of approximately $55 \%$ are observed when combination chemotherapy is used instead of single-agent therapy (77). Currently the best chemotherapy regimes are the cyclophosphamide-methotrexate-5-fluorouracilvincristine-prednisone (CMFVP) variants $(18,27,71,77,79$, 113) and Adriamycin (doxorubicin) based variants (ie: Adriamycin-cyclophosphamide and Adriamycin-cyclophosphamide5 -fluorouracil) $(53,77,79,119)$. The chances of survival of the patient with metastatic breast cancer treated with adjuvant chemotherapy is best illustrated in a report released in 1986 by the medical statistician Dr. R Peto $(121,155)$. This report analyzed the cumulative survival data of approximately 15,000 women who have participated in adjuvant chemotherapy trials over the years. It is very statistically powerful because of the high number of participants involved. The report states that adjuvant combination chemotherapy in premenopausal patients with metastatic breast cancer results in approximately a 30-35\% decrease in risk of death as compared to patients not receiving therapy. This $30-35 \%$ decrease in risk of death translates into a benefit to approximately $10-20 \%$ of the patients. For example, instead of $55 \%$ rate of mortality after 10 years, combination chemotherapy will result in a $38 \%$ rate of mortality. Postmenopausal patients experienced little significant benefit (12 $\pm 5 \%$ ) in risk of death (116). The long term survival of the first successful CMF trials is illustrated in Figure 1. 


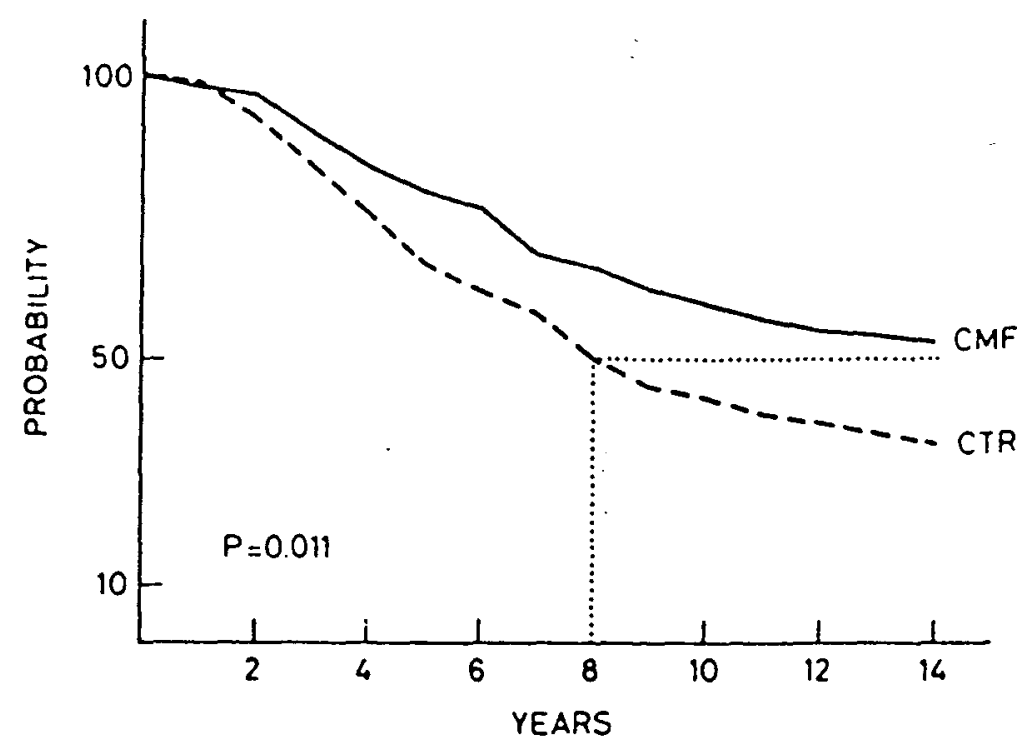

Figure 1. Total survival of premenopausal patients with advanced breast cancer after CMF chemotherapy.

(From: Bonadonna G. (1989) Conceptual and practical advances in the management of breast cancer. J. Clin. Oncol. 7:13801397).

\section{The Basis of Chemotherapy}

Chemotherapeutic drugs, for the most part, are cytostatic and/or cytotoxic agents. The exception to these are those agents which act as biological response modifiers. Examples of biological response modifiers are the interferons and the interleukins, which act to enhance the immume system (172). Most of the cytostatic/cytotoxic anticancer drugs can be categorized as agents that damage DNA, antimetabolites, mitotic spindle poisons, hormones and antihormones. Table 2 lists the mechanisms of action of many of the currently available anticancer drugs. The basis of the treatment of malignancy with cytostatic and cytotoxic drugs is that tumor cells are growing and dividing faster than nonmalignant cells and anticancer drugs tend to be more 
effective against rapidly growing and dividing cells than quiescent cells (163). This accounts for the hair loss, myelosuppression and gastrointestinal problems associated with chemotherapy, since the epithelial cells of the hair follicle, the bone marrow stem cells and the epithelium lining the gut are all rapidly dividing cells. Unfortunately not all cancer cells are rapidly dividing (158); some cells have slow rates of division and some cells are quiescent, thereby making erradication of the tumor difficult. In addition, not all tumor cells are sensitive to chemotherapeutic drugs. These topics are discussed further in the Kinetics of Tumor Growth and the Drug Resistance sections.

Table 2; Known mechanisms of action of chemotherapeutic agents.

1. Damage to the DNA template

2. Interference with normal microtubule function

3. Enzyme inhibition

4. Enzyme stimulation

5. Growth inhibition via a hormone receptor

6. Modification of the immune system

*Adapted from: Yarbro J.W. (1992) The scientific basis of cancer chemotherapy. In: The Chemotherapy Source Book (Perry M.C., ed). Williams and Wilkins, Baltimore. pp 3 .

\section{The Rinetics of Tumor Growth}

\section{3a. Skipper's Laws}

In 1964, Skipper, Schabel and wilcox using the in vivo L1210 mouse leukemia model made two historical observations (150). The first was that this tumor's growth rate is 
logarithmic. This means that the doubling time of a population of cells from this tumor is constant, regardless of the number of cells in that population. For example, if it takes 2 cells 24 hours to divide and form 4 cells, then it will take 24 hours for 2000 cells to divide and form 4000 cells. This logarithmic growth implies that all the cells in the population are actively growing and dividing. A plot of tumor cell number vs time of this type of growth will yield a straight line on a semilog plot (Figure 2).

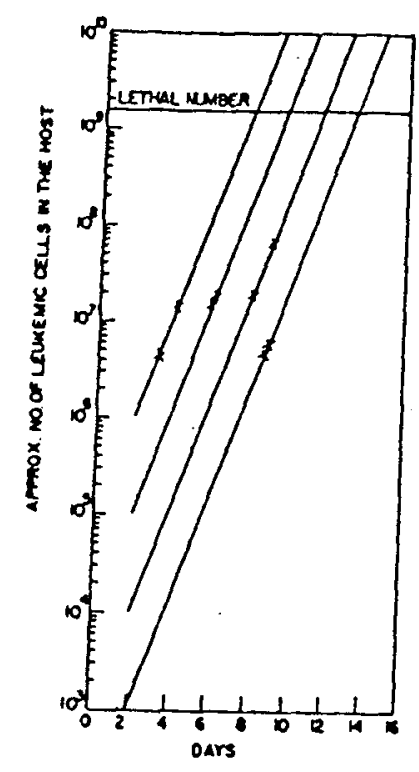

Figure 2. Skipper-Schabel curve for tumor growth. From: Skipper H.E., Schabel F.M., Jr. and Wilcox W.S. (1964) Experimental evaluation of potentail anticancer agents. XIII. On the criteria and kinetics associated with "curability" of experimental leukemia. Cancer chemother. Rep. 35: 1-111.

The second observation Skipper and colleagues made was that treatment of this L1210 tumor with a cytotoxic agent resulted in a specific percentage of the tumor cells being 
killed (depending on dose of drug administered), regardless of the original tumor cell number. For example, if the drug killed $90 \%$ of the cells in an original population of 1000 cells, after the first treatment 100 cells would survive. After the second treatment with the same dose, 10 cells would survive, and after the third treatment 1 cell would survive. Furth and Kahn in 1937 demonstrated that leukemia can be transmitted from one mouse to another with a single cell (56). Therefore the survival of a single malignant cell after treatment can result in relapse. In the example presented earlier, 4 treatments with our chemotherapeutic agent would be required to erradicate the tumor (ie: to get the surviving cell number $<1$, assuming that all cells are drug sensitive).

\section{3b. The Goldie-Coldman Model}

One of the greatest obstacles in the treatment of malignancy is the development of drug resistance. The mechanisms of drug resistance are varied and are discussed later under the Drug Resistance section. In 1952, Law demonstrated that resistance to a chemotherapeutic agent is a trait that can be acquired randomly through genetic mutation prior to exposure to that agent (88). A mathematical model relating drug sensitivity of tumors to this random acquisition of resistance has been constructed by Goldie and Coldman (58). According to their model, the proportion and the absolute number of drug-resistant cells 
within a tumor will increase with time. The fraction of the tumor that is composed of drug-resistant cells will vary between tumors, depending on how early or late the mutation event occured. Goldie and Coldman have calculated that the probability (P) of a tumor consisting of $\mathrm{N}$ cells not having a mutation that results in resistance to a given drug is:

$$
P=\exp \{-x(N-1)\}
$$

where $\mathrm{x}=$ spontaneous mutation rate

Studies have indicated that the probability of a genetic mutation occuring in a nonmalignant cell is in the order of magnitude of $10^{-6}(1,32,41,143)$, whereas in malignant cells the probability is increased to $10^{-5}$ (31, $41,143)$. The minimum size of early detection of a tumor is considered to be approximately 1 gram of tumor which corresponds to roughly $10^{9}$ cells (174). Thus the probability of a tumor at the time of detection not having any cells resistant to a given drug is:

$$
\mathrm{P}=\exp \left\{-10^{-5}\left(10^{9}-1\right)\right\}{ }_{-} 0
$$

The Goldie-Coldman model is based on the following assumptions:

1. The growth of the tumor is based on Skipper's model of exponential growth.

2. Drug-resistant cells are resistant to all concentrations of drug.

3. Treatment is based on single-agent chemotherapy. 
simplistic representation of the evolution of drugresistance within a tumor, one can still conclude with reasonable certainty that the appearance of drug-resistant cells is a major reason for treatment failure $(58,151)$. Several recommendations for improved chemotherapy can be put forth as a result of the Goldie-Coldman hypothesis:

1. The earlier chemotherapy is initiated, the increased probability of a cure being obtained.

2. Combination chemotherapy would be more effective in obtaining a cure than single-agent chemotherapy since the probability of a cell mutating to become resistant to several drugs is much less than it becoming resistant to a single agent.

The treatment of many different patients representing a variety of neoplasms has demonstrated that skipper's model of exponential growth and cell kill is not a true reflection of tumor growth. Patients who have been treated with combination chemotherapy to induce remission are responsive to the same chemotherapeutic regime following relapse (78, 162). The achievement of a second remission is opposite of what one would expect if adhering to Skipper's model of exponential growth and the Goldie-Coldman hypothesis. It would be expected that a second round of chemotherapy would result in very little or no response since most or all the drug-sensitive cells should have been erradicated by the first drug treatment. Assuming that the drug-sensitive and drug-resistant cells have equal cycling times, the ratio of 
drug-sensitive cells to drug-resistant cells should be less than one (152). Consequently no response should be observed since more drug-resistant cells are being added to the population than drug-sensitive cells being killed. This observation of a second remission indicates that drugresistant cells are reverting back to a drug-sensitive phenotype after treatment and/or a substantial number of drug-sensitive cells are not being killed by the first treatment of chemotherapy. There is experimental evidence that the former can occur $(36,80)$, but a kinetic explanation, the Norton-Simon model, has been put forward to account for the treatment failure $(110,111)$.

\section{3c. Gompertzian Growth and the Norton-simon Model}

The growth of experimental animal tumors (87) and clinically observed tumors $(68,109)$ when plotted (cell number vs time) yields a Gompertzian curve (Figure 3). This shape of growth curve indicates that this type of tumor growth is much more complex than that of Skipper's in vivo L1210 tumor model. In order to explain this observed Gompertzian growth, the concept of "growth fraction" must be introduced. Mendelsohn in 1960 suggested the notion that tumors are mixtures of proliferating and nonproliferating cells (97). He defined the growth fraction of a tumor as the ratio of proliferating cells to total cells. In 1968 Tannock demonstrated that vascularity of a tumor influenced the growth fraction (158). Using a unique mouse mammary tumor 
model in which the tumor cells grew uniformly around straight blood vessels, he observed that tumor cells in the immediate vicinity of the oxygen and nutrient supply had the fastest growth rates and the highest growth fraction, whereas those cells further away from the blood supply had slower rates of division and lower growth fractions. The cells farthest from the blood vessels were observed to be necrotic.

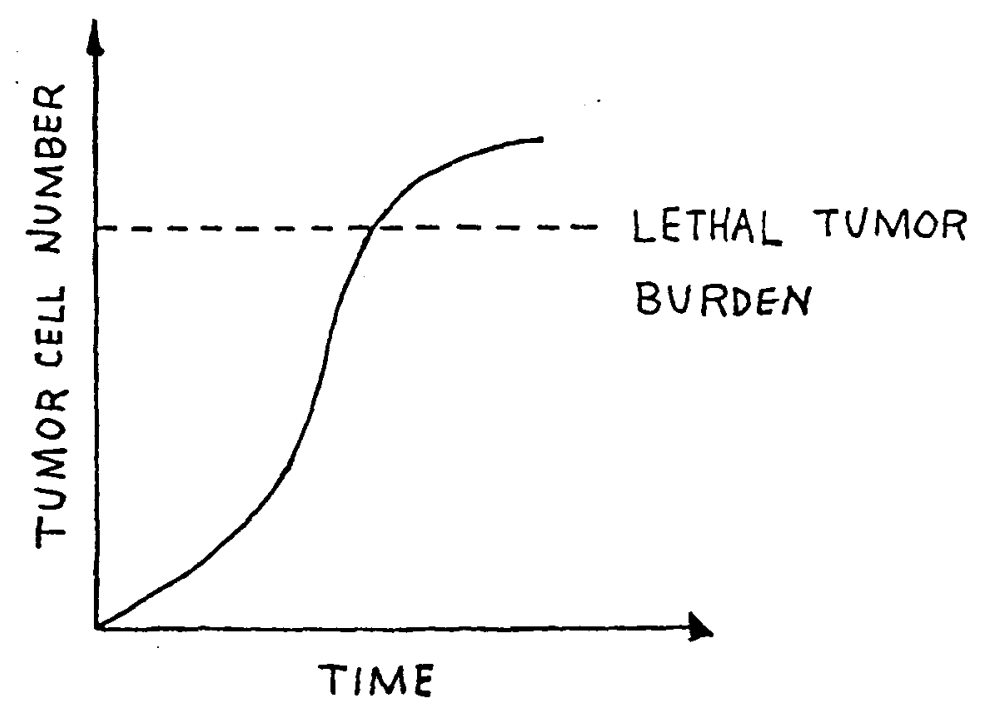

Figure 3. Gompertzian Curve for Tumor Growth.

The initial portion of the Gompertzian curve represents a small number of rapidly dividing tumor cells (171). This portion of the Gompertzian curve resembles Skipper's model of exponential growth. Since cell number is so low, the overall slope of the curve is low, despite the fact that the growth fraction of the tumor is high. As the tumor expands and begins to outgrow it's blood supply, the growth fraction of the neoplasm decreases $(158,111)$. At the other end of 
the curve, where the tumor becomes lethal to the patient, tumor cell number is maximal and growth fraction is minimal, thereby resulting in a low slope of the curve. Maximal tumor growth (slope) is observed in between these two extremes where neither cell number nor growth fraction is maximal, but when their product is. The Norton-simon model for Gompertzian tumor growth can be represented by the following equation (111):

$$
\begin{aligned}
d N(t) / d t=G F(N) x N(t) & -K x L(t) x G F(N) x N(t) \\
\text { where } N & =\text { cell number } \\
t & =\text { time } \\
G F & =\text { growth fraction } \\
\mathrm{K} & =\text { constant } \\
L & =\text { level of chemotherapy }
\end{aligned}
$$

or more simply stated:

change in tumor cell number = cell generation - cell death.

Cell death is dependent on the growth fraction of the tumor, since chemotherapeutic agents are more effective against mitotic cells than quiescent cells (163). The main implications of this equation is that the rate of tumor cell kill and the rate of regrowth increases as tumor size decreases and thus the level of therapy required to initiate a regression may not be adequate to maintain the regression and to produce a cure. A greater level of cell kill is counterbalanced by a greater fractional regrowth, so that 
the only way a cure can be achieved is to use more intensive chemotherapy against very small tumors. To be curative, such intense chemotherapy will require the patient to have autologous bone marrow transplants and hematopoietic growth factor support to counteract the myelosuppresive action of the intense chemotherapy. In summary, it now appears that chemotherapy treatment failure is not entirely due to the development of drug resistance, but is also due in part to the kinetic paremeters of Gompertzian tumor growth and the Iimitation in dosage of chemotherapy due to host toxicity.

\section{Drug Resistance}

One of the reasons for chemotherapy treatment failure is the acquisition of drug resistance by the tumor cells. This acquisition of drug resistance can occur randomly prior to treatment (88) or it can evolve during the course of chemotherapy $(15,90)$. The mechanisms by which cancer cells can become refractory to chemotherapy are diverse $(35,173)$ and some of the more important methods are summarized as follows:

1. Increased expression of the plasma membrane protein P-glycoprotein (Pgp).

2. Changes in expression of drug detoxifying enzymes (glutathione-s-transferase, dihydrofolate reductase)

3. Qualitative and/or quantitative changes in DNA repair enzymes (topoisomerase I and II, polymerase alpha and beta, thymidylate synthase). 
4. Genomic alterations.

\section{4a. P-Glycoprotein and Multidrug Resistance}

One of the factors responsible for unsuccessful cancer chemotherapy is the acquisition of multidrug resistance (MDR) . Multidrug resistance is a phenotype characterized by resistance to a drug which arises upon exposure of the cell to that specific agent $(15,90)$. Multidrug-resistant cells also exhibit a cross resistance to a number of compounds that are structurally and functionally unrelated to the drug that induced the mar phenotype $(6,10,92)$. Multidrug resistance has been observed to be associated with increased levels of a $170 \mathrm{kDa}$ plasma membrane protein, P-glycoprotein (Pgp) (15, 164). Significant levels of Pgp have been identified in a wide variety of malignancies, including sarcomas, carcinomas, lymphomas and leukemias $(59,76)$. Structural analysis of Pgp predicts that it is an ATPbinding pore forming pump, and that it brings about drug resistance by actively pumping drugs out of the cell (28, $63,76)$. The gene coding Pgp has been termed the mar1 gene. Pgp has been detected at low levels in a variety of normal tissues and is believed to have a role in normal physiology $(54,69)$. Amino acid sequencing confirms that Pgp shares extensive sequence homology with numerous bacterial and eukaryotic transport proteins $(22,76)$. This conservation of structure of Pgp throughout evolution indicates that this protein is a fundamental membrane transport protein. Pgp levels are regulated by gene copy number $(81,164)$, by rates 
of transcription (15) and by post transcriptional modifications (15).

From a clinical point of view, the two most important questions are 1) does Pgp predict response to chemotherapy and 2) can the mar phenotype be circumvented? The answer to the first question at this point in time in not entirely clear, since there is little data relating Pgp expression and patient response to chemotherapy (89). Two preliminary studies involving breast cancer have observed a correlation between Pgp expression (as determined by immunohistological methods) and response to chemotherapy $(131,166)$. A confounding problem associated with using Pgp to predict a response to chemotherapy is that many normal tissues express Pgp and it may be difficult to discriminate between normal and neoplastic tissue (30). Some in vitro studies using cancer cell lines $(47,140,164)$ and malignant tissue in primary culture $(5,59,81,144)$ have correlated increased expression of Pgp with decreased sensitivity to chemotherapy, but other in vitro and in vivo experiments utilizing both cell lines and fresh tissue could not establish a strong correlation between Pgp expression and chemosensitivity $(59,65,126)$. Although Pgp expression may be high, pump function may be zero.

In vitro experiments have established that inhibition of the energy-dependent Pgp-mediated drug efflux can result in circumvention of mdr. Calcium antagonists such as verapamil, diltiazem, nifedipine and others have enhanced 
the cytotoxicity of the Vinca alkaloids (vincristine and vinblastine) and the anthracyclines (Adriamycin) against cell lines representing a variety of tumor types $(98,101$, $159,176)$. This enhanced cytotoxicity is a result of competition of binding to Pgp between the calcium antagonists and the antitumor agents $(137,176)$. The calcium channel blockers act to circumvent the mar phenotype in a calcium-independent manner (19). A problem encountered in the use of calcium antagonists in circumvention of mar is that the maximal clinically achievable dose of the antagonist is limited because calcium antagonists cause detrimental cardiovascular side effects in vivo (8). As a result, the maximal in vivo dose is below that required to reverse the mar phenotype (98).

Calcium influx blockers are not the only agents that compete with binding of antitumor agents to increase intracellular drug concentration. Calmodulin inhibitors (85, 160), monoclonal antibodies $(7,16)$, dihydropyridines (175), several of the steroid hormones, especially progesterone $(70,108)$, and the antiestrogen tamoxifen (50) have all been shown to interfere with Pgp-mediated efflux of anticancer drugs. With respect to mdr and breast cancer, the use of the progestins and tamoxifen may prove to be interesting since both are relatively nontoxic $(75,77)$ and both are used for treatment of breast cancer $(24,125)$. 


\section{Historical Background of Anticancer Drug Development}

The first nonhormonal antitumor agents to demonstrate activity in humans were the nitrogen mustards $(60,72,128)$. These alkylating agents, which were used in the chemical warfare programs of World War I, demonstrated significant antitumor activity in patients with lymphomas. These observations signalled the beginning of the search for new anticancer agents. The pursuit for anticancer drugs prior to the 1950's was performed mainly by the pharmaceutical industry (38). Sixteen of our current armament of approximately forty drugs were developed during this era. In 1955, the Developmental Therapeutics Program at the National Cancer Institute (NCI), based in Bethesda Md, initiated its drug discovery and development program $(38,62)$. This program has been the main driving force behind the search for new anticancer drugs since its inception. of the sixteen commercially available drugs introduced between 1955 and 1985, the NCI discovered eight of them. In addition, the NCI

was involved in the clinical evaluation of all sixteen of these drugs (38).

\section{5a. Preclinical Drug Discovery and Development}

There were two methods by which the NCI approached new drug discovery: rational drug design and mass screening of synthetic and natural products. Anticancer drugs such as asparaginase, cisplatin, mitotane, levamisole and antimetabolites such as fluorouracil and $\mathrm{N}-($ phohonacetyl)-L- 
aspartate (PALA) were discovered both by logical reasoning and serendipity $(25,38,48,66,84,132,148)$. Although rational drug design had an important role in the discovery of anticancer drugs, it was more commonly used in improving leads discovered via mass screening. Biological screening of compounds so far has accounted for approximately half of the current repertoire of chemotherapeutic agents (Table 3). Screening of acquired compounds was performed using a series of in vivo tumor models. These models measured the increase in life span (ILS) of tumor-bearing mice receiving treatment with a potential anticancer drug vs tumor-bearing mice not receiving treatment. An ILS of at least $25 \%$ was required for the agent to be considered "active" so it can be forwarded to the next stage of testing (62). The evolution of these in vivo tumor models from 1955 to 1982 is presented in Table 4.

Table ${ }_{*}$. Pathways to the discovery of current anticancer drugs.

\begin{tabular}{|c|c|c|c|c|}
\hline Tergeted synuticsis & $\begin{array}{l}\text { Scroening of } \\
\text { neturil products }\end{array}$ & $\begin{array}{l}\text { Screening of } \\
\text { chemicals }\end{array}$ & $\begin{array}{l}\text { Analogue } \\
\text { synthesis }\end{array}$ & $\begin{array}{l}\text { Serendipity and } \\
\text { rational application }\end{array}$ \\
\hline $\begin{array}{l}\text { Antimetabolites: } \\
\text { Methotrexate } \\
\text { Thiogunnine } \\
\text { Mercsptopurine } \\
\text { Fuurouracil } \\
\text { Crambine } \\
\text { PALA } \\
\text { Hormunes: } \\
\text { Steroids } \\
\text { Tamoxifen } \\
\text { Flutamule } \\
\text { Leuprolick } \\
\text { Octrevide }\end{array}$ & $\begin{array}{l}\text { Dactinomycin } \\
\text { Vincristine } \\
\text { Vinblastine } \\
\text { Plicamycin } \\
\text { Daunonbicin } \\
\text { Doxorubicin } \\
\text { Mitomycin C } \\
\text { Bleomycin } \\
\text { Streprozocin } \\
\text { Taxol }\end{array}$ & $\begin{array}{l}\text { Busulfan } \\
\text { Decertazine } \\
\text { Procarbazine } \\
\text { Hydroxyurea } \\
\text { Thiotepa } \\
\text { Carmustine } \\
\text { Lomustine } \\
\text { Mitoxantrone } \\
\text { Aliretamine } \\
\text { Pentostatin }\end{array}$ & $\begin{array}{l}\text { Cyclophosphemide } \\
\text { Chlorambucil } \\
\text { Melphalan } \\
\text { lfosfamide } \\
\text { Eloposide } \\
\text { Teniposide } \\
\text { Carboplatin }\end{array}$ & $\begin{array}{l}\text { Mechloretrumine } \\
\text { Asparaginase } \\
\text { Mitotene } \\
\text { Cisplatin } \\
\text { Levamisole } \\
\text { Interferons }\end{array}$ \\
\hline
\end{tabular}

*From: Sikic B.I. (1991) Anticancer Drug Discovery. J. Natl. Cancer Inst. (U.S.A.) 83: 738-742. 
Table 4. Historical Evolution of In Vivo Screens at the NCI.

\begin{tabular}{ll} 
YEAR & \multicolumn{1}{l}{ IN VIVO SCREEN } \\
1955 & sarcoma $180 * *$ carcinoma 755, leukemia L1210 \\
1960 & L1210 +2 models from a pool of 21 \\
1965 & L1210 + Walker carcinoma 256 \\
1968 & L1210 for synthetics, L1210 and P388 leukemia \\
& for natural products \\
1972 & L1210 for synthetics, P388 for natural \\
& products, B16 melanoma and Lewis lung \\
1975 & Carcinoma for special testing \\
& P388 prescreen, followed by a panel of 8 \\
& models, including human xenografts
\end{tabular}

*From: Staquet M.J., Byar D.P., Green S.B. and Rozencweig M. (1983) Clinical predictivity of transplantable tumor systems in the selection of new drugs for solid tumors: Rationale for a three-stage strategy. Cancer Treat. Rep. 67: 753-765.

All tumor models are murine except where noted.

The NCI's preclinical drug development protocol for the years 1975 to 1985 is illustrated in Figure 4. The first step (Stage I) of this protocol was a P-388 murine leukemia prescreen to eliminate the supposedly large number of clinically inactive compounds. Any agent considered "active" (ILS > 25\%) in this prescreen was then forwarded to the in vivo tumor panel (Stage II) which consisted of a variety of human tumor xenographs and murine malignancies. If the agent demonstrated any activity (ILS > 50\%) in Stage II, it was further investigated (formulation/toxicology stage) to determine structure, production, mechanism of action, dosage, toxic effects on animals and so on. The animal toxicology studies, which were usually performed on two 
species of animals, were performed to characterize the drug's absorption (if oral), clearance, half-life, metabolism, excretion and either or both the maximum tolerated dose (MTD: dose which produces severe reversible toxicity) and the $\mathrm{LD}_{10}$ (dose which is lethal to $10 \%$ of the population given that dose). These studies helped to determine if the agent was suitable for clinical trials and which dose to administer in clinical trials. The initial dose is usually a fraction of either the MTD or the $L D_{10}$ (26). 


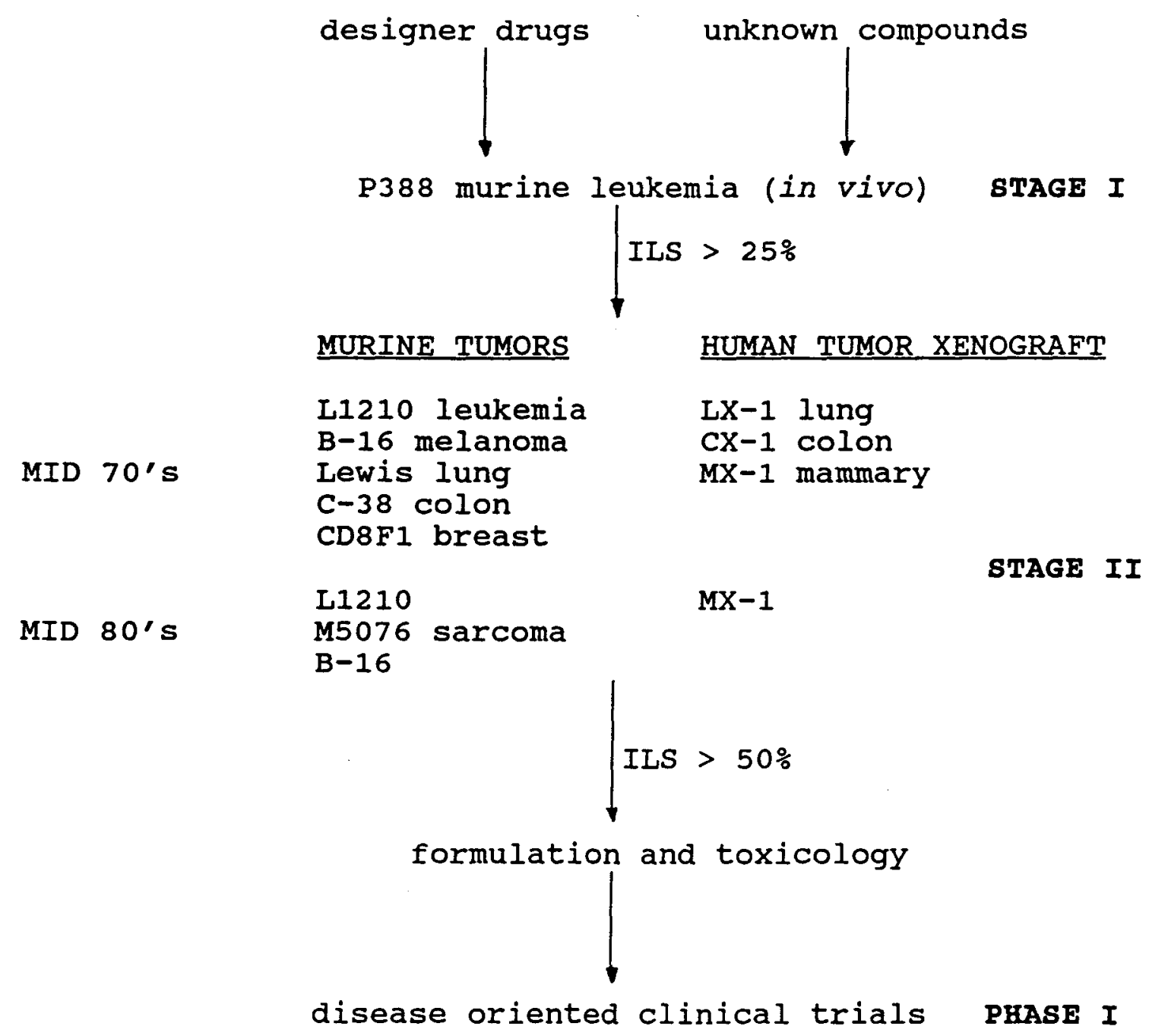

Figure 4. NCI preclinical drug development strategy (19751985).

\section{5b. Clinical Evaluation of New Anticancer Drugs}

Once the preclinical drug research phase is completed, the compound is introduced into clinical trials. Clinical trials are composed of three phases (I-III) $(26,94)$. The goal of Phase I is to assess the drug's qualitative and quantitative (maximum tolerated dose) toxicity upon the patient. The patients involved in Phase I are those who have 
tumor types in which there is no suitable treatment available. In addition, patients are selected so that a broad spectrum of tumor types are represented by the patient panel. The assumption in cancer chemotherapy is that anticancer drugs are most effective when administered near to or at their MTD (55). For most clinically active drugs the bone marrow is usually the dose limiting factor, but the CNS, kidney, liver and other organs may also be dose limiting (94). The maximum tolerated dose for patients with a common tumor type is determined by using a "modified Fibonacci scheme" (26). The initial dose is extrapolated from the animal toxicology studies and is administered to three patients. If acceptable toxicity is observed with these patients, the dose is increased for the next three patients who enter the study. As long as the toxicity remains acceptable, the dosage will be escalated with decreasing increments for new patients entering the study. The main goal of Phase II studies is to establish which tumor types the drug is effective in treating and to further define the drug's side effects. The patients in this phase comprise the Human Tumor Panel. This panel was created in 1975 and consists of patients with the same types of malignancies (lung, colon, breast, lymphoma, leukemia and melanoma) as those in the preclinical in vivo tumor panel. The purpose of selecting these two panels is to determine if results obtained from the in vivo preclinical tumor models correlate with those obtained using the Human Tumor Panel. 
The goals of Phase III are to determine the response rate, response duration, survival, toxicity and relative activity (when compared to standard treatment) of the drug in patients with tumor types that were responsive in Phase II. In addition, Phase III studies explore the incorporation of the agent with other drug combinations, alternate routes of administration and high dose therapy in combination with rescue procedures.

\section{5c. Evaluation of the National Cancer Institute's Drug}

\section{Discovery and Development Program}

In 1984 it became evident that the NCI's criteria for identifying new chemotherapeutic drugs was unsatisfactory. This situation was illustrated in a report released in 1987 which evaluated the Phase II activity of all cytotoxic drugs introduced into clinical trials by the NCI between the years 1970 and 1985 (95). During this time period, 83 drugs were introduced into Phase I trials. Of these 83,11 were terminated at the end of Phase $I$ and 5 remained in Phase I at the time of the report. Of the 67 drugs that proceeded onto Phase II, 13 were still in Phase II and 7 were not evaluated properly. After Phase II testing, 24 of the remaining 47 agents demonstrated significant activity against at least one type of malignancy. Only 14 of 24 active agents were new chemical structures; the remaining 10 were analogues of already known chemotherapeutic drugs. With the NCI drug discovery program screening up to 40,000 
compounds annually with the cost in the tens of millions of dollars per year ( $\$ 29 \mathrm{M}$ in 1984)(21), only 14 novel compounds discovered after 15 years was highly unsatisfactory. Of a more serious concern was that of the active agents, $74 \%$ were rated active against lymphoma, $35 \%$ against leukemia and only marginal activity was observed against the solid tumors. It became apparent that the P-388 murine leukemia prescreen was not a valid representation of all types of malignancies. It is believed that the P-388 prescreen was filtering out agents that are potentially effective in treating solid tumors. The P-388 model was assumed to be a valid representation of all tumor types because of the P-388's and the L-1210's (P-388's predecessor) historical predominance in anticancer drug screening and of the fact that more agents discovered by the NCI program were effective against the in vivo L-1210 and P388 leukemic bioassays than any other in vivo bioassay (156, 165), which of course is faulty logic. When the NCI's drug screening program was initiated, the $\mathrm{L} 1210$ and $\mathrm{P}-388$ in vivo tumor models seemed to be the appropriate choices because of their technical feasibility. The NCI at the time was screening 7,000-12,000 compounds per year. At this level of screening, the use of a single in vivo preliminary screen required that the tumor model used have a doubling time of 10-15 hours so that the antitumor assay could be completed in 30 days (157). The NCI eventually dropped the colon and lung human tumor xenografts from their stage II screen 
because they were deemed too insensitive for drug screening $(62,114)$. This is somewhat ironic since lung and especially colon neoplasms are known to be clinically resistant to chemotherapy $(59,106)$. In fact, it would seem that the most important tumor models would be those that are nonresponsive to drugs currently in use. This is supported by the observation that out of 979 compounds rated not active in an in vivo L1210 leukemic prescreen, 119 were later found to have activity in at least one of the in vivo solid tumors from the stage II secondary screen (165).

Another flaw in the NCI's use of murine tumor models was that for the P-388 stage I screen and many of the murine tumor models in the stage II screen, both the tumor and the drug were injected intraperitoneally (62). This form of tumor model, nicknamed "test tube in the mouse", does not represent the true in vivo environment since no physiological barriers have to be passed by the drug. As a result, drug activity is falsely magnified and the assay tends to isolate drugs that do not cross physiological barriers well (62).

In the mid 1980's the NCI reevaluated its drug discovery program. Several alternatives to the drugscreening system were proposed (21):

1. Abandonment of all drug discovery contracted out by the NCI. Approximately 50\% of all compounds acquired for the NCI drug-screening program have been via a chemical synthesis 
contractor and a collection contractor (38). Instead the NCI would redirect these funds towards drug discovery grants and clinical development of compounds submitted from outside the NCI. Active compound acquisition by the NCI and voluntary submission of agents to the NCI, which normally account for approximately $20 \%$ and $30 \%$ respectively of all compounds aquired, would then become the major sources of agents entering the greatly scaled down NCI drug-screening program. This proposal was rejected because it was felt that this would be too much of a negative signal to the few remaining private sector companies involved in drug-discovery programs.

2. Development of new molecular screening targets. With the science communities' ever-expanding knowledge of tumor biology and scientific technique, we are identifying more and more intracellular targets involved in induction and maintenance of neoplasia. These intracellular targets can be utilized in a screening protocol to identify agents that may inhibit the neoplastic process. Some examples of these targets are protein kinases, growth-factor inhibitors, oncogene products and proteins involved in multidrug resistance. The NCI rejected the development of this type of screen for two reasons. The first is that this type of screen utilizes a cell free system and thus is too far removed from the in vivo environment. Secondly, the importance of any one specific intracellular target involved 
in the malignant process is still not clear (21). Many independent laboratories have adopted this screening process and, as our understanding of molecular biology increases, this format of drug discovery will become more prominent (73, 154). The NCI recognizing this, has established the National Cooperative Drug Discovery Groups, an organization that brings together molecular biologists, chemists and biochemists so as to expand the role of rational drug discovery $(154,157,165)$.

3. Creation of an in vitro human tumor cell line panel for initial testing of compounds. To avoid the "filtering" effect observed with the use of the P-388 leukemia prescreen, the NCI decided to utilize an initial screening panel representing all the major categories of tumor types $(14,21,103)$. An in vitro human tumor cell line panel was selected instead of an in vivo panel because it is economically and technically impractical to use in vivo models for mass screening.

\section{Current status of the National Cancer Institute's}

\section{Preclinical Drug Discovery and Development Program}

Figure 5 is a schematic representation of the preclinical antitumor drug screening protocol implemented at the NCI in $1985(14,62)$. In order to avoid the diseasespecific stage I screen and the "filtering" effect observed with the screening protocol used in earlier prescreens, the 
NCI switched to a disease-oriented in vitro human tumor cell line panel. The ultimate goal is to have the human tumor cell line panel consisting of 120 cell lines representing 10-12 different tumor types $(14,103)$. Currently the pilotscale cell line panel utilizes 60 human tumor cell lines organized into subpanels representing melanoma, leukemia and cancers of the lung, colon, kidney, ovary and central nervous system (103). Each tumor type is represented by multiple cell lines because the use of subpanels will allow for detection of agents that are specific for certain categories of malignancies (ie: histiospecificity) or, conversely, agents that are active but not tumor-specific $(14,103,148)$. In addition, the use of just 1 or 2 cell lines originating from 1 type of cancer would not emulate the heterogeneity observed in naturally occuring tumors (51, 122). Cell lines are used instead of fresh tumor tissue in primary culture because the cells are plentiful, easy to grow and well characterized (ie: for mechanisms resulting in drug resistance). Previous attempts at using fresh tumor tissue from a variety of solid tumors (in conjunction with the human tumor colony-forming assay) was shown to be impractical for high volume screening $(145,146)$. The use of cell lines in the primary screen is also advantageous, because many human tumor cell lines can be propagated subcutaneously in athymic nude mice $(14,114)$, thereby providing a means of evaluating agents in vivo (stage II of figure 5). This stage II screening involves the testing of 
agents in athymic nude mice with subcutaneous implants of the most chemosensitive cell lines from stage $I$. In addition to the use of these subcutaneous human tumor xenografts, the NCI can further investigate promising compounds more thoroughly in vivo by using an orthotopic tumor model and the microencapsulated tumor assay (META) $(14,61,157)$. In the orthotopic tumor model, the tumor cells are implanted in vivo in sites corresponding to the presumed origin of the malignancy rather than subcutaneously. For example, if an agent was observed to be active against renal carcinoma, the tumor cells would be implanted in the kidney. In the META, tumor cells are encapsulated in microcapsules, which in turn are implanted in the peritoneal cavity of nude mice. The capsules are designed to confine the tumor cells while still exposing them to an in vivo environment. Following drug exposure, the capsules are removed and the surviving cell number counted and compared to controls. Neither the META nor the orthotopic xenograft methods are to be used for first line in vivo screening since they are too technically impractical (14). Instead, these tumor models are to be used for more specialized preclinical investigation of promising anticancer compounds. 


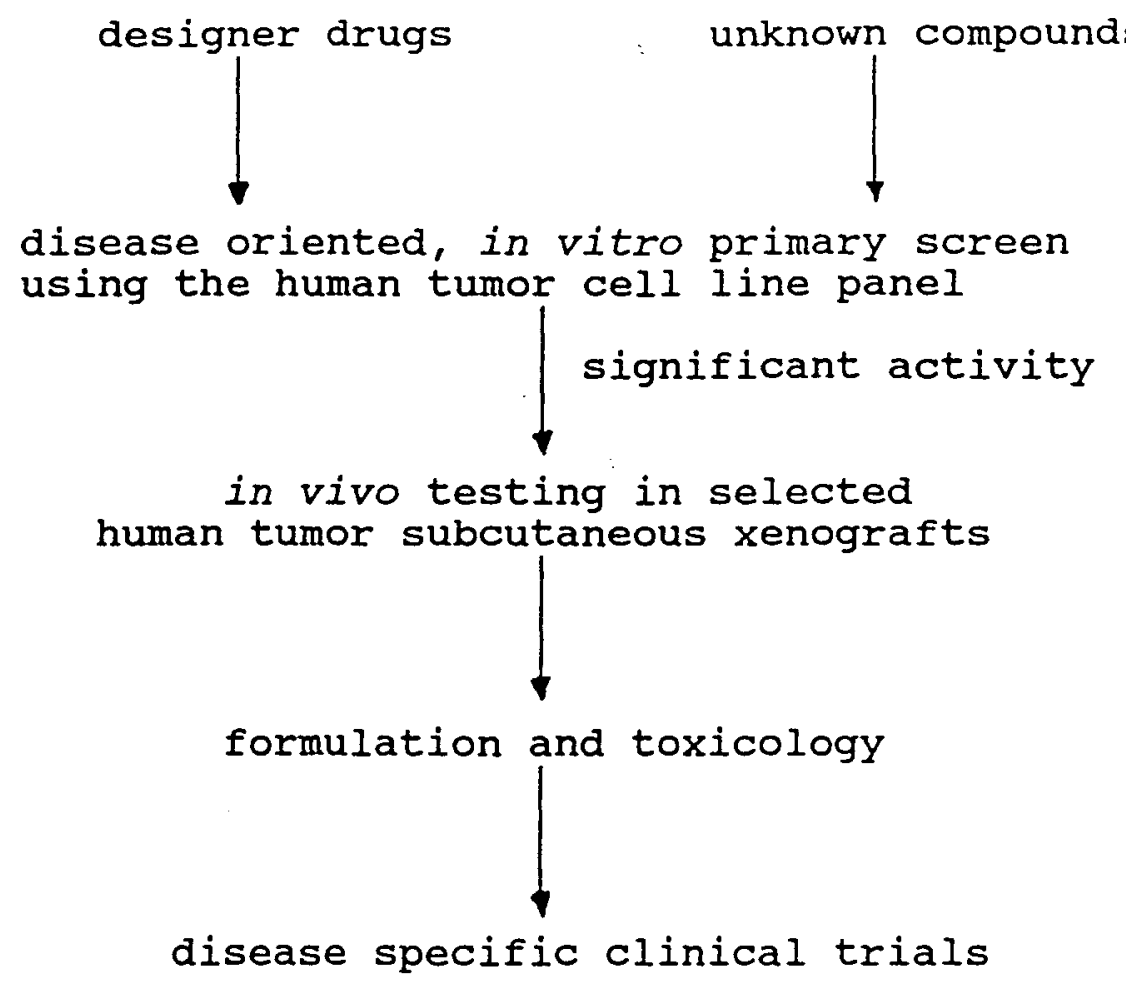

STAGE I

STAGE II

Figure 5. NCI preclinical drug development protocol (1985present).

A drawback of using murine tumor models for chemosensitiviy testing is that clinically achievable doses are 2- to 10- fold higher than that achievable in mice (148). In humans, we have ways we can support the myeloproliferative cells in the bone marrow (ie: growth factor and bone marrow transfusions and gene therapy) and thus we can increase the dose intensity $(57,82)$. But in mice, myelosuppression is the dose-limiting factor, therefore agents that are myelosuppresive in mice but not in humans could potentially be filtered out. A possible way to get around this problem is to use a transgenic mouse that has its bone marrow cells expressing the marl gene (102). 
Inclusion of non-neoplastic myeloid colony forming cells as a control in the human tumor panel may give an indication of the therapeutic index (minimum toxic dose/minimum effective dose) of the test agent (21).

Once preclinical drug development is completed, the agent under study is introduced into disease-specific clinical trials. This strategy is based on the assumption that in vitro activity against specific tumor types will translate to in vivo activty in patients who have those tumor types. There is some evidence that histiospecific activity does exist for certain antitumor agents. Mitotane, asparaginase and ipomeanol demonstrate preferential activity for adrenocortical carcinomas, lymphoblastic leukemias and lung cancers respectively $(23,148)$. Several earlier studies investigating the feasibility of alternative drug screening methodologies have demonstrated that agents previously shown not to be active in a leukemic prescreen demonstrated activity in non-leukemic screens. An NCI pilot screen investigating the feasibility of the (in vitro) human tumor colony forming assay for large-scale drug screening detected activity for 14 of 79 compounds that were negative in the P388 leukemic prescreen (145). Of 1085 compounds tested against a panel of in vivo murine tumors representing a variety of murine and human tumor types, 106 were active in L1210 leukemia. Of the 979 compounds that were inactive in the L1210 tumor model, 78 were active against melanoma, 45 against human breast carcinomas, 18 against murine breast 
carcinomas, 10 against murine lung cancers, 9 against murine colon cancers, 5 against human colon cancers and 1 against human lung cancer $(156,165)$.

To aid detection of potential histiospecific activity of anticancer agents, the NCI has developed the mean graph and the COMPARE computer program (118). The mean graph, which is a type of bar graph, displays cytotoxic activity of the test agent against each cell line in relation to the average activity observed against all cell lines of the tumor panel. The graph is constructed by projecting bars horizontally, to the right or left of the mean, depending on whether or not cell sensitivity to the test agent is greater or less than average. The length of the projection bars is directly proportional to the difference from the mean. Consequently, a "fingerprint" pattern is generated for each compound tested against the human tumor cell line panel. This COMPARE computer program can then compare this fingerprint pattern to patterns generated with other test agents, thereby identifying similarities in biological properties and/or chemical structure and properties (118).

\section{Methods to Assess Chemosensitivity}

One of the difficulties associated with in vitro drug screening is how to accurately measure tumor cell viability following exposure to a test agent. Numerous assays have been developed, but unfortunately each has its limitations. These assays include the human tumor colony forming 
(clonogenic) assay (HTCFA) $(64,139,145,146)$, the sulforhodamine B (SRB) assay (149), tritiated thymidine uptake $(74,161)$, neutral red assay $(12,13,49)$, the Coomassie blue protein assay (147), the Hoechst 33342 assay (39, 129), the fluorescien diacetate assay (133), the methylene blue assay (112), the XTT tetrazolium dye reduction assay (141), the MTT tetrazolium dye reduction assay $(2,20,33,67,107,134,167)$ and many others.

The HTCFA, MTT, XTT, and SRB were all investigated as possible tools in the NCI's drug-discovery and development program. The HTCFA (Figure 6) was deemed not suitable for large-scale screening because it is labour intensive, is plagued by low plating efficiencies for certain tumor types and is difficult to obtaining single-cell suspensions (145, 146) 


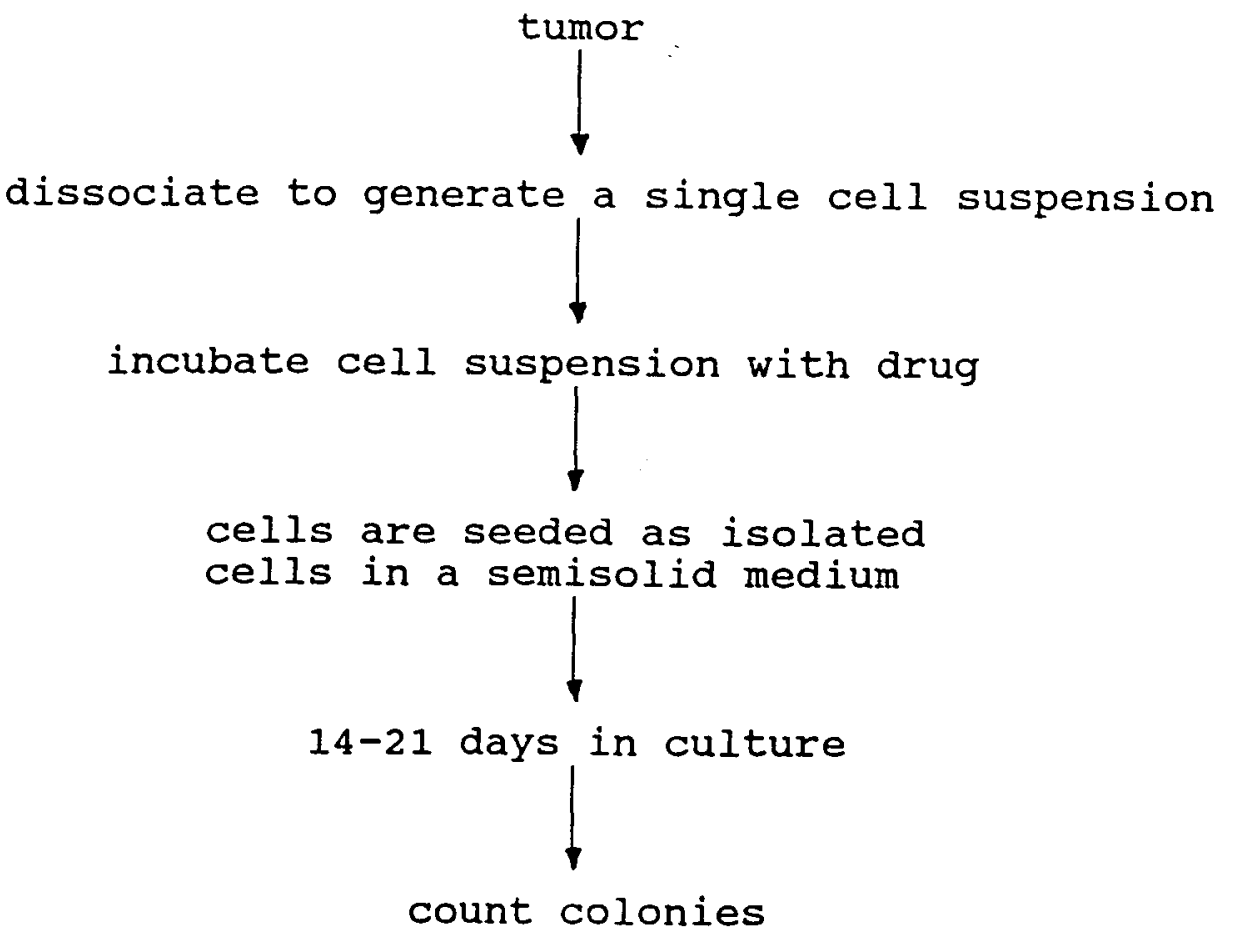

Figure 6. The human tumor colony forming assay.

The assay originally selected by the NCI to use in the in vitro stage I screen was the colorimetric MTT (1- $[4,5-$ dimethylthiazol-2-yl]-2,5-diphenyl tetrazolium bromide) tetrazolium dye reduction assay (Figure 7) (2). The MTT assay was observed to be a rapid, sensitive, and reproducible method for in vitro anticancer drug screening $(2,20,67$, 134). MTT is a soluble yellow substrate that is cleaved by the dehydrogenase enzymes of mitochondria in living cells to form an insoluble purple formazan product (153). The amount of formazan produced by a population of cells is proportional to the number of viable cells in the population (107). Formazan levels are measured with a spectrophotometer designed to read 96-well microculture plates (ELIZA reader), which is interfaced with a computer to analyze results. The use of the 96-well microtiter plates in conjunction with the 
ELIZA reader and the computer makes this procedure highly efficient.

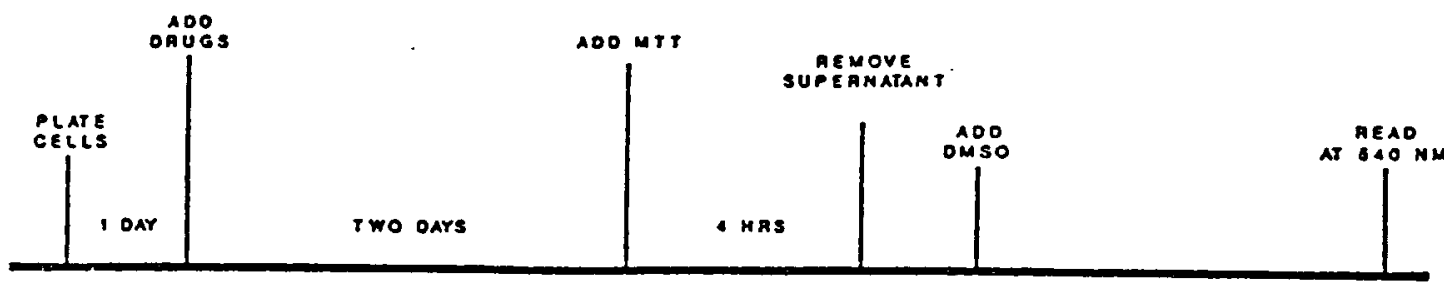

Figure 7. NCI MTT assay protocol.

From: Rubenstein L.V., shoemaker R.H., Paull K.D., simon R.M., Tosini S., Skehan P., Scudiero D.A., Monks A. and Boyd M.R. (1990) Comparison of in vitro anticancer-drug-screening data generated with a tetrazolium assay versus a protein. assay against a diverse panel of human tumor cell lines. $J$. Natl Cancer Inst. (U.S.A.) 82: 1113-1118.

A slight variation of this assay was developed to eliminate the aspiration/solubilization step (the insoluable formazan must be dissoled in solvent prior to colorimetry). The reduction of XTT $(2,3-b i s[2-m e h t o x y-4-n i t r o-5-$ sulfophenyl]-5-[ (phenylamino) carbonyl]-2H-tetrazolium hydroxide) results in a formazan product that is water soluble, thereby eliminating the need for additional solvents. Some serious drawbacks associated with the MTT and XTT assays are i) agents that reduce tetrazolium salts by direct chemical action may yield erroneous results (2), ii) agents that block cell-mediated MTT reduction indirectly by inhibiting cellular respiration may confound results (2), iii) MTT formazan production varies between cell lines and 
culture age, iv) agents that alter the number of mitochondria per cell may confound results and v) the color intensity of the dissolved formazan is not stable, and has to be measured at a precise time point (136). The variation of formazan production between cell lines and culture age is related to the availability of glucose at the time of the assay. Low levels of available glucose is related to decreased mitochondrial activity, which in turn is related to decreased formazan production (167). With the NCI's stage I screen operating at 1,000 microtiter plates/day, it became difficult to coordinate microculture plate reading. As a result the NCI was prompted to develop the SRB assay (Figure 8) (149). SRB is a aminoxanthene dye with two sulfonic groups that binds to basic amino acid residues of protein (91). The SRB assay was determined to be a sensitive and rapid method of measuring the cellular protein content of adherent and suspension cultures. Unlike the MTT and XTT assays, the SRB's colorimetric endpoint is indefinitely stable (136, 149). A study comparing the SRB assay and the MTT assay observed that the two perform similarly (136). 


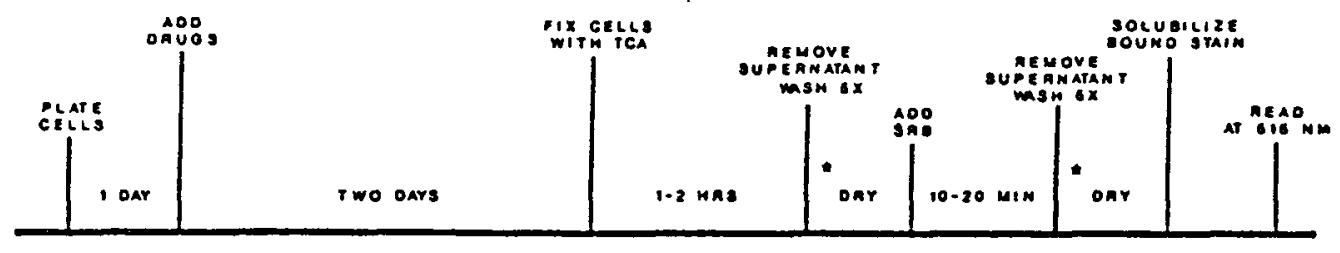

Figure 8. NCI SRB assay protocol.

From: Rubenstein L.V., Shoemaker R.H., Paull K.D., Simon R.M., Tosini S., Skehan P., Scudiero D.A., Monks A. and Boyd M.R. (1990) Comparison of in vitro anticancer-drug-screening data generated with a tetrazolium assay versus a protein assay against a diverse panel of human tumor cell lines. $\mathrm{J}$. Natl. Cancer Inst. (U.S.A.) 82: 1113-1118.

\section{Predictive Value of In Vitro Chemosensitivity Assays}

The most paramount question to be answered with regard to in vitro assays is whether or not in vitro activity translates into in vivo activity. In vitro chemosensitivity assays can be categorized as patient-oriented or as drugoriented. The former is used to predict the response of a patient to cytotoxic drugs. The latter is used for measuring the chemosensitivities of compounds. Although most of the studies addressing whether in vitro activity correlates with in vivo activity have been performed with respect to patient oriented in vitro assays, many of the conclusions are relevant to in vitro drug screening. The HTCFA (Figure 6), first described by Hamburger and Salmon (64) has been the most studied of the in vitro assays. In this assay, stem cells are exposed to various concentrations of drugs and the 
proportion of colonies that develop relative to a control is plotted against the dose level of the agent. A review of 2,300 different in vitro-in vivo clinical correlations using clonogenic based assays was presented by Von Hoff in 1990 (170). The results of this review are as follows:
Sensitive in vitro and in vivo 512
Sensitive in vitro but resistant in vivo 226
Resistant in vitro but sensitive in vivo 135
Resistant in vitro and in vivo
$\underline{1,427}$
Total
2,300

An analysis of these numbers reveals that if an agent is active in vivo, an in vitro assay will predict it $79 \%$ of the time. Conversely if the agent is not active in vivo, an in vitro assay will predict it $86 \%$ of the time. Since the number of correlations involved in generating these numbers is very large, these results are statistically powerful. Another study, in which patients with advanced metastatic cancer were randomized to receive single-agent chemotherapy as decided by an oncologist or by a clonogenic assay, demonstrated that an in vitro clonogenic assay could improve the response rates to chemotherapy (169). Patients who received chemotherapy as decided by the assay were observed to have a response rate of $21 \%$, whereas those who were administered chemotherapy as selected by a clinician were observed to have a response rate of $3 \%$. No difference in 
survival was observed between the two arms of the study, but this can be attributed to the current stock of anticancer drugs and the single-agent chemotherapy regime administered. Although the results of these two reports confirm that in vitro activity can reasonably predict in vivo activity, several comments must be made in order to keep these results in perspective: 1) Only certain tumor types are suitable for the HTCFA $(142,145,170)$. Von Hoff in his review of in vitro-in vivo correlations only examined solid tumors. of the 13,932 tumors involved in the prospective randomized study mentioned above, approximately $30 \%$ of the tumors displayed adequate growth in vitro. Adequate growth in vitro has been considered to be $\cdot 30$ colonies per $5 \times 10^{5}$ cells plated (142). The tumor types which were found to be the most suitable for the HTCFA are mesothelioma, ovary, corpus uteri and kidney, whereas leukemias, lymphomas and myelomas were observed to be not suitable for the HTCFA. 2) clonogenic assays have been plagued by quality control problems (ie: cell clumping) which have resulted in erroneous results $(145,146)$. Recent technical advances and the establishment of stringent assay parameters and controls have minimized these quality control problems (145). There are several limitations associated with the predictive value of all in vitro assays. The most obvious is the inability of in vitro assays to detect agents that require metabolic activation, factors that could inhibit angiogenesis, invasion or metastases or agents that act via 
effector cells of the immune system such as macrophages and natural killer cells. One method proposed to minimize the former of these is inclusion of liver microsomal preparations in the incubation mixture $(3,86)$.

Another problem associated with in vitro assays is that it is difficult to determine the appropriate drug concentrations and exposure times in culture that reflect those attainable in vivo. This problem is further compounded by the fact that drug penetration barriers exist within the tumor, thus different sites within the tumor may be exposed to different concentrations of drug (96). For patientoriented predictive in vitro assays this is a serious problem. For drug-screening oriented in vitro assays, this problem is not as important since the purpose of these tests is to determine if a given agent has the potential for antitumor activity. Usually the drug concentrations used in preliminary drug-screening studies are five ten-fold dilutions starting with the highest soluble concentration or an arbitrarily selected concentration (usually $10^{-3} \mathrm{M}$ for pure compounds or $250 \mu \mathrm{g} / \mathrm{mL}$ for crude extracts) $(14,103)$. A knowledge of the potency of the test compound in vitro may provide a reference point on which to base in vivo drug dosages $(122)$.

The basis of all in vitro chemosensitivity assays is the hypothesis that response in vivo is determined by the inherent chemosensitivity of the cells in vitro. Experimental evidence has demonstrated that this is not 
always the case and that other factors determine tumor responses in vivo $(4,122)$. A study by Phillips et al.(122) demonstrated that a murine colon adenocarcinoma cell line grown in vivo exhibited varying responses to chemotherapy depending on the site of tumor growth (subcutaneous or intraperitoneal). The reasons for this site-dependent response to chemotherapy is believed to be due to the drug's ability to access different tumor sites, tumor hypoxia and cell kinetics $(4,96)$. Furthermore, factors affecting chemosensitivity such as the proliferative status of tumor cells, the 3-dimensional tumor geometry, the presence of an extracellular matrix and variations in $\mathrm{pH}, \mathrm{O}_{2}$ tension and osmolarity observed in vivo may not necessarily be reproduced in vitro $(37,122)$.

The validity of the HTCFA has been examined by testing the assay against a panel of standard agents $(10$ clinical agents, 5 highly toxic compounds with no therapeutic efficacy and 5 nontoxic clinically ineffective compounds) (145). Using a $20 \%$ in vitro response rate (decrease in colony number as compared to control) as activity criterion, 9 of the 10 clinical agents were observed to be active, as were all 5 of the highly toxic compounds. None of the nontoxic clinically ineffective compounds demonstrated significant activity. A study comparing the MTT and the HTCFA using a range of anticancer drugs on a variety of cell lines demonstrated that the two assays produce similar results $(2,20)$, as do both the MTT 
and SRB assays with one another (149). Differences in relative chemosensitivities between cell lines were maintained when comparing the MTT and HTCFA assays (20). Other experiments comparing in vitro chemosensitivities of leukemia cell lines with carcinoma cell lines against a panel of cytotoxic agents has demonstrated that carcinoma cell lines tend to be more chemoresistant than leukemic cell lines, especially when exposed to DNA binding drugs $(4,52$, 115). These results suggest that the refractoriness of carcinomas as compared with leukemias is due to inherent resistance of the tumor cells themselves. Ultimately, however, only results from clinical evaluations will tell whether or not an in vitro human tumor cell line panel is a valid means to detect clinically effective anticancer agents $(14,62,122,148)$

\section{Natural Products as a source of New Anticancer Drugs}

The NCI has not only changed the way they investigate new potential anticancer drugs, but also the way it selects compounds for screening. In addition to screening some acquired synthetic compounds, the NCI is putting a greater emphasis on screening natural products because they represent a vast untapped source of agents with novel modes of action and unique structures. Currently approximately 2025\% of U.S. prescriptions contain natural plant products, even though only a handful of a quarter of a million species 
of tropical plants have been examined for pharmaceutical purposes (127). The yield of cytotoxic agents from natural sources is generally considered to be several orders of magnitude greater than randomly acquired synthetic agents $(21,83)$. Table 3 lists currently available anticancer agents that are derived from natural sources. In 1959, the NCI initiated its fermentation broth and plant screening programs. In 1972, the marine acquisition program was initiated. By 1980, approximately 200000 fermentation broth extracts, 114000 plant extracts and 17000 marine extracts were tested $(127,157)$. Of these, samples from marine sponges and tunicates exhibited exceptional activity (157). These marine organisms produce toxins as a mechanism of self-defence (168). Many interesting and important compounds have been isolated from marine organisms. For example, the development of cytarabine, a widely used antileukemic chemotherapeutic agent, was based on leads provided by the isolation of 1-ß-arabinofuranosyl derivatives of uracil from the Caribbean sponge Cryptotethya crypta (9, 89). Didemnin-B (Figure 9), a metabolite of the tunicate Trididemnin solidium (130), has entered Phase II human cancer trials $(157,168)$. The bryostatins, a family of metabolites isolated from the bryozoan Bugula neritina (120), is also undergoing clinical trials $(157,168)$. Palytoxin (Figure 10), whose structural analysis represents a considerable triumph in natural product research, is derived from the Palythoa species and is the most toxic non-proteinous agent 
ever discovered (104). As the structures of these agents illustrate, the structural diversity of compounds isolated from marine organisms appears boundless.

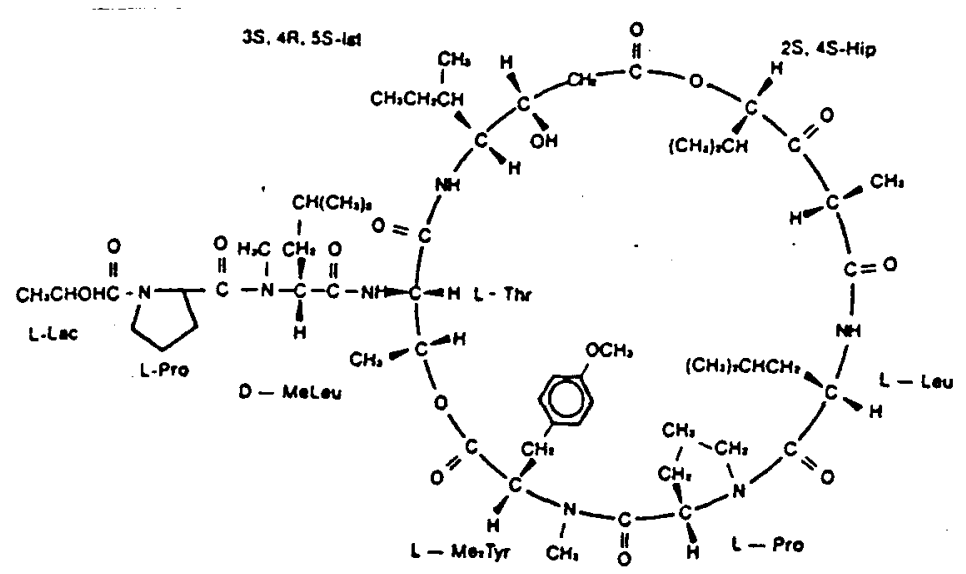

Figure 9. Molecular structure of Didemnin B. From: Suffness M. and Thompson J.E. (1988) National Cancer Institute's role in the discovery of new antineoplastic agents. In: Biomedical Importance of Marine organisms (Fautin D.G., ed). California Academy of Sciences, San Francisco. pp 155. 


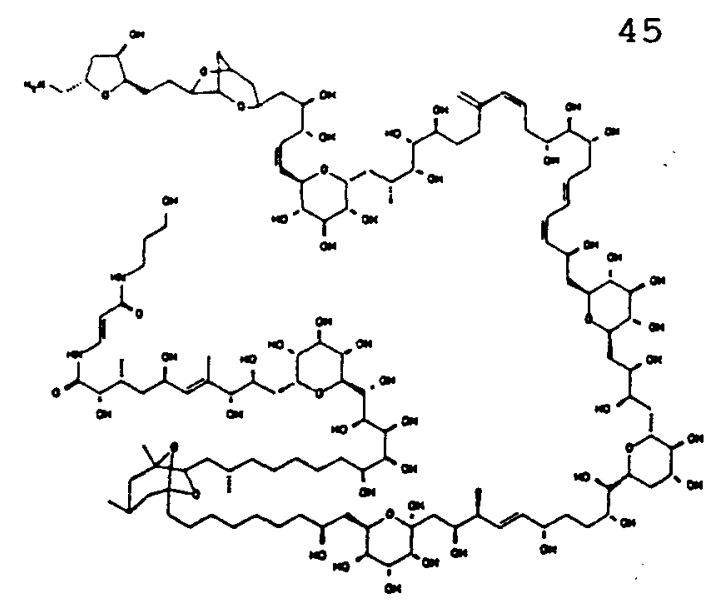

Figure 10. Molecular structure of palytoxin. From: Ireland C.M., Roll D.M., Molinski T.F., McKee T., Zabriski T.M. and Swersey J.C. (1988) Uniqueness of the marine chemical environment: Categories of marine natural products from invertebrates. In: The Biomedical Importance of Marine Organisms (Fautin D.G., ed), California Academy of Sciences, San Francisco. pp 54.

The sources and number of samples collected by the NCI from 1986 to 1991 is summarized in Table 5. This acquisition program is devised so that the greatest possible diversity of plant and marine life is acquired.

Table 5. Sources and number of samples collected by the NCI (1986-1991).

MARINE MICROORGANISMS

5000 shallow water, Indo-Pacific

5000 deep water, Caribbean and Atlantic

TROPICAL RAINFOREST PLANTS

7500 Southeast Asia

7500 Africa and Madagascar

7500 Central and South America

MICROORGANISMS

1500 fungi, soil origin

1500 cyanobacteria, soil and other origins

2000 marine microorganisms

\footnotetext{
*From: Suffness M. and Thompson J.E. (1988) National Cancer Institute's role in the discovery of new antineoplastic agents. In: Biomedical Importance of Marine Organisms (Fautin D.G., ed). California Academy of Sciences, San Francisco. pp 155.
} 
There are several problems associated with natural product screening:

1. Crude extracts may not be readily soluble.

2. The active ingredient in a crude extract may be present in exceedingly small amounts, so that even though it may potentially be extremely active, it may not be detected. 3. It may be difficult to isolate the active ingredient in the crude extract.

4. It may be difficult to acquire sufficient quantities of the active agent once it is identified.

This last problem is usually considered to be the most severe. Several options to resolve this obstacle have been proposed $(11,157)$ :

1. Use tissue culture to grow the cell(s) responsible for the production of the agent of interest.

2. Identify a precursor to the agent in question that is easier to isolate.

3. Maintain rare marine invertebrates in tanks and plants in greenhouses.

4. Collect close relatives of the plant or animal in question.

5. Utilize genetic engineering techniques. 


\section{Thesis objectives}

The first objective of this thesis was to select and implement an in vitro assay suitable for evaluating the effects of various test agents on the cellular viability of human breast cancer cell lines and normal and malignant human breast epithelial cells (HBEC) in primary culture. This laboratory has, in the past, relied on the incorporation of radiolabelled thymidine as an indicator of cell growth. It was felt that this assay, although reproducible, was not suitable for larger scale screening. After a review of the literature, the MTT tetrazolium dye reduction assay was selected. Unfortunately, there was a great variation in the literature regarding the protocol for the assay, especially for assay parameters such as solvent, MTT incubation concentration and MTT incubation time. An MTT assay protocol had to be elucidated that would optimize the sensitivity and the accuracy of this assay for use on human breast cells.

The principal objective of this thesis was to determine the effects of 7 crude extracts and 8 pure metabolites derived from marine organisms on the cellular viability of 4 drug-sensitive and 2 drug-resistant cell lines. In addition, it was a perogative to see if any agents that demonstrated significant cytotoxicity against the drug-resistant human breast cancer cell lines may circumvent the MDR phenotype. This thesis also investigated the cytotoxicity of the more potent test agent on normal and malignant human breast 
epithelial cells (HBEC) in primary culture, which more closely resemble counterpart cells in vivo than do cell lines. The normal HBEC were included in the screening protocol to detect tumor-specific agents. 


\section{CHAPTER 2}

\section{MATERIALS AND METHODS}

\section{Isolation and Purification of compounds}

The procedures used for the isolation and purification of the geodiamolides (34), bromotopsentin (105), xestospongin E (99), bastidin-4 (100), imbricatine (17), chromodorolide A (40), jaspamide (29), glaciasterol A (123) and the Garvea extract (46) have previously been described. The crude extracts of the other organisms were prepared by homogenizing the organisms in methanol, filtering and evaporating the methanol in vacuo. The isolation and purification of compounds used for cytotoxicity testing did not constitute part of this thesis work. They were provided by Dr. Raymond Andersen, Departments of Chemistry and Oceanography, U.B.C.

All samples were stored lyophilized in a refrigerator until ready for use. When ready for use, some of the compound was transferred to a $250 \mu 1$ microfuge tube, weighed and then dissolved in enough solvent so that all of the sample is dissolved but the volume is still workable (typically about $100 \mu \mathrm{l}$ ). The solvent used for all samples except for imbricatine was ethanol. Sterile saline was used for dissolving imbricatine. The $250 \mu 1$ microfuge tubes containing dissolved samples were then placed within $1.5 \mathrm{ml}$ screw cap microfuge tubes and these were then wrapped in parafilm (to minimize any evaporation of solvent) and stored in the freezer at $-5^{\circ} \mathrm{C}$. 


\section{Cell Line culture}

The MCF-7, T-47D, ZR-75-1 and MDA-MB-231 cell lines, which originated from effusions from women with metastatic breast cancer, were obtained from the American Type culture Collection (ATCC). The MDA-A ${ }^{\mathrm{r}}$ cell line was furnished by Dr. W. McGuire at the University of Texas, and the MCF-7 $\mathrm{Ad}^{\mathrm{r}}$ cell line was obtained from Dr. K. H. Cowan at the National Institute of Health $(\mathrm{NIH})$. The cell lines were maintained in $25 \mathrm{~cm}^{2}$ Corning tissue culture flasks containing $10 \mathrm{ml}$ of growth medium consisting of Ham's F12/Dulbecco's modified Eagle medium [F12/DME; $1: 1$ (v/v); Terry Fox Media Preparation Services] supplemented with $10 \mathrm{mM}$ HEPES (H) and either $10 \%$ fetal bovine serum (FBS; Gibco Laboratories; for MDA-MB-231), 5\% FBS and $5 \mu \mathrm{g}$ insulin/ml (sigma; for MCF-7, T-47D and ZR-75-1), 10\% FBS and $1 \mu \mathrm{g}$ Adriamycin/ml (ADR; Adria Laboratories; for $\mathrm{MDA}-\mathrm{Al}^{\mathrm{r}}$ ), or $5 \% \mathrm{FBS}, 5 \mu \mathrm{g}$ insulin/ml and $0.5 \mu \mathrm{g} \mathrm{ADR} / \mathrm{ml}$ (for $\mathrm{MCF}-7 \mathrm{Ad}^{\mathrm{r}}$ ) (Appendices 1-4). All of these cell lines grow adherent to the tissue culture plastic.

Cultures were maintained in a humidified atmosphere consisting of $5 \% \mathrm{CO}_{2}$ and $95 \%$ air at $37^{\circ} \mathrm{C}$. Media changes were every second to third day (ie: $M-W-F$ ). Multiple flasks of each cell line were maintained. The rationale for this was that the drug samples were dissolved in very small amounts of ethanol (_ $100 \mu \mathrm{l})$. As a result of this small working volume, it was felt that repeated opening and closing of the drug-containing microfuge tubes would result in excessive 
evaporation of the solvent, thus altering the concentration of the drug. To minimize the number of opening and closing of the tube, multiple flasks of cells were used to independently set up (ie: no cell pooling) separate drugtesting cultures on microtiter plates at one time. If at any time the stock drug concentrations became suspicious, either the vehicle was evaporated in a $\mathrm{N}_{2}$ atmosphere and the sample was reweighed and redissolved, or a fresh stock solution was prepared from previously undissolved drug.

Cells were subcultured when approaching confluence by removing the growth medium, washing the culture with $5 \mathrm{ml}$ of F12/DME/H (to remove any residual FBS), and adding $7 \mathrm{ml}$ of either warmed saline-trypsin-versene (MCF-7, T-47D, 2R-75-1, MDA-MB-231 and MCF-7 $\mathrm{Ad}^{\mathrm{r}}$ ) (Appendix 5) or warmed calcium and magnesium-free phosphate-buffered saline (PBS) supplemented with $1 \mathrm{mM}$ ethylenediaminetetraacetic acid (EDTA; MDA${ }_{A 1}{ }^{r}$ ) (Appendix 6). Gentle agitation of the tissue culture flasks for 3-5 min resulted in a single-cell suspension. Too much or too little agitation resulted in cell clumping, which was found to be irreversible. The cell suspension was then centrifuged in a clinical centrifuge at $100 \times \mathrm{g}$ for 3 min. The supernatant was then removed and $2 \mathrm{ml}$ of the appropriate growth medium (Appendices 1-4) were then added to resuspend the cells. A small fraction $(0.4 \mathrm{ml})$ of this suspension was then used to seed a new tissue culture plate. At the time of the experiment the cells were resuspended and centrifuged at $100 \mathrm{x} \mathrm{g}$ for $3 \mathrm{~min}$. The supernatant was then 
removed and the pellet was resuspended in $2 \mathrm{ml}$ of $\mathrm{F} 12 / \mathrm{DME} / \mathrm{H}$. An aliquot of the cell suspension $(0.1 \mathrm{ml})$ was placed in a small glass test tube and a drop of trypan blue dye was added. Viable cells are able to prevent the trypan blue dye from penetrating the plasma membrane, whereas dead cells take up the dye and thus stain blue. The viable cell number was then determined by counting on a hemacytometer. After cell counting, the remaing $1.9 \mathrm{ml}$ of cells suspended in F12/DME/H was centrifuged at $100 \times \mathrm{g}$ for $3 \mathrm{~min}$, the supernatant removed and the cell pellet resuspended in F12/DME/H supplemented either 5\% FBS and $5 \mu \mathrm{g}$ insulin/ml (MCF-7, T-47D, ZR-75-1 and MCF-7 $\mathrm{Ad}^{\mathrm{r}}$ ) or $10 \%$ FBS (MDA-MB-231 and $\mathrm{MDA}-\mathrm{A} 1^{\mathrm{r}}$ ) to result in a final viable cell concentration of $4 \times 10^{4} \mathrm{cells} / \mathrm{ml}$. Cells were then seeded at $4 \times 10^{3}$ cells/well onto $96-$ well microtiter plates in $100 \mu l$ volume of the appropriate medium (Appendices 7 and 8 ) and then reincubated. Cells were only seeded in the inner $10 \times 6$ matrix of the $12 \times 8$ microtiter plate, whereas cell-free F12/DME/H was placed in the wells bordering the edge of the microtiter plate. This was done to minimize any discrepancies in the microenviroments between wells bordering the plate edge and those that do not. In addition, only the $8 \times 6$ matrix towards the left side of the microtiter plate was used for the T-47D cell line since it was observed in early experiments that alterations in $\mathrm{pH}$ of the growth medium stimulated the growth of this cell line. Since I work right to left when removing and adding media, 
the cells to the right side of the microtiter plate were exposed to the air of the laminar flow hood longer than those towards the left side of the plate, and thus had the $\mathrm{pH}$ of their growth media altered to a greater extent.

\section{Human Breast Epithelial cells in Primary culture}

Normal tissue cells from reduction mammoplasties and malignant tissue from biopsies and mastectomies were obtained from collaborating surgeons at local hospitals. Malignant breast tissue was used only from patients who had no previous chemotherapy. During surgery, the tissue was aseptically placed into plastic sterile cups containing transport media (Appendix 9). Immediately following surgery, the cups were placed on crushed ice in a cooler and transported to the tissue culture room. Under sterile conditions, excess fat was removed from the tissue samples and the samples were finely minced using 2 scalpels. The minced tissue was then transferred to $1.7 \mathrm{ml}$ cryotubes so that the tubes were half filled. Freezing medium (Appendix 10) was then added to bring the volume to $1 \mathrm{ml}$. The tissue was then gradually frozen in liquid nitrogen to be used at a later date. At the time when the tissue was needed, the vial was removed from liquid nitrogen and quick-thawed by agitating in a $37^{\circ} \mathrm{C}$ waterbath. The vial was wiped with a Kim-wipe saturated with $70 \%$ ethanol prior to opening. Once opened, the minced tissue was transferred to a $15 \mathrm{ml}$

centrifuge tube. The vial was then rinsed with a few $\mathrm{ml}$ of 
F12/DME/H which was also placed into the centrifuge tube. The tube was then centrifuged at $100 \mathrm{x} \mathrm{g}$ for $3 \mathrm{~min}$ and the supernatant discarded. Following this, the pellet was washed with $5 \mathrm{ml}$ of $\mathrm{F} 12 / \mathrm{DME} / \mathrm{H}$, recentrifuged at $100 \mathrm{x} \mathrm{g}$ for $3 \mathrm{~min}$ and then resuspended in $5 \mathrm{ml}$ warmed dissociation medium (Appendix 11). This mixture was then transferred to a $125 \mathrm{ml}$ Bellco dissociation flask. The $15 \mathrm{ml}$ centrifuge tube was rinsed several times with warmed dissociation medium that was also transferred to the dissociation flask. The total volume of dissociation medium in the flask was then brought up to $50 \mathrm{ml}$. The flask was covered first with sterile tin foil followed by parafilm, then placed in a gyrating shaker inside a $37^{\circ} \mathrm{C}$ incubator for $16-18 \mathrm{~h}$ (until no large tissue fragments remained). After dissociation, the solution had a cloudy appearance with a layer of liquid fat floating on top. The dissociation mixture was transferred to a $50 \mathrm{ml}$ centrifuge tube. The flask was rinsed twice with $5 \mathrm{ml}$ of F12/DME/H, with each rinsing being added to the $50 \mathrm{ml}$ centrifuge tube. The tube was then centrifuged at $40 \mathrm{x} \mathrm{g}$ for $30 \mathrm{sec}$ to separate undigested tissue fragments from the cell suspension. The supernatant was transferred to a second 50 ml centrifuge tube. The pellet in the first tube was washed with $5 \mathrm{ml}$ of $\mathrm{F} 12 / \mathrm{DME} / \mathrm{H}$, spun at $40 \mathrm{xg}$ for $30 \mathrm{sec}$, with the supernatant being added to the second $50 \mathrm{ml}$ centrifuge tube. This washing and centrifuging of the pellet was repeated, with the supernatant being added to the second centrifuge tube and the pellet being discarded. The cell suspension of 
the second tube was centrifuged at $80 \times \mathrm{g}$ for $4 \mathrm{~min}$ to separate the epithelial fraction (pellet) from the stromal cells, undigested stroma and cellular debris (supernatant). After discarding of the supernatant, the pellet was resuspended in $1 \mathrm{ml}$ of $\mathrm{F} 12 / \mathrm{DME} / \mathrm{H}$ and viable cells determined by trypan blue exclusion and counted on a hemacytometer. Following cell counting, the suspension was centrifuged at $100 \mathrm{x} \mathrm{g}$ for $5 \mathrm{~min}$, the supernatant discarded and the epithelial cell pellet resuspended in growth medium (Appendix 12) such that the final cell concentration was $10^{5}$ cell/ml. These cells were plated into as many wells as possible in the inner $10 \times 6$ matrix of collagen coated 96well microtiter plates. The wells were collagen coated by adding one drop of rat tail collagen (Appendix 14) to each well, swirling the plates to ensure complete coverage of the well and then allowing the plate to dry for $1 \mathrm{~h}$ in a laminar flow hood under UV light. Since the cell yield from each tissue sample was very small, usually only a portion of each microtiter plate was utilized. Tissue samples which had insufficient cell yields were discarded. All wells not receiving cells contained $\mathrm{F} 12 / \mathrm{DME} / \mathrm{H}$. The cell concentration used was $10^{4}$ cells/well in $0.1 \mathrm{ml}$ of growth medium. The cultures were incubated at $37^{\circ} \mathrm{C}$ in $5 \% \mathrm{CO}_{2}$ and $95 \%$ air. The growth medium of these cultures contained the patient's own serum (Appendix 13). Culturing cells in the serum of the patient from whom the tissue was received is the routine protocol for chemosensitivity testing in our laboratory (42, 
43). It has been observed that fibroblasts in serumcontaining media are stimulated to grow (44). As a result of this situation, the tissue culture plates during their 5 day culturing period were monitored using a phase contrast microscope to ensure that the dominant cell population $(>80 \%$ ) had an epithelial-like morphology (ie: polygonal shaped) .

\section{Compound-Testing Protocol}

On day 0 , the cells (cell lines and HBEC in primary culture) were seeded onto the microtiter plates in the appropriate growth medium (Appendices 7, 8 and 13) as described earlier. After $24 \mathrm{~h}$, the medium was removed and $100 \mu 1$ of fresh medium containing either 5 serial dilutions (typically $100,10,0.1,0.01$ and $0.001 \mu \mathrm{g} / \mathrm{ml}$ ) of the agent to be tested or 5 serial dilutions of the corresponding drug vehicle (ethanol or saline) were added to the wells. Drug control cultures received the appropriate growth medium with no drug or vehicle. Each drug concentration, drug vehicle concentration and control condition (no drug or vehicle) was represented by 4 to 6 wells within each experiment. Each experiment was repeated 2-4 times, using independent cultures each time. Cultures were incubated with the drugs or drug vehicles for $48 \mathrm{~h}$. The cells were then washed once with F12/DME/H to remove any residual drug and cultured in the appropriate drug-free medium (Appendices 7 and 8 ) for 48 h. A 48 h drug incubation period was selected to ensure that 
all cells passed through at least one cell cycle, thus allowing phase-specific and cell-cycle-specific agents to exert their effects. The cell-cycle times of MCF-7, T-47D, ZR-75-1, MDA-MB-231, MCF-7 $\mathrm{Ad}^{\mathrm{r}}$ and MDA-A1 ${ }^{\mathrm{r}}$ cells used in this laboratory are $30,22,44,21,23$ and $18 \mathrm{~h}$, respectively. A $48 \mathrm{~h}$ drug recovery period was selected to ensure enough time had been allowed for the cytotoxic effects of the drug to be realized. Inhibitors of protein synthesis usually require a drug recovery period of approximately $24 \mathrm{~h}$, whereas inhibitors of DNA synthesis require a recovery period of 48-96 h (135). After the recovery period, viable cells were quantified by the MTT assay.

In some experiments performed to detect agents that might circumvent the MDR phenotype, MCF-7 $\mathrm{Ad}^{\mathrm{r}}$ cells were incubated in medium containing the concentration of Adriamycin that results in a $50 \%$ decrease in cell growth for this line $\left(\mathrm{ED}_{50}, 5 \mu \mathrm{g} / \mathrm{ml}\right)$ as well as serial dilutions of the drug to be tested.

\section{Preparation of standard Curves for Each Cell Line}

Since the relationship between absorbance at $540 \mathrm{~nm}$ and cell number is not necessarily linear when using the MTT assay (124), a standard curve for each cell line was prepared. Serial dilutions $\left(2 \times 10^{3}\right.$ to $65 \times 10^{3}$ cells/well) of each cell line were seeded onto 96-well microtiter plates in the appropriate growth medium (Appendices 7 and 8 ). 
Fifteen hours after cell seeding, the cells were quantified using the MTT assay.

\section{MTT Assay}

\section{a. Preparation of MTT}

MTT (Sigma) powder was weighed, placed in a 17 × $100 \mathrm{~mm}$ polypropylene test tube and dissolved in $8 \mathrm{ml}$ of warmed serum-free and phenol red-free F12/DME/H (Sigma). With the use of a small spatula, the aggregates of MTT were broken up and the solution stirred until all the MTT was dissolved. The solution was filter sterilized through a Millex GV 0.22 $\mu \mathrm{m}$ syringe filter to remove any pathogens, undissolved MTT and any spontaneously formed formazan crystals. Warmed serum-free and phenol red-free F12/DME/H was then added to bring the final concentration to $1 \mathrm{mg} \mathrm{MTT} / \mathrm{ml}$.

\section{b. MTT Assay Protocol}

The procedure for the MTT assay used in all drug chemosensitivity experiments is summarized in Figure 11. The medium was removed and $100 \mu \mathrm{l}$ of $\mathrm{MTT}(1 \mathrm{mg} / \mathrm{ml})$ dissolved in serum-free and phenol red-free F12/DME/H were added to each well. Serum-free medium is used so that there is no precipitation of any residual serum protein upon addition of the solvent, thereby decreasing background absorbance levels. Similarily, phenol red-free medium is used to prevent interference of the red $\mathrm{pH}$ indicator during the absorbance readings. Following a $5 \mathrm{~h}$ incubation period at 
$37^{\circ} \mathrm{C}$ in $5 \% \mathrm{CO}_{2}$ and $95 \%$ air, $100 \mu 1$ of $20 \%$ formol in saline were added to each well. Following $30 \mathrm{~min}$ at room temperature, the medium was removed using a multichannel pipette (Titertek) and $100 \mu l$ of anhydrous isopropanol were added to each well to dissolve the formazan crystals. After $1 \mathrm{~h}$, the plates were gently agitated, and absorbance values of each well were determined at $540 \mathrm{~nm}$ using a 96-well microtiter plate reader (model EL 311, Biotek Instruments) interfaced with a MacIntosh Apple computer. 
Figure 11. MTT assay protocol.

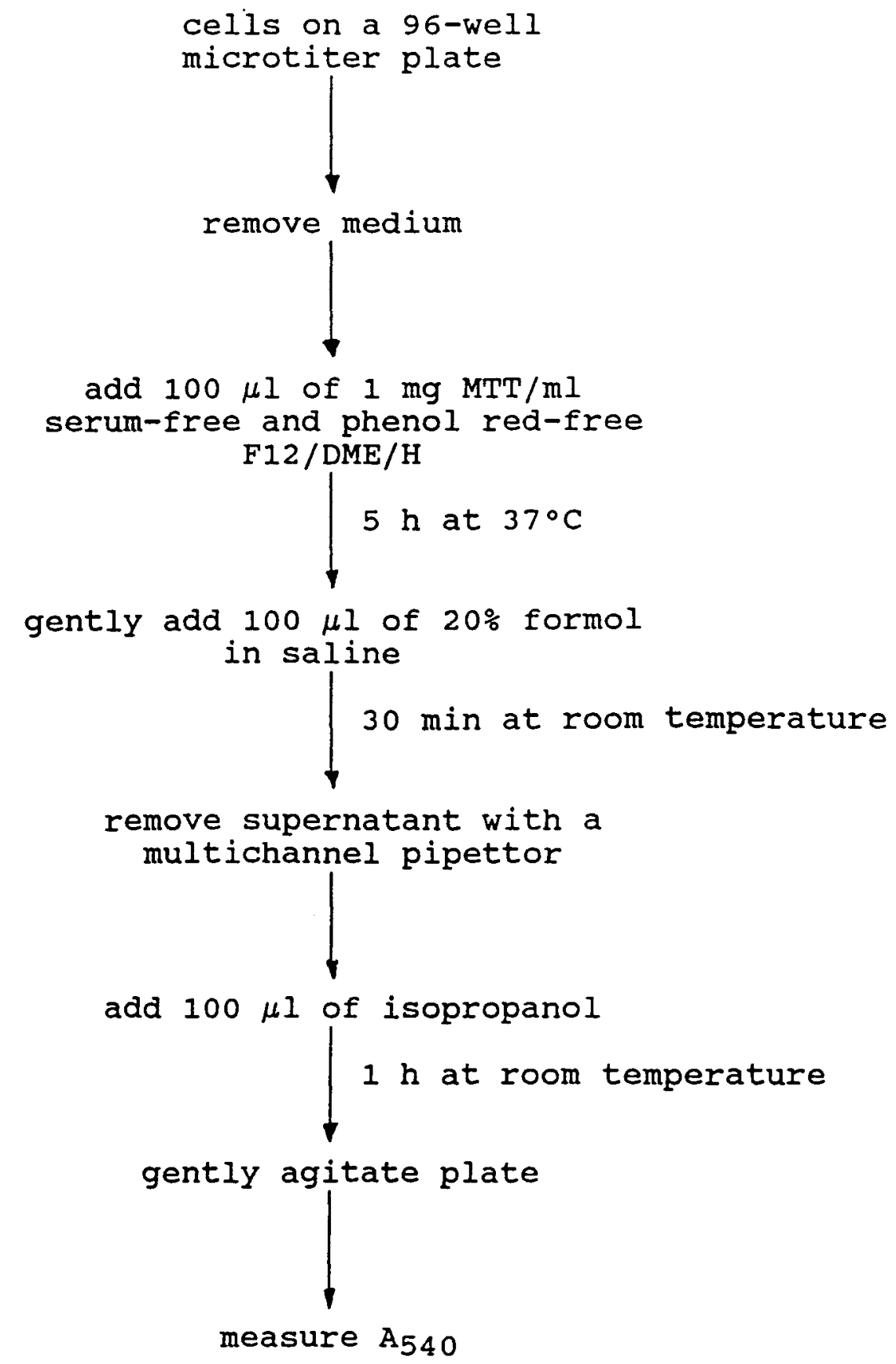

To take into account any absorbance due to residual MTT, MTT control wells (which do not contain cells) were incorporated into the experiment. Absorbance values obtained for these MTT control wells were subtracted from absorbance 
values obtained for cell-containing wells. The corrected absorbance values were then converted to cell numbers via standard curves specific for each cell line. Cytotoxicity was determined by comparing drug-treated cultures with control cultures (which are assigned a value of $100 \%$ ). The $\mathrm{ED}_{50}$ value was then determined from the dose response curve. A control to monitor reduction of MTT to formazan by drugs that have reducing properties was not included in the experiments. Previous studies have demonstrated that reducing agents do not influence results generated by the assay (20).

The elucidation of the various assay parameters (solvent, MTT incubation concentration and MTT incubation time) presented in this assay protocol were determined as described below (c-e).

\section{c. Selection of solvent for the MTT Assay}

\section{i) With No Removal of supernatant Prior to solvent Addition}

MCF-7 cells were seeded at $1.3 \times 10^{5} \mathrm{cells} / \mathrm{ml}$ in $430 \mu 1$ of $1 \mathrm{mg} \mathrm{MTT/ml}$ serum-free and phenol red-free $\mathrm{F} 12 / \mathrm{DME} / \mathrm{H}$ in 3 $12 \times 75 \mathrm{~mm}$ polypropylene test tubes. Following a $4 \mathrm{~h}$ incubation at $37^{\circ} \mathrm{C}$ in $5 \% \mathrm{CO}_{2}$ and $95 \%$ air, $870 \mu \mathrm{l}$ of either anhydrous isopropanol, ethanol or spectrophotometric grade dimethyl sulfoxide (DMSO) were added to each tube. The cell generated formazan was allowed to dissolve in the solvent for $2 \mathrm{~h}$ at room temperature. The formazan solvent mixture was then transferred to a glass cuvette and a wavelength 
scan from 400 to $640 \mathrm{~nm}$ was generated for each solvent mixture using a UV/Visible scanning spectrophotometer (Beckman Instruments). The reference cell for each of the 3 wavelength scans was the solvent containing $1.3 \times 10^{5}$ dead (1ysed) MCF-7 cells and $430 \mu \mathrm{l}$ of $1 \mathrm{mg} \mathrm{MTT} / \mathrm{ml}$ in F12/DME/H.

\section{ii) With Removal of MTT supernatant Prior to solvent}

\section{Addition}

MCF-7 cells were seeded at $2 \times 10^{5} \mathrm{cells} / \mathrm{ml}$ in $1.3 \mathrm{ml}$ of $1 \mathrm{mg} \mathrm{MTT/ml}$ serum-free and phenol red-free F12/DME/H in 3 $12 \times 75 \mathrm{~mm}$ polypropylene test tubes. Following a $4 \mathrm{~h}$ incubation at $37^{\circ} \mathrm{C}$ in $5 \% \mathrm{CO}_{2}$ and $95 \%$ air, the tubes were centrifuged at $100 \mathrm{x} \mathrm{g}$ for $3 \mathrm{~min}$, the supernatant was removed and $1.3 \mathrm{ml}$ of either isopropanol, ethanol or DMSO were added to each tube. The cell generated formazan was then allowed to dissolve in the solvent for $1 \mathrm{~h}$ at room temperature. The formazan-solvent mixture was then transferred to a glass cuvette and a wavelength scan from 400 to $640 \mathrm{~nm}$ was generated for each solvent mixture using a UV/visible scanning spectrophotometer. The reference cells used for each of the 3 wavelength scans was the solvent containing $2.6 \times 10^{5}$ dead (lysed) MCF-7 cells (cells that were not exposed to MTT). 


\section{d. Selection of Optimal MTT concentration}

Multiple wells of serial dilutions of MCF-7 cells (312 to $5 \times 10^{5}$ ) were seeded onto 96 -well microtiter plates in $100 \mu \mathrm{l}$ of growth medium (Appendix 1). Following a $24 \mathrm{~h}$ incubation at $37^{\circ} \mathrm{C}$ in $5 \% \mathrm{CO}_{2}$ and $95 \%$ air, the growth medium was removed and serial concentrations $(0.125-5 \mathrm{mg} / \mathrm{ml})$ of MTT dissolved in $100 \mu 1$ serum-free and phenol red-free F12/DME/H were added to the wells. MTT addition was such that every concentration of MTT tested was exposed to the entire spectrum of cell densities. Following a $4 \mathrm{~h}$ incubation period at $37^{\circ} \mathrm{C}$, the medium was removed and $100 \mu 1$ of isopropanol were added to each well. The formazan was allowed to dissolve for $1 \mathrm{~h}$ at room temperature and then the plates were read on a 96-well microplate reader at $540 \mathrm{~nm}$.

\section{e. Selection of optimal MTT Incubation Time}

MCF-7 cells were seeded at $4 \times 10^{3}$ cells/well in growth medium (Appendix 1) on 7 different 96-well microtiter plates. Following a $24 \mathrm{~h}$ incubation at $37^{\circ} \mathrm{C}$ in $5 \% \mathrm{CO}_{2}$ and 95\% air, the growth medium was removed and $100 \mu \mathrm{l}$ of $1 \mathrm{mg}$ $\mathrm{MTT} / \mathrm{ml}$ serum-free and phenol red-free F12DME/H were added to all the wells. The cells were reincubated at $37^{\circ} \mathrm{C}$ and at $1 \mathrm{~h}$ intervals for $7 \mathrm{~h}$, a single microtiter plate was taken out of the incubator and the mean absorbance of each plate was measured at $540 \mathrm{~nm}$. 


\section{f. Removal of MTT supernatant}

In the initial experiments outlined above (c-e), it was observed that removal of the MTT-F12/DME/H supernatant with a multichannel pipettor (Titertek) resulted in cell loss and therefore increased assay error. It became apparent that MCF-7 cells, once they have formed intracellular formazan, become easily detached from the tissue culture plastic. To correct for this problem, a variety of alternative methods were tested for removing the MTT supernatant. Briefly, MCF-7 cells were seeded at $4 \times 10^{3}$ cells/well in 42 wells on 5 different 96-well microtiter plates. Following a $24 \mathrm{~h}$ incubation period at $37^{\circ} \mathrm{C}$ in $5 \% \mathrm{CO}_{2}$ and $95 \%$ air, the growth medium (Appendix 1) was removed and $100 \mu \mathrm{l}$ of $1 \mathrm{mg} \mathrm{MTT/ml}$ serum-free and phenol red-free F12/DME/H were added to each well. Following a $5 \mathrm{~h}$ MTT incubation period, the MTT supernatant was removed by a variety of methods: 1) The cells, prior to MTT supernatant removal, were fixed to the tissue culture plate by the addition of $100 \mu 1$ of $20 \%$ formol in saline (to result in a final concentration of $10 \%$ formol). After $30 \mathrm{~min}$ at room temperature the MTT supernatant was gently removed using a multichannel pipette. 2) The MTT supernatant was removed by submersing the plate in saline and then blotting the plate on paper towels. 3) The MTT supernatant was removed by first inverting the plate and "flicking" it with a sudden wrist motion, then dipping the plate in saline and finally by blotting on paper towels. 4) The MTT supernatant was removed by pipetting with a 
multichannel pipette.

Following removal of the MTT supernatant, $100 \mu 1$ of isopropanol were added to each well and the absorbance value at $540 \mathrm{~nm}$ of each cell-containing well was measured. From these values, the coefficient of variation (the ratio of the standard deviation (S) relative to the mean (X) expressed as a percentage; $S-X \cdot 100 \%$ ) was determined for each plate.

\section{g. Absorbance Limit of the MTT Assay}

To determine the upper limit of absorbance at $540 \mathrm{~nm}$ in which the assay becomes insensitive to differences in formazan concentration (ie: cell number), the absorbances of serial dilutions $(1-800 \mu \mathrm{g} / \mathrm{ml})$ of pure MTT formazan (Sigma) dissolved in isopropanol were measured using a spectrophotometer. The absorbance values were used to construct a graph relating absorbance to formazan concentration.

To relate the absorbance spectrum of pure formazan to cell-generated formazan, a wavelength scan (400-640 nm) of pure formazan dissolved in isopropanol at $30 \mu \mathrm{g} / \mathrm{ml}$ was generated using a UV/Visible scanning spectrophotometer. 
CHAPTER 3

\section{RESULTS}

\section{Optimization of MTT Assay Parameters}

\section{a. Selection of solvent for the MTT Assay}

The MTT tetrazolium dye reduction assay utilizes formazan production as an index of cell population viability. Figure 12 shows the wavelength scan from 400 to $640 \mathrm{~nm}$ of cell-generated formazan dissolved in isopropanol, ethanol and DMSO in the presence of serum-free and phenol red-free F12/DME/H. A peak in absorbance was observed for isopropanol and ethanol at approximately $560 \mathrm{~nm}$. The height of the isopropanol peak (0.71) was slightly higher than that for the ethanol peak (0.68). A peak in absorbance for the DMSO curve was observed at a wavelength of $520 \mathrm{~nm}$. The height of this DMSO peak $(0.53)$ was substantially lower than that for isopropanol and ethanol. It was observed in this experiment that it was difficult to get the formazan crystals to dissolve in DMSO in the presence of F12/DME/H, even when the formazan dissolving period was extended to 2 h. As a consequence, the experiment was repeated with the modification that the MTT supernatant was removed prior to solvent addition.

Figure 13 shows the wavelength scan from 400 to $640 \mathrm{~nm}$ of cell-generated formazan dissolved in isopropanol, ethanol and DMSO. A peak in absorbance was observed for isopropanol at $540 \mathrm{~nm}$, for ethanol at $580 \mathrm{~nm}$ and for DMSO at $500 \mathrm{~nm}$. The height of the isopropanol peak (2.67) was slightly higher 
than that for the ethanol peak (2.39) and the DMSO peak (2.35). Since the ELIZA reader was equipped with a $540 \mathrm{~nm}$ filter, these results indicated that isopropanol was the most suitable solvent for the MTT assay. No difficulty in dissolving the formazan crystals was observed when using DMSO as the solvent in this second experiment. The heights of all the peaks for the 3 different solvents in the second experiment (removal of MTT supernatant) were several magnitudes higher than those generated in the first experiment (no removal of MTT supernatant). 
Figure 12. Wavelength scans of cell-generated formazan dissolved in DMSO, isopropanol and ethanol in the presence of the MTT supernatant.

MCF-7 cells were incubated in $1 \mathrm{mg}$ MTT/ml serum-free and phenol red-free $\mathrm{F} 12 / \mathrm{DME} / \mathrm{H}$ for $4 \mathrm{~h}$. Following the incubation period, $100 \mu \mathrm{l}$ of either DMSO, isopropanol or ethanol were added to the cells to dissolve the cell-generated formazan. Two hours later, a wavelength scan from $400-640 \mathrm{~nm}$ was generated for each formazan-solvent mixture. The results indicated that isopropanol was the most suitable solvent for reading $A_{540}$ since it generated the highest peak $(0.71)$ at this wavelength. 
FIGURE 12

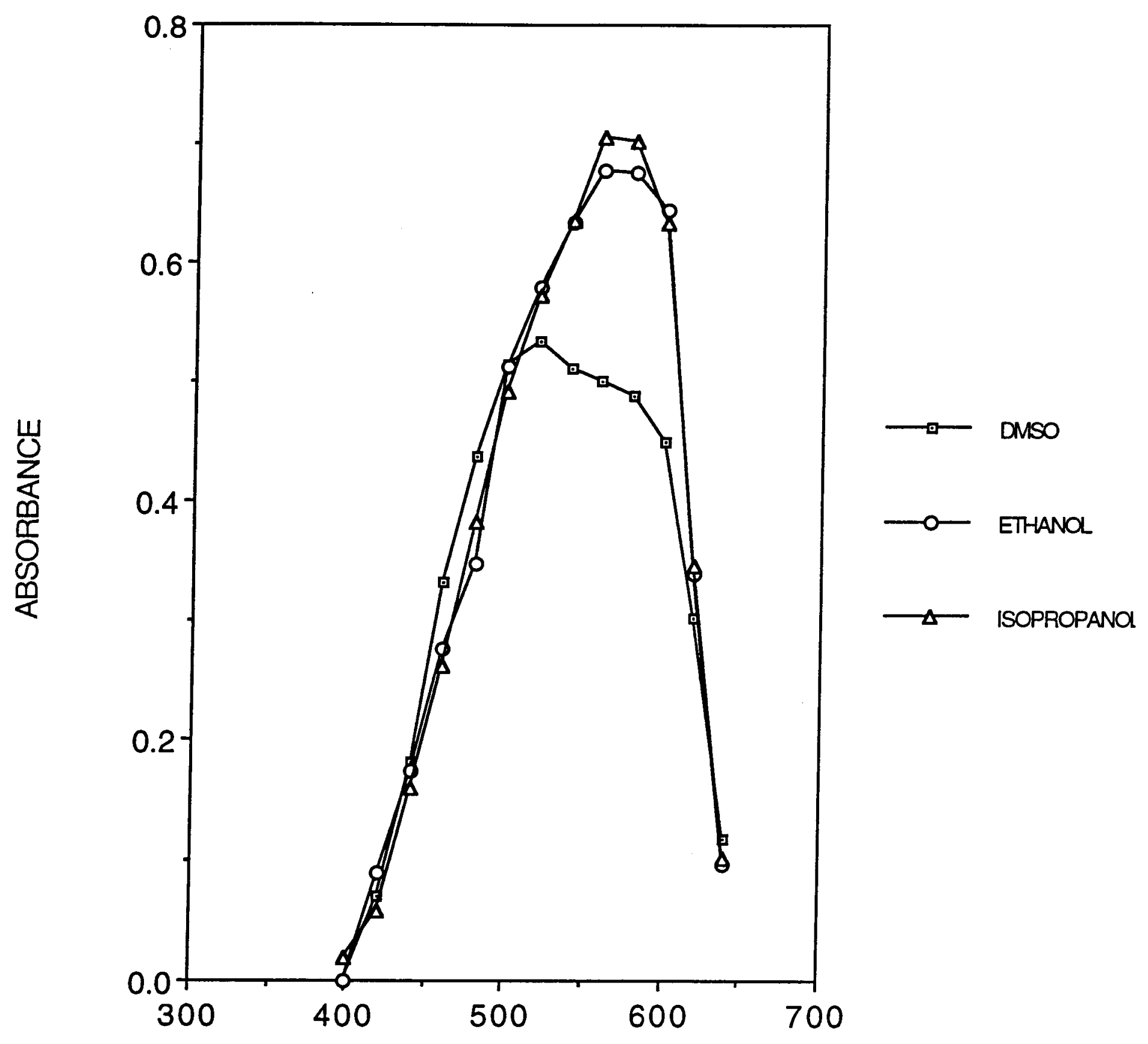

WAVELENGTH $(\mathrm{nm})$ 
Figure 13. Wavelength scans of cell-generated formazan dissolved in DMSO, isopropanol and ethanol.

MCF-7 cells were incubated in $1 \mathrm{mg} \mathrm{MTT} / \mathrm{ml}$ serum-free and phenol red-free $\mathrm{F} 12 / \mathrm{DME} / \mathrm{H}$ for $4 \mathrm{~h}$. Following the incubation period, the supernatant was removed and $100 \mu \mathrm{l}$ of either DMSO, isopropanol or ethanol were added to the cells to dissolve the cell-generated formazan. One hour later, a wavelength scan from $400-640 \mathrm{~nm}$ was generated for each formazan-solvent mixture. The results indicated that isopropanol was the most suitable solvent for reading $A_{540}$, since it generated the highest peak (2.67) at this wavelength. 
FIGURE 13

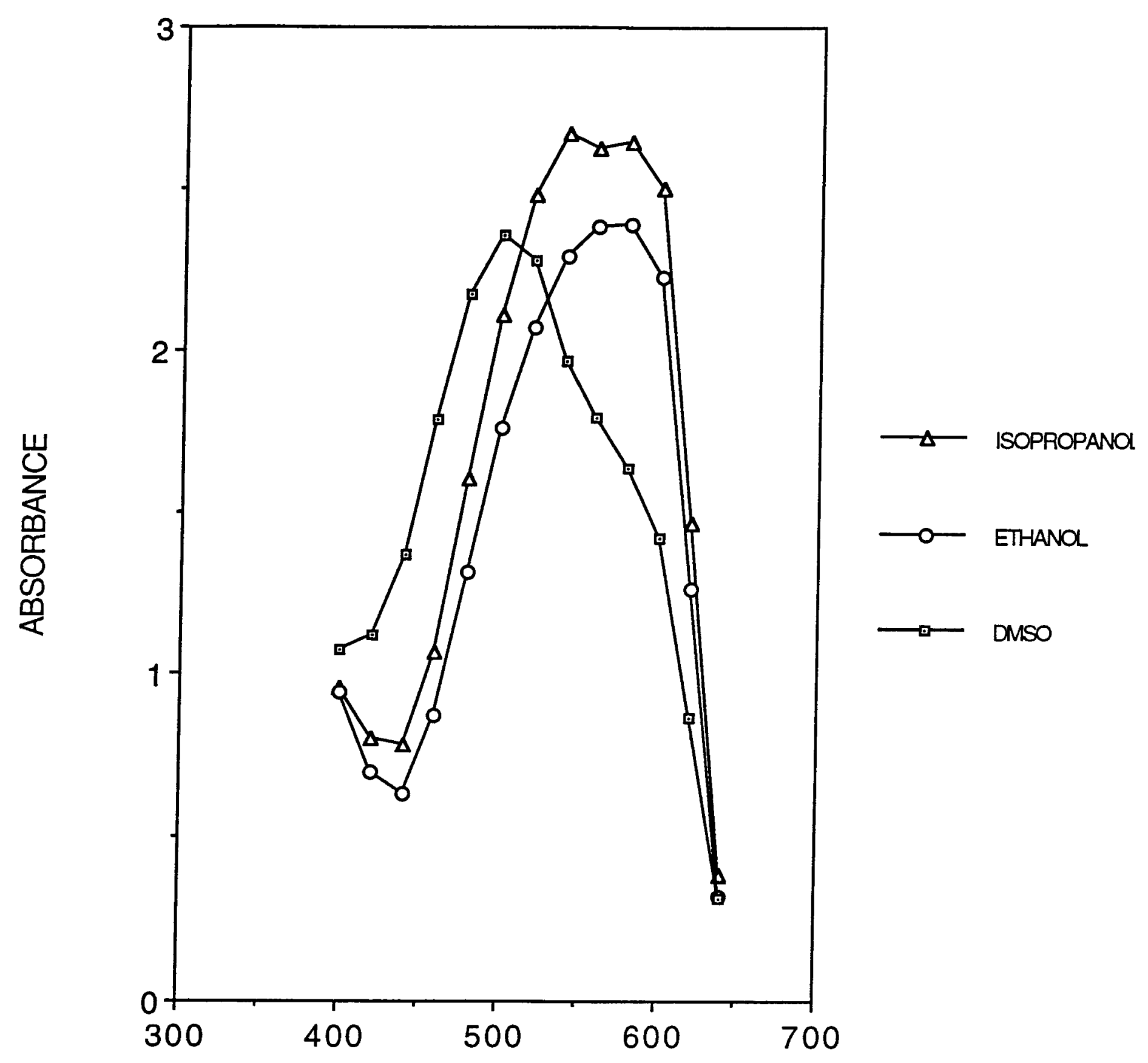

WAVELENGTH $(\mathrm{nm})$ 


\section{b. Selection of optimal MTT concentration}

Figure 14 illustrates the relationship between MTT concentration and absorbance over a variety of cell densities. At lower cell densities, slight differences in absorbance were observed between all the concentrations of MTT, with $1 \mathrm{mg}$ MTT/ml being optimal. As cell number increases, the difference in absorbance between the different concentrations of MTT also increases. At the highest cell density ( $5 \times 10^{5}$ cells/well), $5 \mathrm{mg} \mathrm{MTT} / \mathrm{ml}$ resulted in the greatest absorbance (0.871), whereas 0.125 $\mathrm{mg} \mathrm{MTT} / \mathrm{ml}$ resulted in the lowest absorbance $(0.239)$. It was expected that cell density at the end of the drug testing experiments would generally be $-2 \times 10^{4}$ cells/well. Consequently, $1 \mathrm{mg} \mathrm{MTT} / \mathrm{ml}$ was selected as the most suitable MTT concentration, because it resulted in the highest $A_{540}$ below this cell concentration. 


\section{Figure 14. Formazan production as a function of MTT} incubation concentration

Serial dilutions of $\mathrm{MCF}-7$ cells $\left(312-5 \times 10^{5}\right)$ were exposed to serial concentrations of MTT $(0.125-5 \mathrm{mg} / \mathrm{ml})$ such that every cell density was exposed to every MTT concentration. Following the MTT incubation period, the supernatant was removed, the formazan crystals were dissolved in isopropanol and the $A_{540}$ was measured. At cell densities below $10^{4}$ cells/well, $1 \mathrm{mg} \mathrm{MTT} / \mathrm{ml}$ resulted in slightly higher absorbance than the other MTT concentrations. Above $10^{4}$ cells/well the higher MTT concentrations resulted in greater formazan production, with $5 \mathrm{mg} \mathrm{MTT} / \mathrm{ml}$ being the optimal at the very high cell densities. Since it was expected that the final cell density following the drug incubation period would generally be $2 \times 10^{4}$ cells/well, $1 \mathrm{mg} \mathrm{MTT} / \mathrm{ml}$ was selected as the optimal MTT concentration. 
FIGURE 14

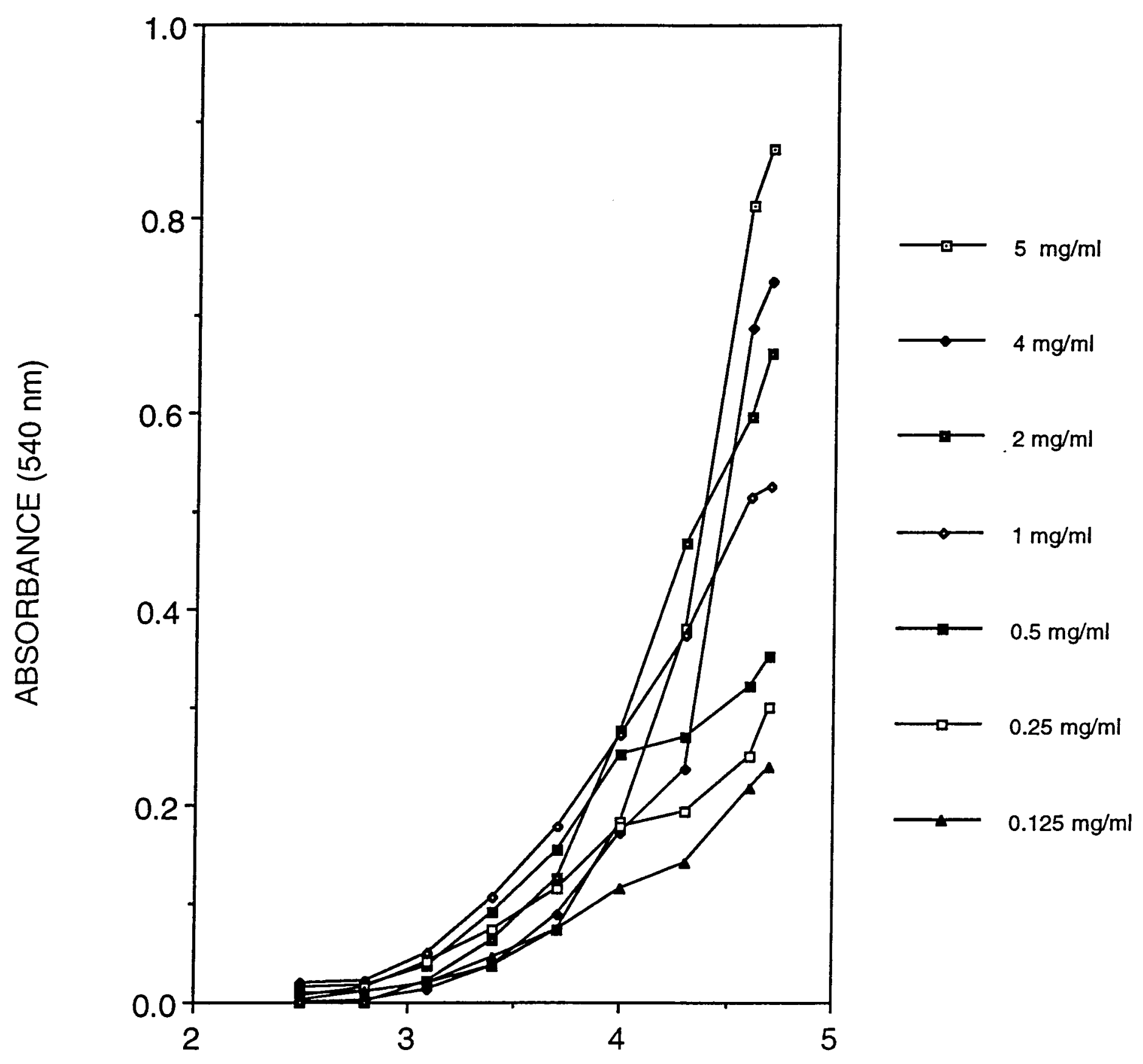

LOG CEU NUMBER 


\section{c. Selection of Optimal MTT Incubation Time}

Figure 15 illustrates the relationship between length of MTT incubation and absorbance at $540 \mathrm{~nm}$. Absorbance (0.302) was highest when the MCF-7 cells were incubated with the MTT solution for $5 \mathrm{~h}$, and consequently a $5 \mathrm{~h}$ MTT incubation time was selected for all further experiments. It is interesting to note that the longer the MCF-7 cells were exposed to the MTT solution after $5 \mathrm{~h}$ MTT incubation, the greater the value was for the coefficient of variation (which is directly proportional to error). This relationship is illustrated in Figure 16. 


\section{Fiqure 15. Formazan production as a function of MTT} incubation time.

MCF-7 cells were seeded at $4 \times 10^{4}$ cells/well on 7 different microtiter plates. Twenty-four hours later, the medium (Appendix 1) was removed and $1 \mathrm{mg} \mathrm{MTT} / \mathrm{ml}$ was added to all the cells. The cells were reincubated at $37^{\circ} \mathrm{C}$ and at $1 \mathrm{~h}$ intervals, a single microtiter plate was removed from the incubator, and the mean $A_{540}$ of its' cell containing wells was determined. A peak in absorbance $(0.302)$ is observed for cells that were incubated for $5 \mathrm{~h}$, thereby indicating that a $5 \mathrm{~h}$ MTT incubation time results in optimal formazan production. The error bars represent the standard error of the mean (standard deviation/" $n$ ) of 2 experiments. 
FIGURE 15

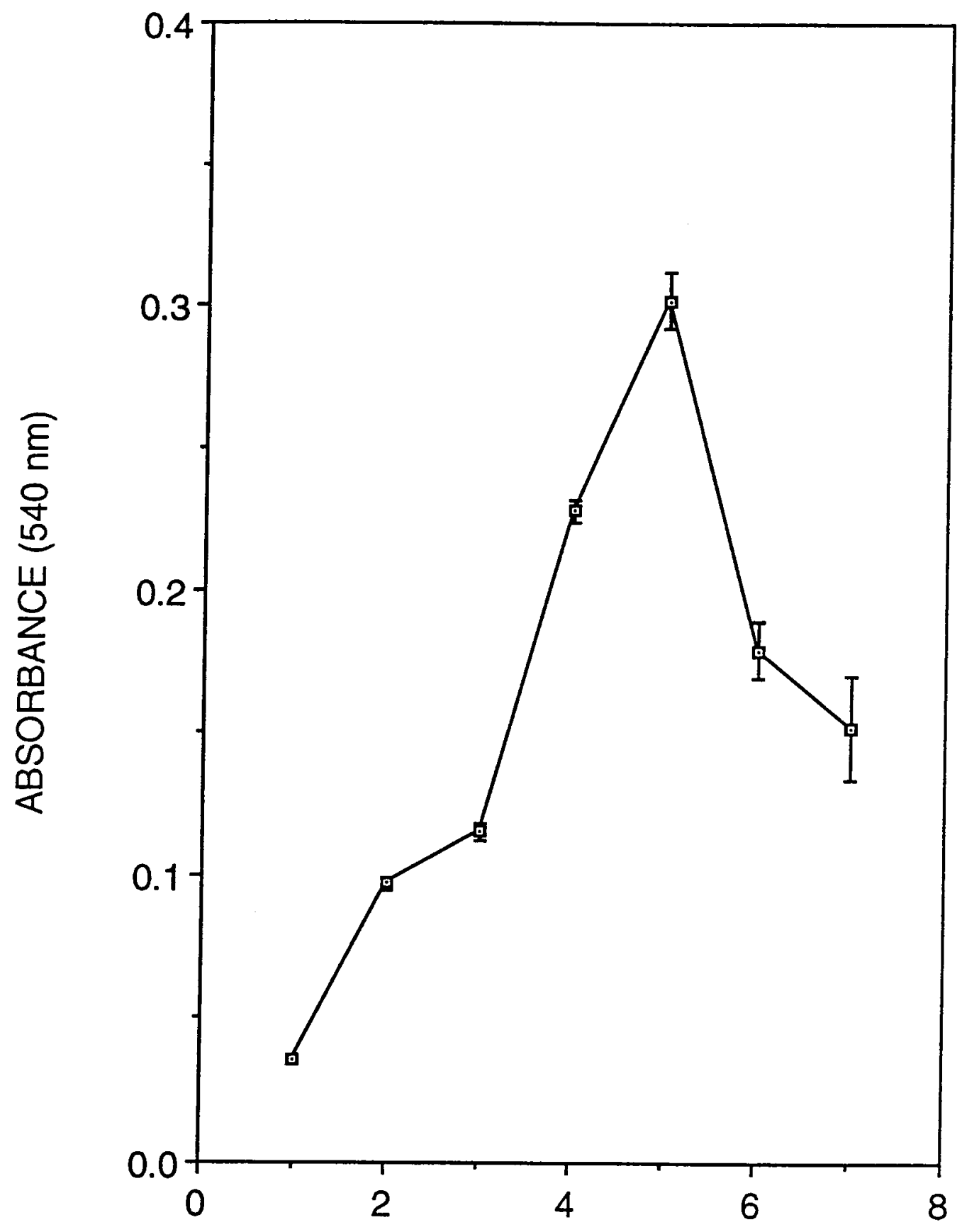

TIME (h) 
Figure 16. Coefficient of variation as a function of MTT incubation time.

The error associated with Figure 15 is represented here as the coefficient of variation (standard deviation/mean $x$ $100 \%$ ). The results demonstrate that the error associatd with the assay increases significantly after $5 \mathrm{~h}$ MTT incubation time. 
FIGURE 16

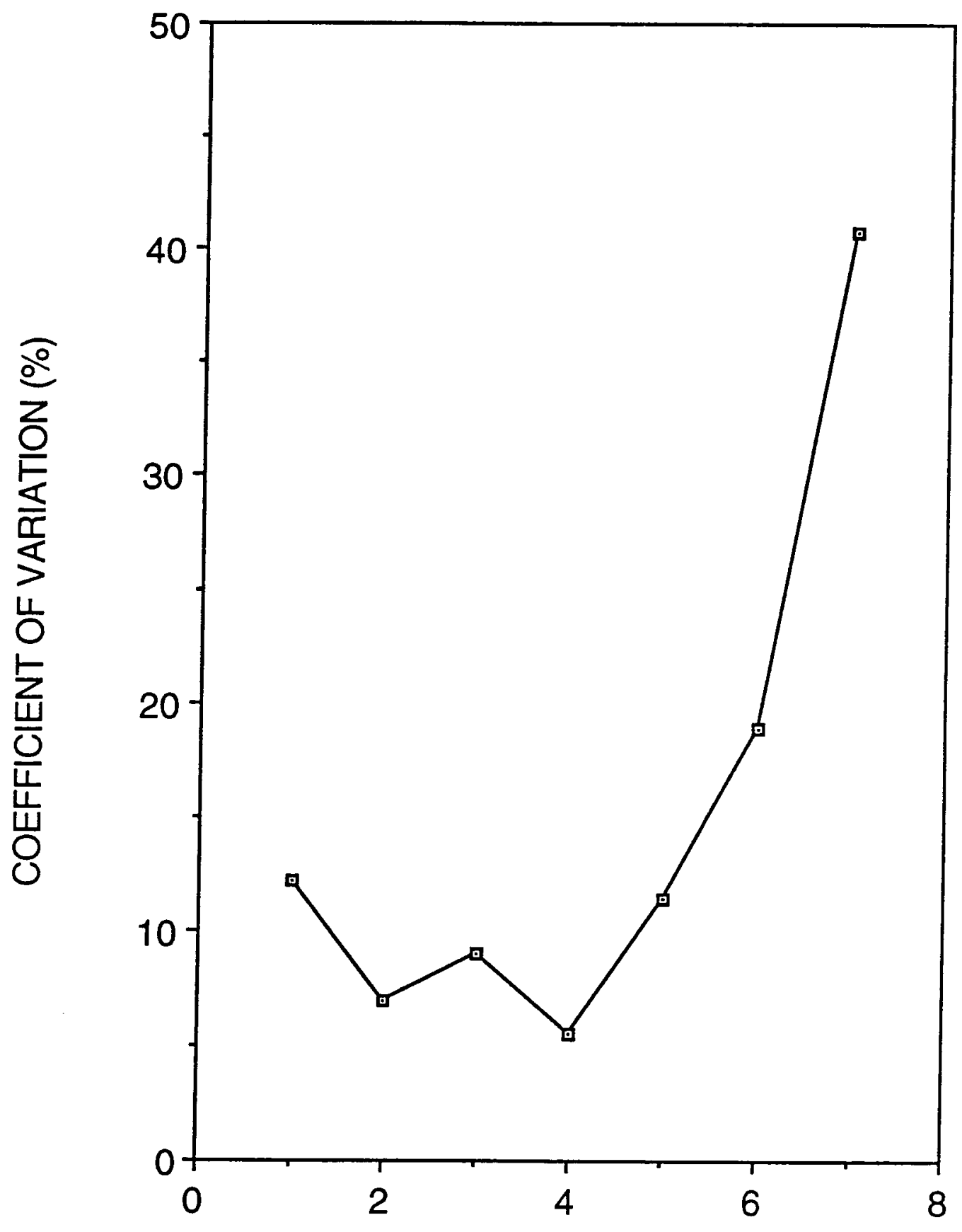

TIME (h) 


\section{d. Removal of MTT supernatant}

Table 6 lists the coefficients of variation for different methods of removal of the MTT supernatant. Formolfixing the cells to the microtiter plate and then removing the MTT supernatant with a mulitchannel pipettor resulted in the lowest coefficient of variation ( $8.8 \%)$, and consequently formol-fixing the cells followed by multichannel pipetting was used for all subsequent experiments. The control studies for this experiment demonstrated that formalin did not interfere with absorbance at $540 \mathrm{~nm}$.

Table 6. Coefficient of variation associated with different methods of MTT supernatant removal.

\begin{tabular}{|c|c|}
\hline $\begin{array}{l}\text { Method of MTT } \\
\text { supernatant removal }\end{array}$ & $\begin{array}{l}\text { Coefficient of } \\
\text { variation (\%) }\end{array}$ \\
\hline $\begin{array}{l}\text { Formol fixing and } \\
\text { multichannel pipetting }\end{array}$ & 8.8 \\
\hline $\begin{array}{l}\text { Saline dipping with } \\
\text { no flicking }\end{array}$ & 15.8 \\
\hline $\begin{array}{l}\text { Saline dipping with } \\
\text { flicking }\end{array}$ & 11.0 \\
\hline Multichannel pipetting & 16.5 \\
\hline
\end{tabular}

\section{e. Absorbance Limit of the MTT Assay}

Figure 17 illustrates the relationship between the concentration of pure formazan and absorbance at $540 \mathrm{~nm}$. The upper limit of absorbance was approximately 3 , which corresponded to a concentration of roughly $200 \mathrm{ug}$ formazan $/ \mathrm{ml}$. Absorbance readings from the drug-screening 
experiments very rarely exceeded 1.0 .

Figure 18 is the wavelength scan of pure formazan from 400 to $640 \mathrm{~nm}$. Included in the Figure is the corresponding wavelength scan of cell-generated formazan (from Figure 13). The peaks of the pure formazan and the culture-generated formazan were both in the 540 to $560 \mathrm{~nm}$ range, thereby indicating it is valid to use pure formazan in the determination of the upper absorbance limit of the MTT assay. 
Figure 17. Absorbance limit of the MTT assay.

Serial dilutions $(1-800 \mu \mathrm{g} / \mathrm{ml})$ of pure formazan were dissolved in isopropanol and the $A_{540}$ of each dilution was measured. The upper limit of absorbance is observed to be approximately 3 . 
FIGURE 17

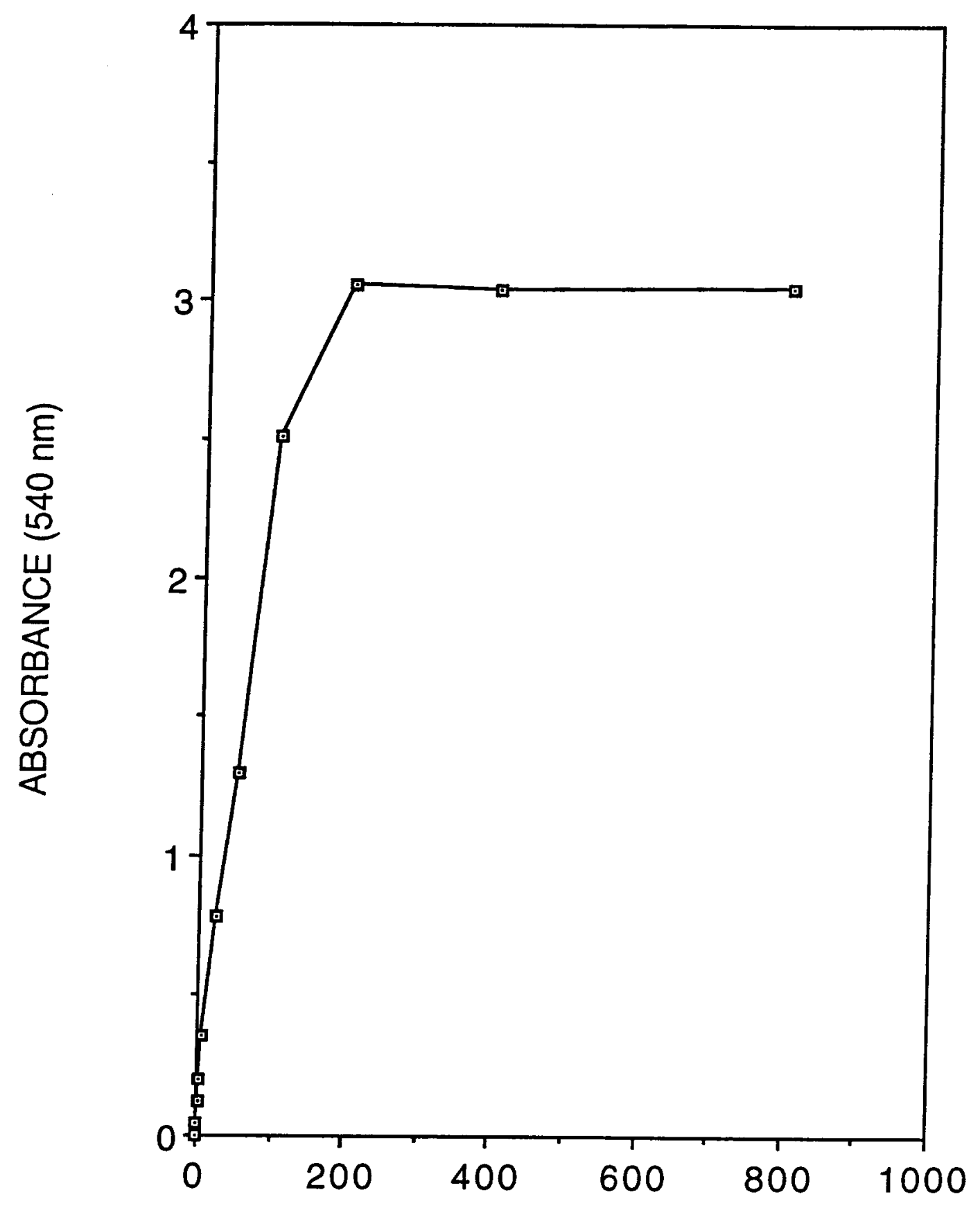

FORMAZAN CONCENTRATION (ug/ml) 
Figure 18. Wavelength scans of pure formazan and cellgenerated formazan dissolved in isopropanol.

Pure MTT formazan dissolved in isopropanol was used to generate a wavelength scan from 400 - $640 \mathrm{~nm}$. The wavelength scan of cell-generated formazan dissolved in isopropanol was also included in Figure 18. Both absorption spectrums had a peak in the $540-560 \mathrm{~nm}$ range. 
FIGURE 18

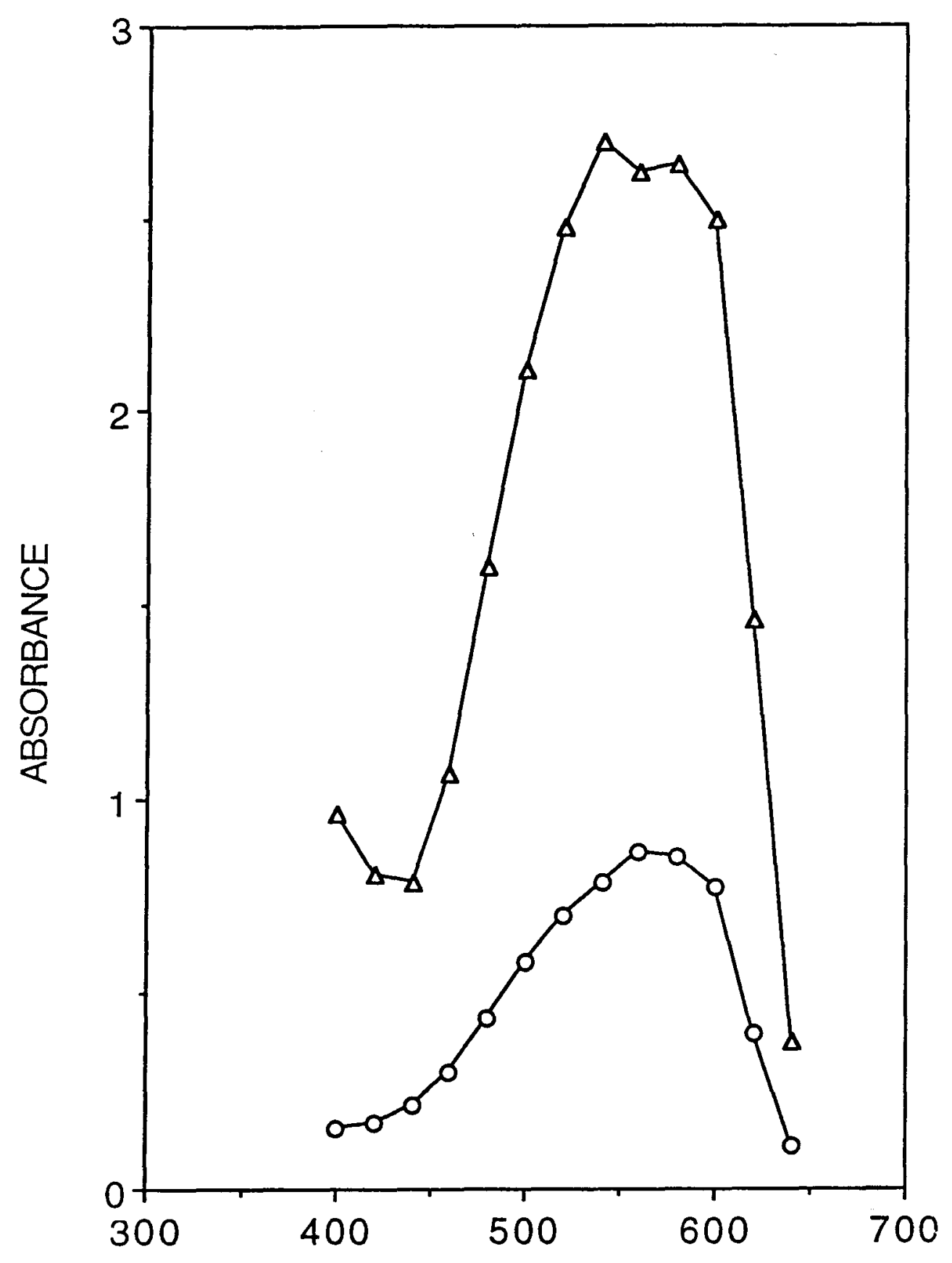

WAVELENGTH $(\mathrm{nm})$ 


\section{Compounds Screened Against Drug-Sensitive Cell Lines}

The MTT assay protocol determined from the experiments described above is briefly described as follows. Following the $48 \mathrm{~h}$ drug recovery period, the medium was removed and $100 \mu \mathrm{l}$ of MTT $(1 \mathrm{mg} / \mathrm{ml})$ were added to each well. Following a $5 \mathrm{~h}$ incubation period at $37^{\circ} \mathrm{C}, 100 \mu \mathrm{l}$ of $20 \%$ formol in saline was added to each well to fix the cells. Following 30 minutes at room temperature, the supernatant was removed and $100 \mu l$ of isopropanol was added to each well. One hour later, the plates were gently agitated and the absorbance values of each well was determined using a 96-well microtiter plate reader.

Figure 19 illustrates the wide range of chemical structures of all the pure samples tested in our in vitro screening protocol. Table 7 summarizes the $\mathrm{ED}_{50}$ values obtained for compounds screened against the MCF-7, T-47D, ZR-75-1 and MDA-MB-231 cell lines. Of the 15 samples screened, 8 demonstrated significant cytotoxicity $\left(E_{50}\right.$, $25 \mu \mathrm{g} / \mathrm{ml}$ ) against either the MCF-7 or the T-47D cell line. Only these 8 samples were screened against $\mathrm{ZR-75-1}$ and MDAMB-231 cells; all 8 compounds were significantly cytotoxic against the former cell line, whereas 6 were significantly cytotoxic against the latter. The $\mathrm{ED}_{50}$ values for Adriamycin were determined in all of these cell lines to provide a standard with which to compare the samples. The $\mathrm{ED}_{50}$ values

recorded for the two pure samples, the geodiamolides and jaspamide, were comparable with or lower than those noted 
Figure 19.

Molecular structures of pure metabolites isolated from marine organisms. 

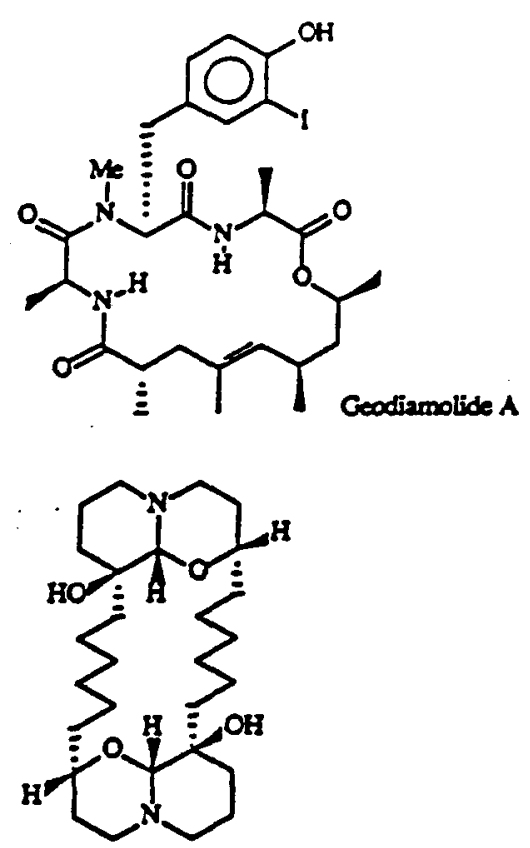

Xestospongin E

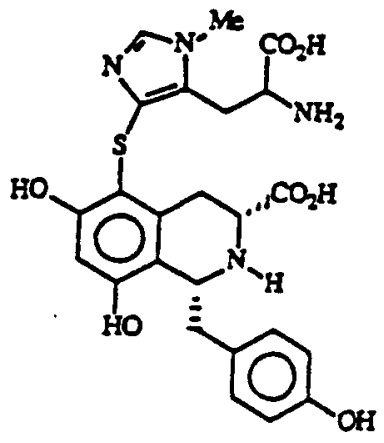

Imbricadixe

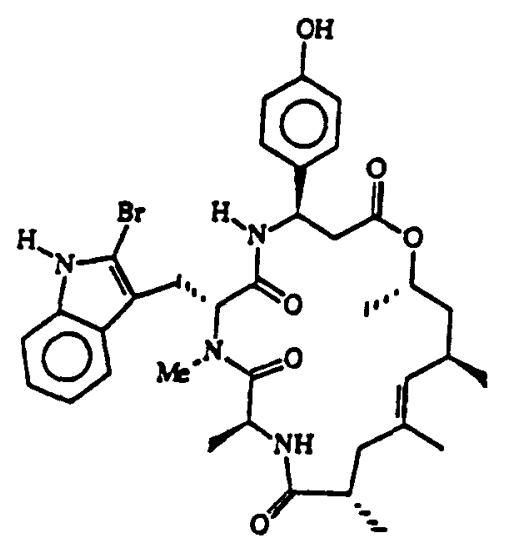

Jaspanide
$80 \mathrm{~A}$<smiles>[H][Y]1cc(C2=CN[C@H](C(=O)c3c[nH]c4cc(O)ccc34)N2)c2ccc(Br)cc12</smiles>

Bromotopsencin

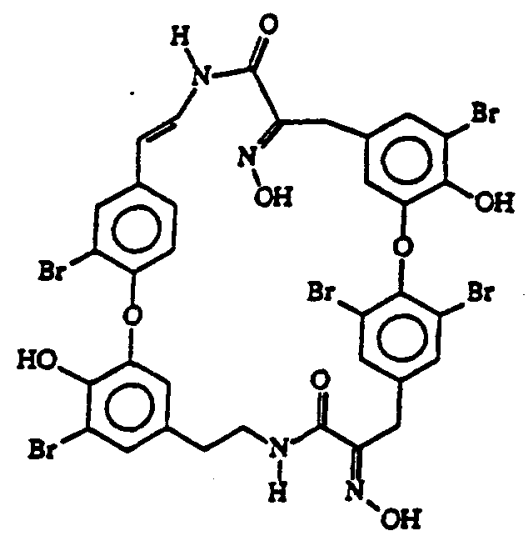

Bastadin-4

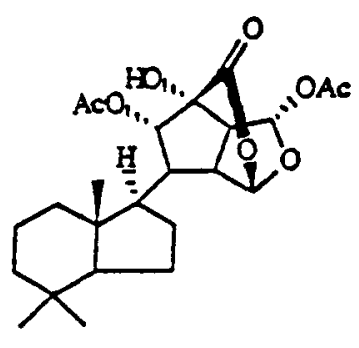

Cromodorolide A

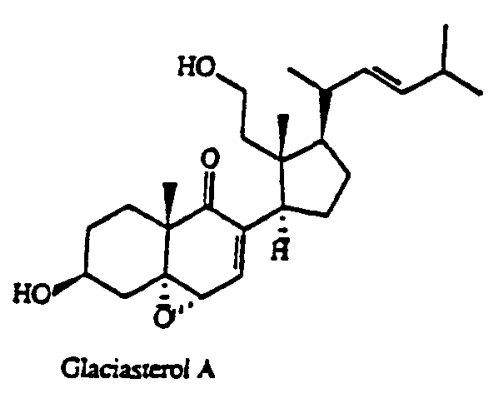

FIGURE 19 
TABLE 7. $E D_{50}$ values obtained for compounds screened against the drug-sensitive breast cancer cellilines MCF-7, T-47D, ZR-75-1 and MDA-MB-231.

\begin{tabular}{|c|c|c|c|c|}
\hline \multirow[t]{2}{*}{ AGENT } & \multicolumn{4}{|c|}{$\mathrm{ED}_{50}$ values $(\mu \mathrm{g} / \mathrm{mI})$} \\
\hline & $\mathrm{MCF}-7$ & $\mathrm{~T}-47 \mathrm{D}$ & $\mathrm{ZR}-75-1$ & $M D A-M B-231$ \\
\hline GEODIAMOLIDES & $0.0068 \pm .0003$ & $30.044 \pm .003$ & $30.033 \pm .024$ & 0.004 \\
\hline XESTOSPONGIN E & $>>50$ & $>50$ & ND & ND \\
\hline BROMOTOPSENTIN & $>>100$ & $32 \pm 5$ & ND & ND \\
\hline PNG $-31 A^{a}$ & $5.4 \pm .5$ & 0.6 & 7 & $24 \pm 1$ \\
\hline BASTIDIN -4 & $6.0 \pm .6$ & $0.58 \pm .05$ & $2.9 \pm .1$ & $2.6 \pm .1$ \\
\hline IMBRICATINE & $>50$ & $23 \pm 9$ & ND & ND \\
\hline CHROMODOROLIDE & $A>>100$ & $>>50$ & ND & ND \\
\hline GARVEA ${ }^{\mathrm{a}}$ & $33 \pm 9$ & $19 \pm 3$ & $21 \pm 1$ & $23 \pm 1$ \\
\hline$Q C I-32^{a}$ & $1.2 \pm .4$ & $0.09 \pm .02$ & $0.09 \pm .01$ & $0.018 \pm .001$ \\
\hline QCI $4-16-89^{a}$ & $>100$ & $50 \pm 22$ & ND & ND \\
\hline PNG $-137 A^{a}$ & $30 \pm 3$ & $13 \pm 3$ & $16 \pm 3$ & $>50$ \\
\hline PNG $-137 B^{a}$ & $98 \pm 2$ & $35 \pm 12$ & ND & ND \\
\hline$Q C I-117^{\mathrm{a}}$ & $>>100$ & $>>100$ & ND & ND \\
\hline GLACIASTEROL A & $19 \pm 1$ & $21 \pm 3$ & $26 \pm 1$ & $>>50$ \\
\hline JASPAMIDE & $.027 \pm .004$ & $0.019 \pm .009$ & $0.042 \pm .002$ & $0.024 \pm .001$ \\
\hline ADRIAMYCIN & $0.10 \pm .01$ & $0.065 \pm .009$ & $0.005 \pm .001$ & $0.038 \pm .006$ \\
\hline
\end{tabular}

Data represent mean values \pm standard error of the mean (standard deviation $/ \sqrt{ } n)$. Only the compounds that exhibited significant cytotoxicity towards the $\mathrm{MCF}-7$ and $\mathrm{T}-47 \mathrm{D}$ cell lines were screened against the $\mathrm{ZR}-75-1$ and MDA-MB-231 cell lines. ND, not done.

a crude extract 
for Adriamycin. The values obtained for another sample, QCI32, which is a crude extract, were 12-, 1.4-, 18- and 0.47fold higher than those found for Adriamycin in screening against the MCF-7, T-47D, ZR-75-1 and MDA-MB-231 cell lines, respectively. $\mathrm{ED}_{50}$ values as low as $0.6 \mu \mathrm{g} / \mathrm{ml}$ were noted for the crude extract PNG-31A in the T-47D cell line; this value is 10-fold higher than that determined for Adriamycin. Values recorded for the 5 remaining compounds that exhibited significant cytotoxicity ranged from 0.58 to $33 \mu \mathrm{g} / \mathrm{ml}$ and were at least 9-fold higher than those found for Adriamycin.

Figures 20-23 represent the standard curves relating absorbance at $540 \mathrm{~nm}$ to cell number for the MCF-7, T-47D, ZR-75-1 and the MDA-MB-231 cell lines. Neither ethanol nor saline had any effect on drug-sensitive cell line viability in the concentrations used in the compound-testing experiments.

\section{Compounds Screened Against Drug-Resistant Cell Lines}

Table 8 summarizes the $E_{50}$ values obtained for the samples and for Adriamycin during screening against the Pgppositive cell lines $\mathrm{MCF}-7 \mathrm{Ad}^{\mathrm{r}}$ and $\mathrm{MDA}-\mathrm{A} 1^{\mathrm{I}}$. of the 8 samples screened, 6 demonstrated significant cytotoxicity against either the $\mathrm{MCF}-7 \mathrm{Ad}^{\mathrm{r}}$ or the $\mathrm{MDA}-\mathrm{A} 1^{\mathrm{r}}$ cell line. The geodiamolides were 54- and 11 600-times more cytotoxic than Adriamycin when screened against the MCF-7 $\mathrm{Ad}^{\mathrm{r}}$ and $\mathrm{MDA}-\mathrm{AI}$ cell lines, respectively. Jaspamide was 6- and 318-times more cytotoxic than Adrimycin when screened against the 
TABLE 8. $E D_{50}$ values obtained for compounds screened against the multidrug-resistant breast cancer cell lines $\mathrm{MCF}-7 \mathrm{Ad}^{\mathrm{r}}$ and $\mathrm{MDA}-$ $A 1^{x}$.

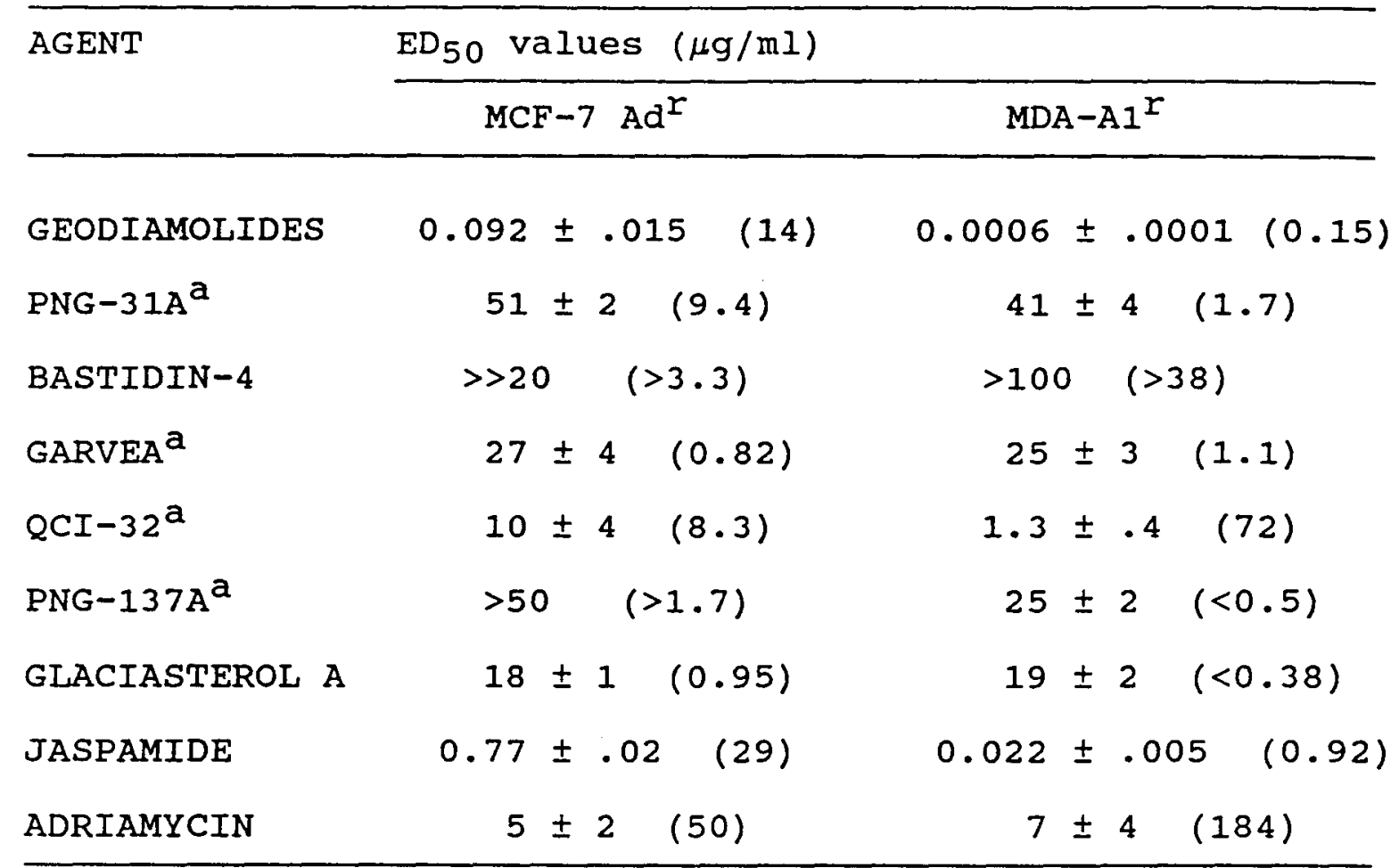

Data represent mean values \pm standard error of the mean (standard deviation $/ \sqrt{ } n$ ) for 2 - 4 experiments. Values in parenthesis indicate the magnitude of increase in resistance noted for the MDR daughter cell lines as compared with the corresponding drugsensitive parent lines ( $E D_{50}$ of the resistant daughter cell line/ED 50 of the sensitive parent line).

arude extract 
MCF-7 $\mathrm{Ad}^{\mathrm{Y}}$ and $\mathrm{MDA}-\mathrm{A1}{ }^{\mathrm{r}}$ cell lines, respectively. MCF-7 cells were 50-times more resistant to Adriamycin than was the parent MCF-7 cell line, whereas MDA-A1 ${ }^{\mathrm{T}}$ cells were 184-times more resistant than was the parent line MDA-MB-231. Table 8 also compares the $E D_{50}$ values found for compounds screened against the MDR cell lines $M C F-7{A d^{Y}}$ and $M D A-A 1^{r}$ with those obtained using the drug-sensitive parent cell lines (ED50 drug-resistant/ED50 drug-sensitive). The geodiamolides Garvea, PNG-137-A, glaciasterol A and jaspamide were observed to have $\mathrm{ED}_{50}$ ratios $\mu 1$ for one or both cell types.

Figures 24 and 25 represent the standard curves relating absorbance at $540 \mathrm{~nm}$ to cell number for the MCF-7 $\mathrm{Ad}^{\mathrm{C}}$ and $\mathrm{MDA}-\mathrm{Al}^{\mathrm{r}}$ cell lines. Neither ethanol nor saline had any effect on cell viability of the drug-resistant cell lines in the concentrations used in the compound-testing experiments. 
Figures 20 - 25. Standard absorbance curves for the MCF-7, T-47D, ZR-75-1, MDA-MB-231, MCF-7 Ad and MDA-A1 cell lines.

Serial dilutions of the cell lines were seeded in the appropriate growth medium (Appendices 7 and 8). Following attachment of the cells to the tissue culture plate $(15 \mathrm{~h})$, the $A_{540}$ value of each cell density was determined (Figure 11). An $A_{54} 0$ versus cell number graph was plotted for each cell line (Figure 20: MCF-7, Figure 21: T-47D, Figure 22: ZR-75-1, Figure 23: MDA-MB-231, Figure 24: MCF-7 $\mathrm{Ad}^{\mathrm{r}}$ and Figure 25: $M D A-A 1^{r}$ ) and a computer generated equation for the best-fit line was determined (MCF-7: $y=8.060 e^{-4}$ * $x^{\wedge} 0.7038, \mathrm{~T}-47 \mathrm{D}: y=0.0048 * x^{\wedge} 0.4852, \mathrm{ZR}-75-1: y=8.924 \mathrm{e}-$ $4 * x^{\wedge} 0.6849, \mathrm{MDA}-\mathrm{MB}-231: y=4.944 \mathrm{e}-4 * x^{\wedge} 0.6968, \mathrm{MCF}-7$ $\mathrm{Ad}^{\mathrm{r}}: y=1.343 \mathrm{e}-4 * x^{\wedge} 0.7953$ and $\mathrm{MDA}-\mathrm{Al}{ }^{\mathrm{r}}: y=0.001$ * $\left.x^{\wedge} 0.6477\right)$. Error bars represent standard error of the mean (standard deviation/ ${ }^{\prime} n$ ) of 2 - 4 experiments. 
FIGURE 20

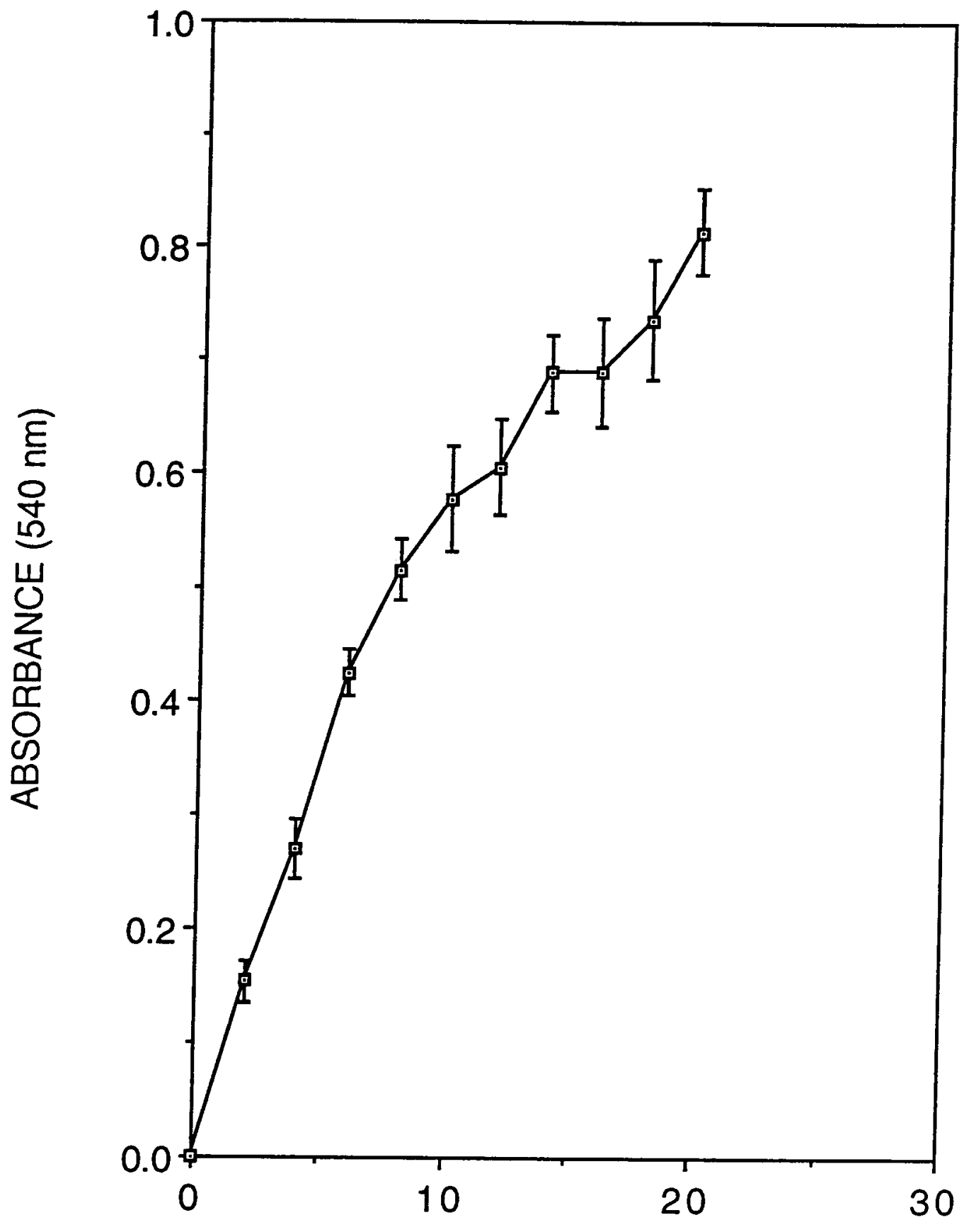

MCF-7 CELL NUMBER ( $x$ 1000) 
FIGURE 21

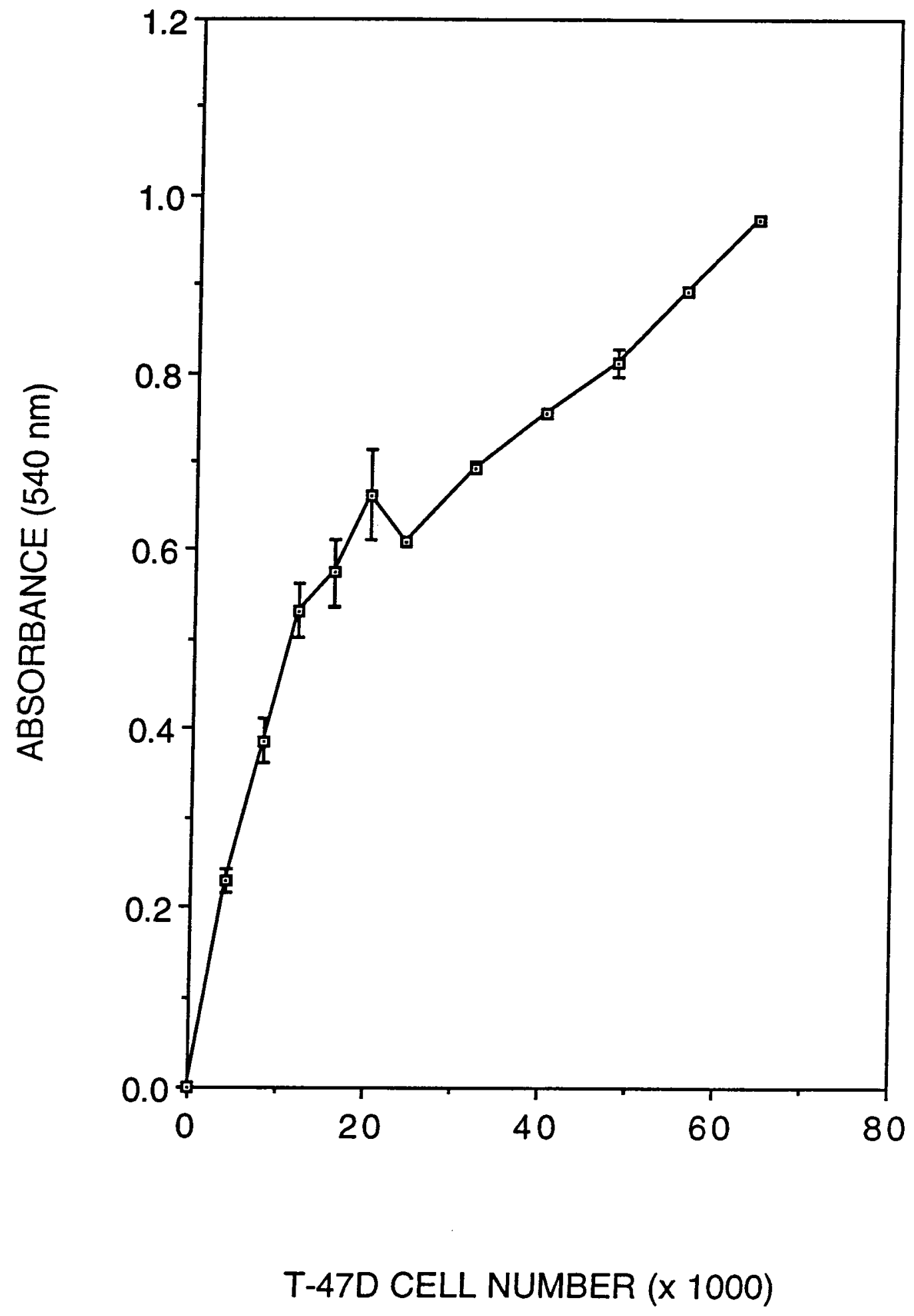


FIGURE 22

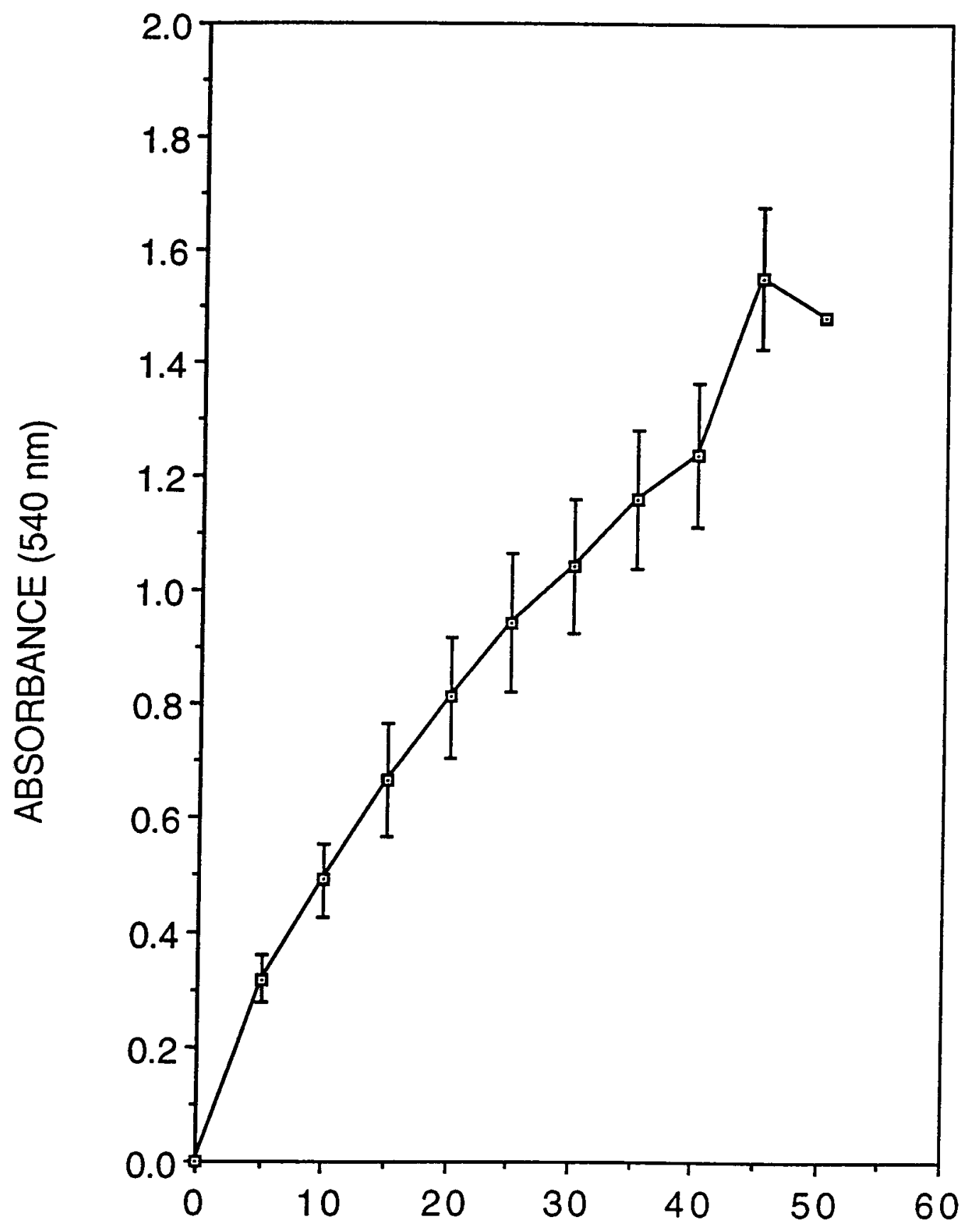

ZR-75-1 CELL NUMBER (x 1000) 
FIGURE 23

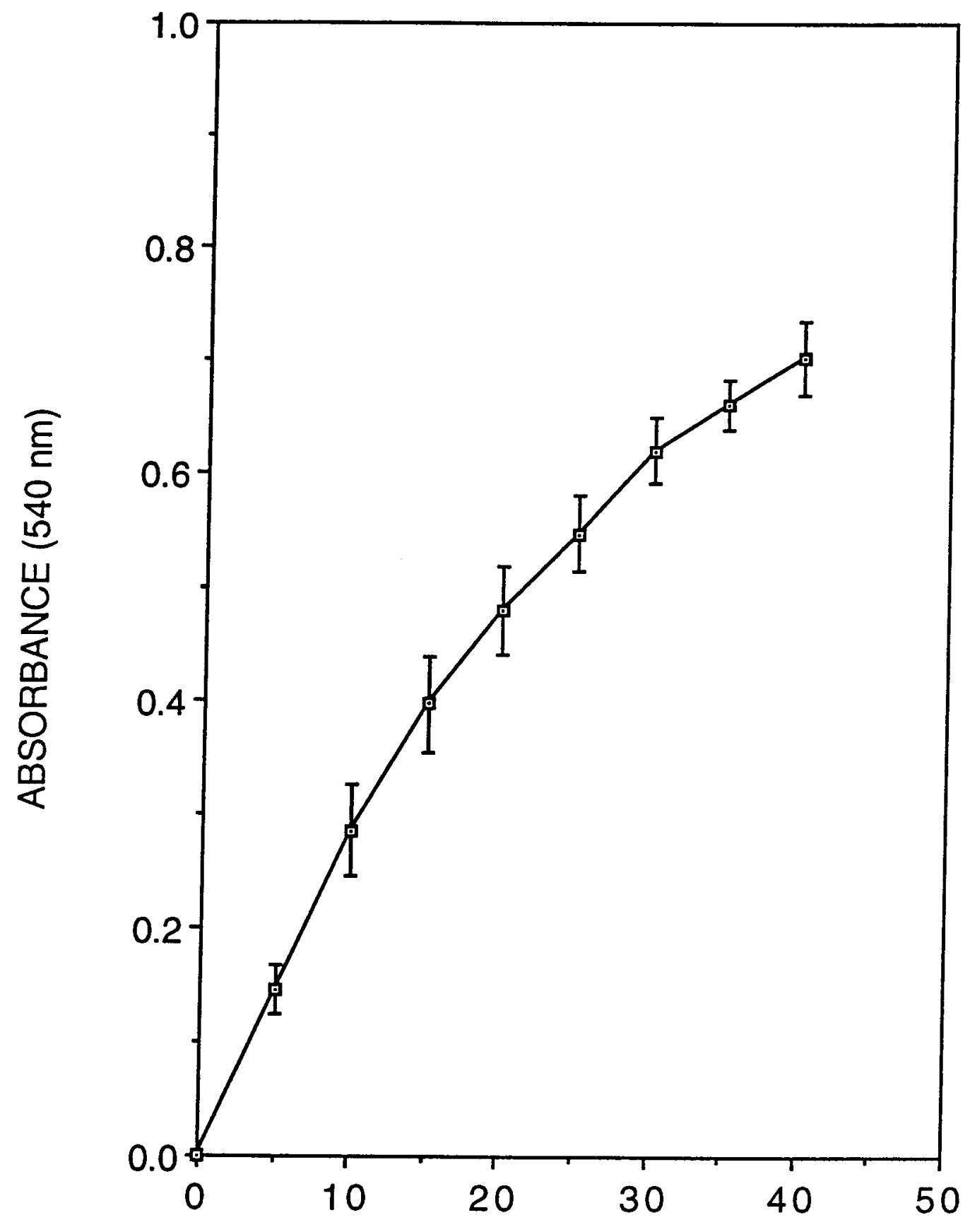

MDA-MB-231 CELL NUMBER (x 1000) 
FIGURE 24

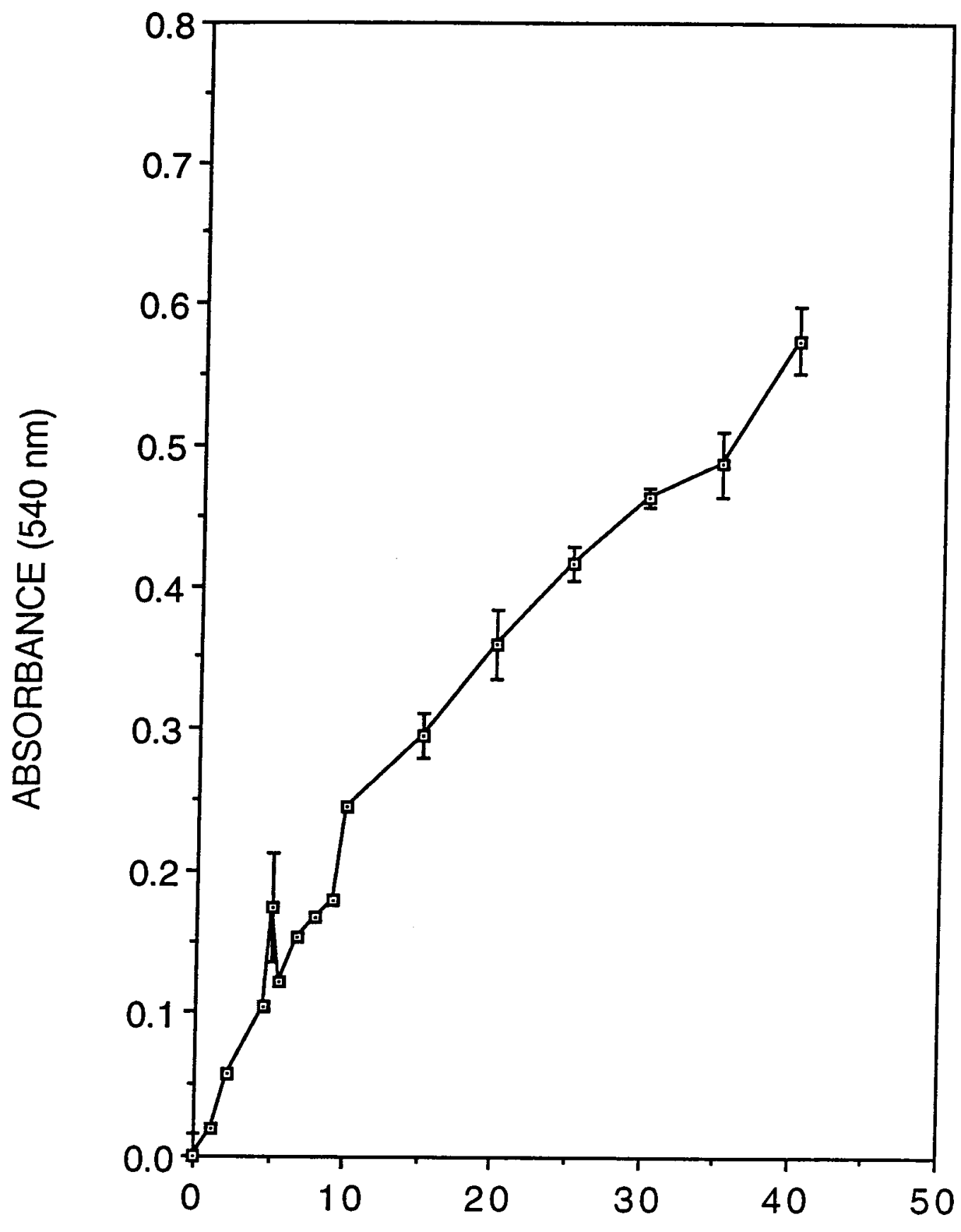

MCF-7 Ad CELL NUMBER ( $x 1000)$ 
FIGURE 25

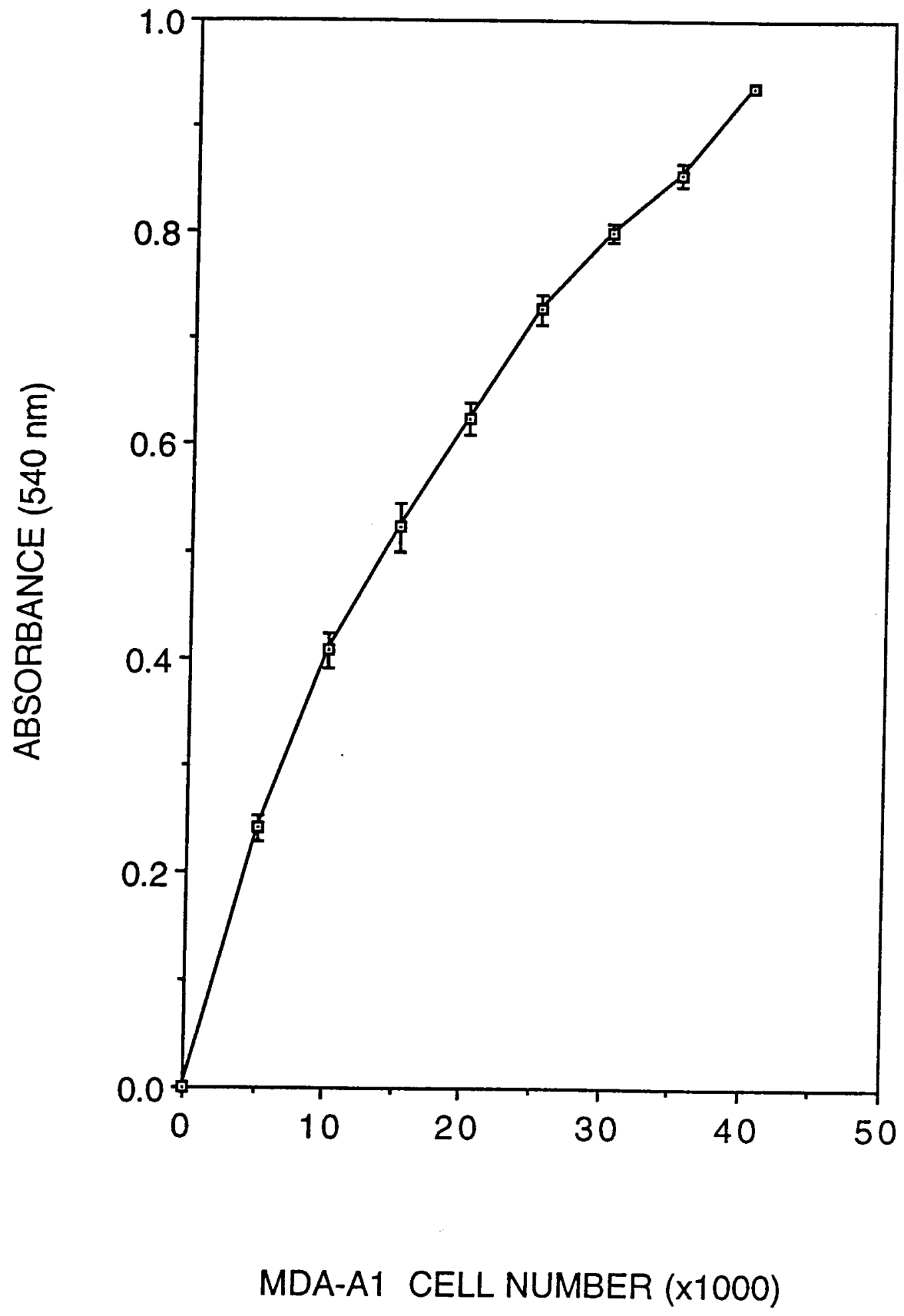




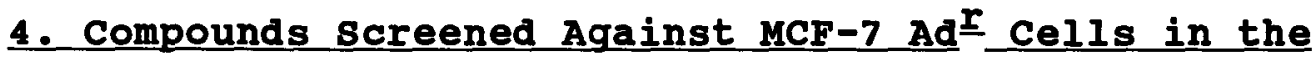 Presence of Adriamycin}

To determine whether compounds whose $\mathrm{ED}_{50}$ ratios were $\mu 1$ might circumvent the MDR phenotype by interfering with Pgp, MCF-7 $\mathrm{Ad}^{\mathrm{r}}$ cells were incubated in the presence of the $\mathrm{ED}_{50}$ concentration ( $5 \mu \mathrm{g} / \mathrm{ml}$ ) of Adriamycin and in varying concentrations of the geodiamolides, Garvea, PNG-137A, glaciasterol A and jaspamide. No synergy was observed between any of the samples and Adriamycin (Figures 26-30), suggesting that these compounds do not interfere with Pgp function. The $\mathrm{ED}_{50}$ values of the various test agents in the presence of Adriamycin are $0.95,11,>50,13$ and $1 \mu \mathrm{g} / \mathrm{ml}$ for the geodiamolides, Garvea, PNG-137A, glaciasterol A and jaspamide, respectively. Additive cytotoxicity was observed between some agents (Garvea, PNG-137A, glaciasterol A and Jaspamide) and Adriamycin (Figures 27 - 30). A 10-fold reduction in the cytotoxic activity of the geodiamolides was observed when $\mathrm{MCF}-7 \mathrm{Ad}^{\mathrm{r}}$ cells were exposed to the geodiamolides in the presence of Adriamycin (Figure 26). 
Figures 26 - 30. Dose response curves of MCF-7 Ad $\underline{\underline{r}}$ cells to varying concentrations of the geodiamolides, Garvea, PNG137A, glaciasterol $A$ and jaspamide in the presence of the ED 50 concentration of Adriamycin.

MCF-7 Ad $\mathrm{Ad}^{\mathrm{r}}$ cells were exposed to serial dilutions of either the geodiamolides, Garvea, PNG-137A, glaciasterol A or jaspamide in the presence of $5 \mu \mathrm{g} / \mathrm{ml}$ Adriamycin. Following the drug recovery period the surviving cells were quantified (Figure 11) and a dose response curve for each compound was constructed (Figure 26: geodiamolides, Figure 27: Garvea, Figure 28: PNG-137A, Figure 29: glaciasterol A and Figure 30: jaspamide). Dose response to $5 \mu \mathrm{g} / \mathrm{ml}$ Adriamycin in the presence of no test compound is plotted as $50 \%$. The dose response of the cells to the various test agents is plotted relative to this $50 \%$ level. No synergy was observed between any of the samples and Adriamycin. The ED50 values of the various test agents in the presence of Adriamycin were 0.95, $11,>50,13$ and $1 \mu \mathrm{g} / \mathrm{ml}$ for the geodiamolides, Garvea, PNG137A, glaciasterol A and jaspamide, respectively. A 10-fold decrease in the cytotoxicity of the geodiamolides is observed. Error bars represent the standard error of the mean (standard deviation/' $n$ ) of 2 experiments. 
FIGURE 26

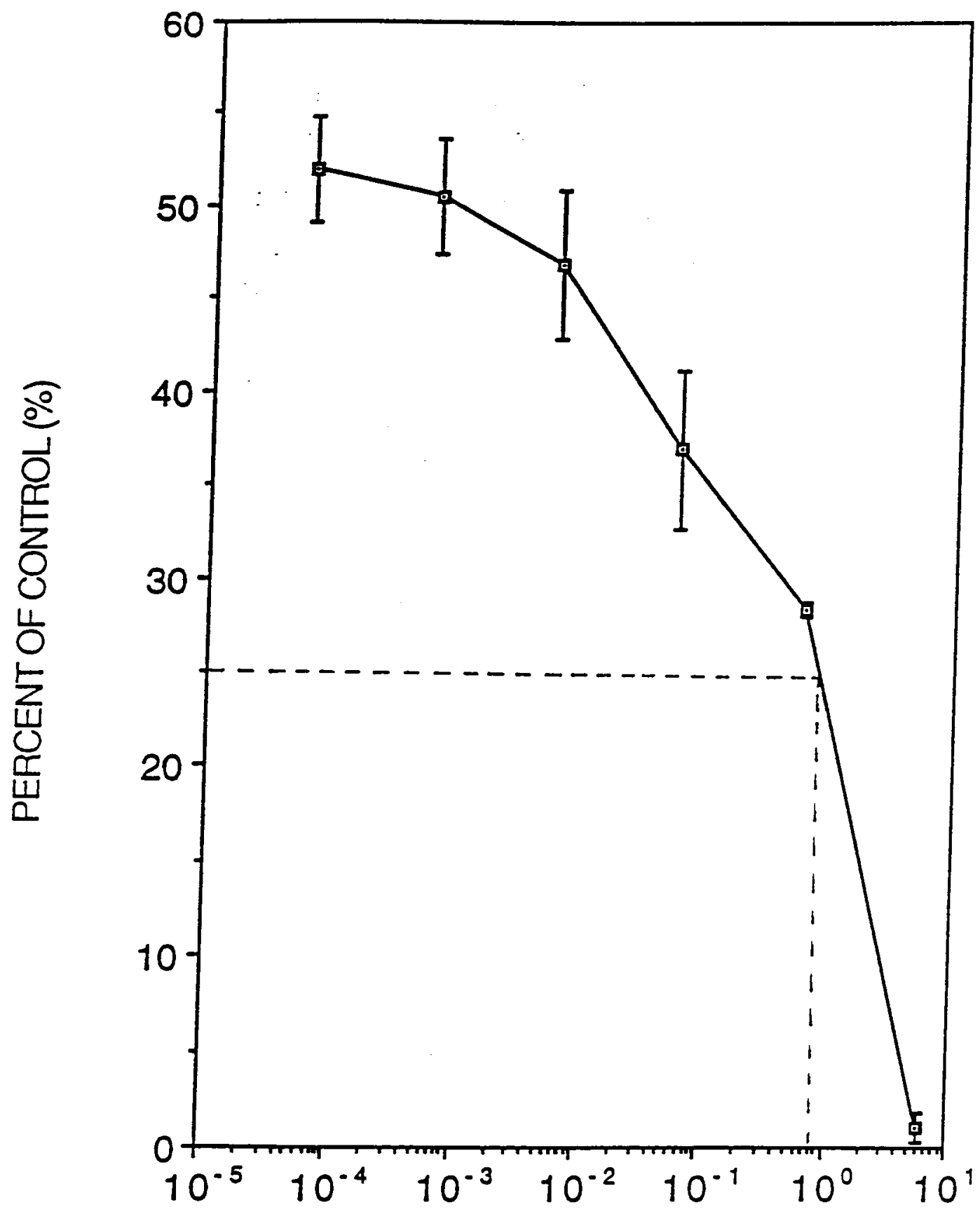

GEODIAMOLIDE CONCENTRATION (ug/ml) 
FIGURE 27

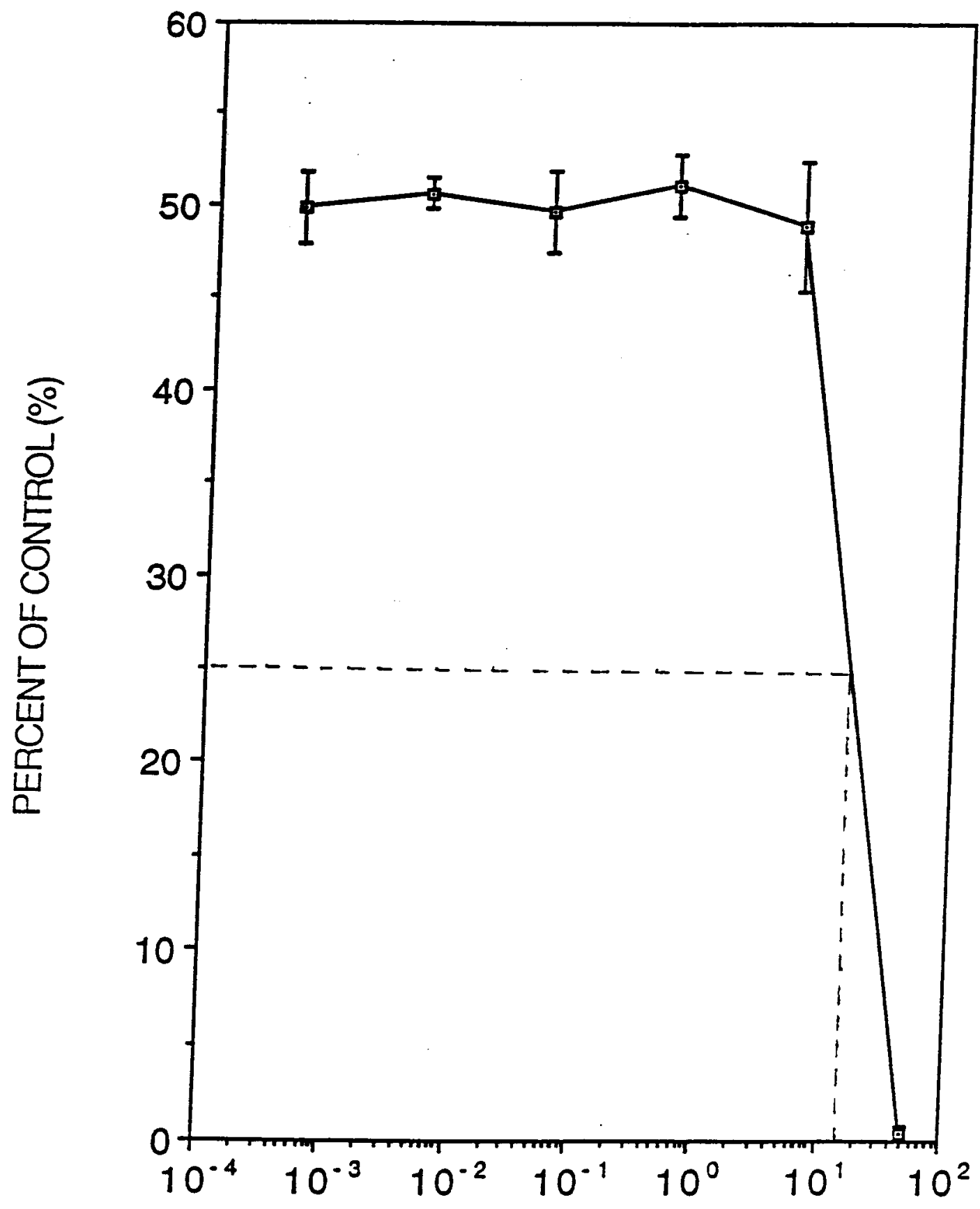

GARVEA CONCENTRATION (ug/ml) 
FIGURE 28

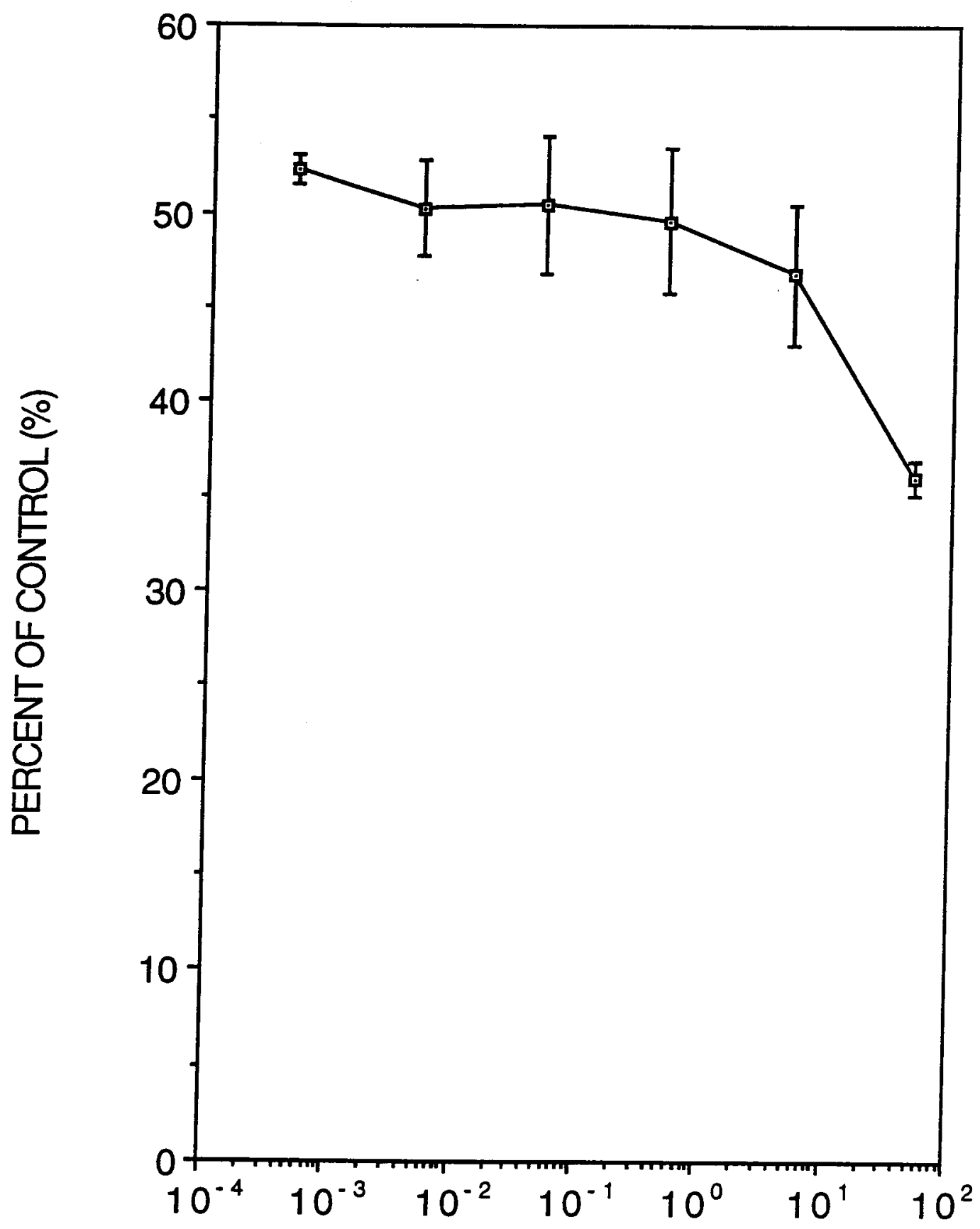

PNG-137A CONCENTRATION (ug/ml) 
FIGURE 29

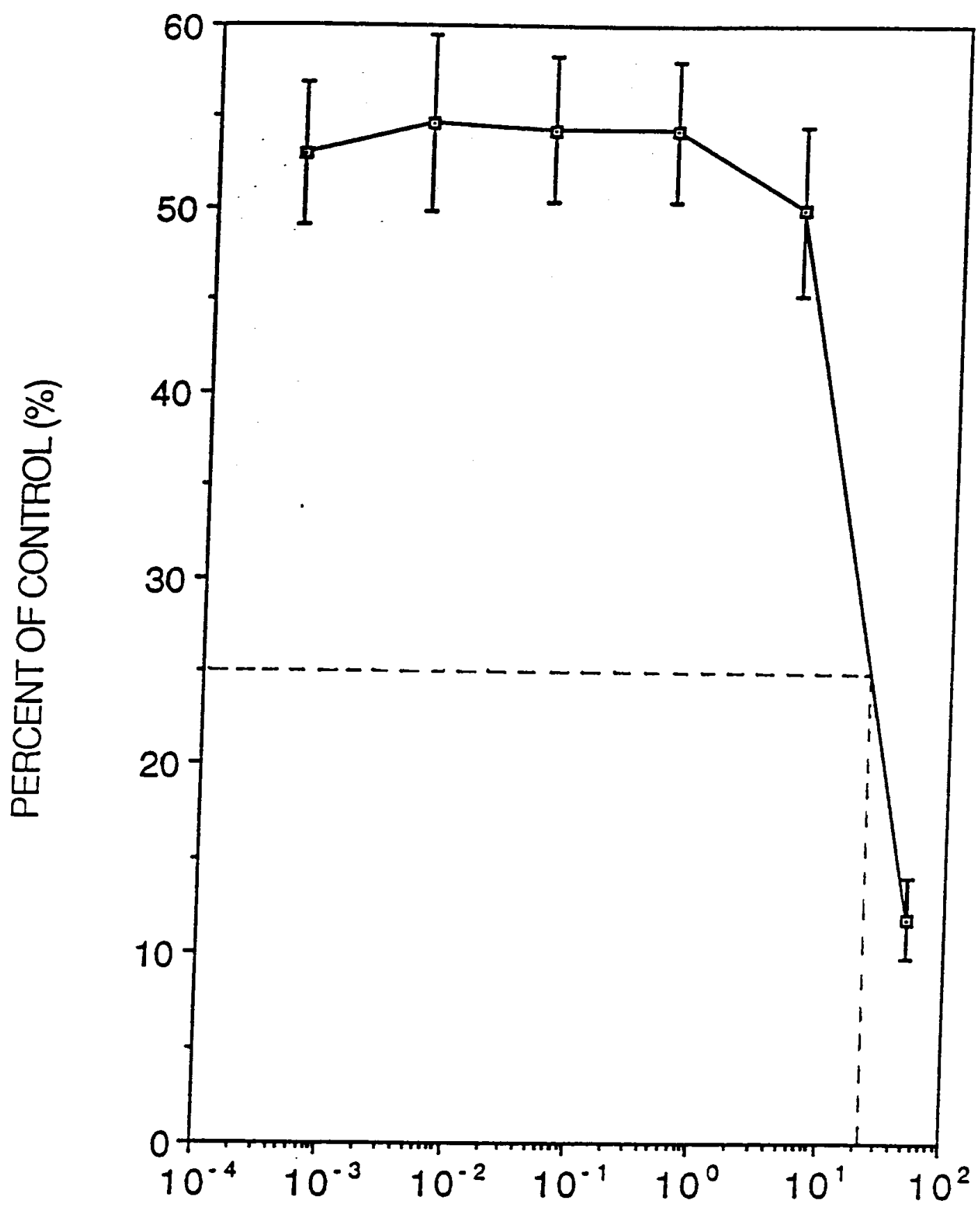

GLACIASTEROL CONCENTRATION (ug/ml) 
FIGURE 30

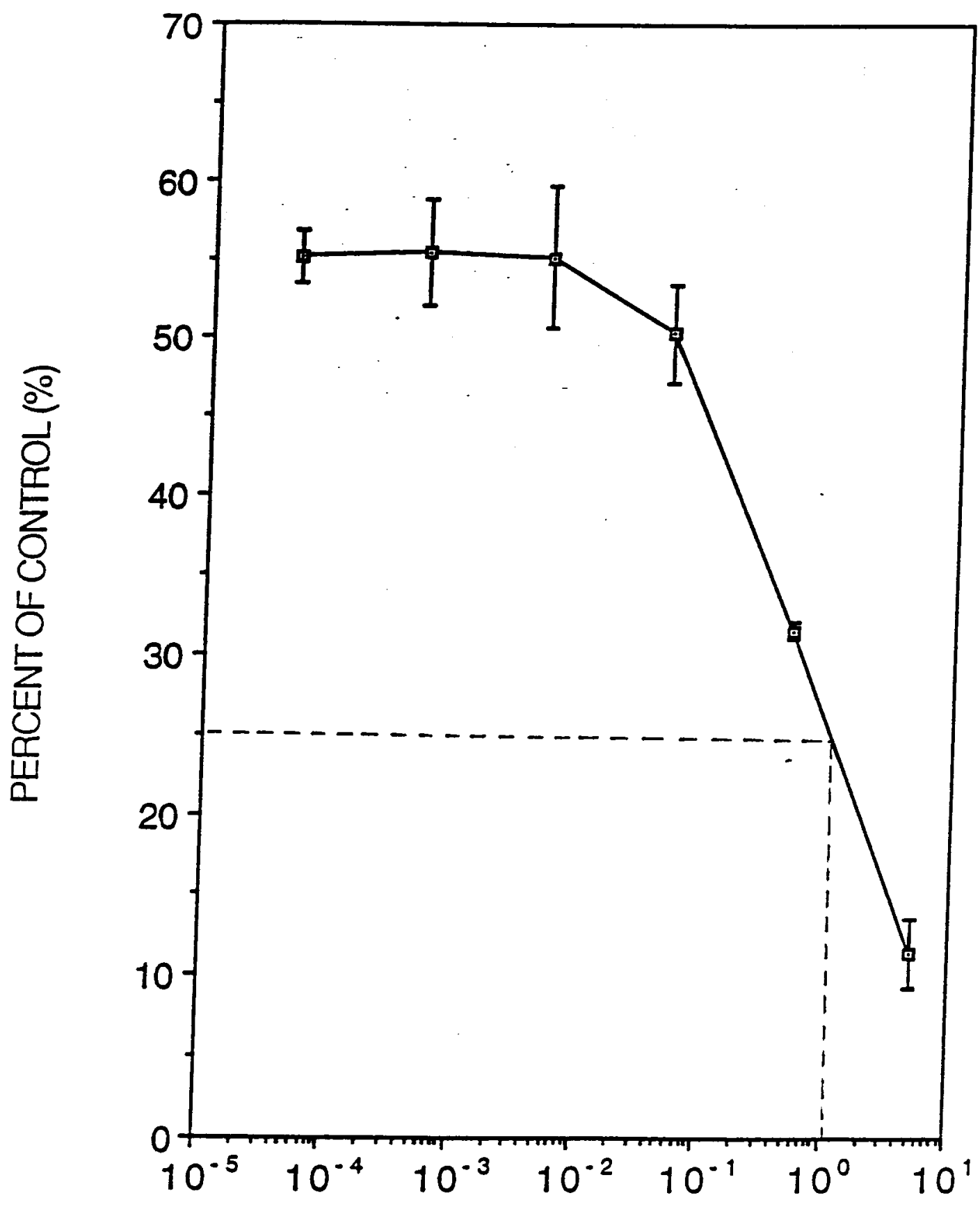

JASPAMIDE CONCENTRATION (ug/ml) 


\section{Compounds Screened Against Normal and Malignant Human}

\section{Breast Epithelial cells in Primary Culture}

Table 9 summarizes the cytotoxicities of the geodiamolides and jaspamide as tested against malignant and normal HBEC in primary culture. No significant trend indicating tumor specificity was observed for the geodiamolides. Minimal data is available for the jaspamide sample due to limited quantity of drug. Large variation was seen in the cytotoxicity for a given agent for different tissue samples: the $\mathrm{ED}_{50}$ values recorded for the geodiamolides ranged from 0.018 to $5.5 \mu \mathrm{g} / \mathrm{ml}$ and from 0.21 to $>10 \mu \mathrm{g} / \mathrm{ml}$ in malignant and normal tissue, respectively, whereas the corresponding values determined for jaspamide ranged from 0.0005 to $3.8 \mu \mathrm{g} / \mathrm{ml}$ and from $<0.05$ to $0.5 \mu \mathrm{g} / \mathrm{ml}$ respectively. Adriamycin $E_{50}$ values were included for reference in cases in which sufficient tissue was available.

Table 9. ED50 values obtained for the geodiamolides and jaspamide tested against normal and malignant HBEC in primary culture.

\begin{tabular}{lccccccccc} 
Agent & \multicolumn{2}{c}{ ED50 } & values & $(\mu \mathrm{g} / \mathrm{ml})$ & & & & \\
& $\mathrm{N} 1$ & $\mathrm{~N} 2$ & $\mathrm{~N} 3$ & $\mathrm{Ca} 1$ & $\mathrm{Ca} 2$ & $\mathrm{Ca} 3$ & $\mathrm{Ca} 4$ & $\mathrm{Ca}$ \\
& & & & & & & & & \\
Geodiamolides & 0.21 & $>10$ & $>6$ & 0.1 & 0.018 & 5.5 & 0.5 & $\mathrm{ND}$ \\
Jaspamide & 0.05 & 0.08 & 0.5 & ND & ND & ND & 0.0005 & 3.8 \\
Adriamycin & ND & 0.25 & 0.29 & ND & ND & ND & ND & ND \\
\hline
\end{tabular}

N, Normal cells; Ca, malignant cells; ND, not done. 


\section{CHAPTER 4}

\section{DISCUSSION}

Past drug-screening programs have illustrated that the incorporation of solid tumors into a drug-screening protocol is essential, since agents that are effective in treating leukemias are not necessarily effective against solid tumors $(21,62,95)$. The crude extracts and pure metabolites evaluated in this thesis had previously been screened and found to be cytotoxic in vitro in the leukemic L1210 bioassay $(34,100,105,117$ and personal communication with Dr. R Andersen). In the present study, mammary carcinoma was used as a solid-tumor model. Breast cancer cell lines were selected for initial screening because the cells are plentiful and easy to grow. However, cell lines result from cell selection and the populations are very homogenous in their characteristics. Therefore, four drugsensitive and two drug-resistant cell lines were used to represent the heterogeneity seen in naturally-occuring tumors. Primary cultures of epithelial cells from malignant breast tissue were incorporated into the screening protocol, because they more closely resemble counterpart cells in vivo. Epithelial cells from normal tissue were also included to determine the tumor specificity of the geodiamolides. As the results illustrate, there was broad variation in the biological activity of cytotoxic compounds tested on different cell lines and on different primary cultures. 
Several assays were considered to measure the cytotoxic effects of the test compounds on the cell lines and the HBEC in primary culture. Incorporation of radiolabelled precursors, protein binding assays, the neutral red assay and the MTT assay were all reviewed. This laboratory has traditionally used incorporation of radioactive thymidine as a measure of cell viability, but this method was rejected because it is impractical for large-scale screening. Also, a potential problem that may arise when using this method to screen drugs that have unknown mechanisms of action is that the drug under study and the radiolabelled precursor may share the same biochemical pathways and/or transport mechanisms, thus there may be competition between the label and the drug resulting in irregularities in the results (Ruben 1988). Protein binding assays measure the total protein content of a population of cells. Consequently, a potential problem with protein binding assays is that they could incorporate the protein content of nonviable cells in the final results (136). This is especially so if the time interval between drug addition and the assay is short. The neutral red assay was deemed inadequate, because it relies on the accumulation of neutral red dye into lysosomes and it was this investigator's opinion that lysosome number would be more susceptible to change when exposing cells to unknown potentially cytotoxic agents. The MTT assay was selected, because it is a measure of cell viability and it has correlated well with the SRB assay (136), a ${ }^{51} \mathrm{Cr}$ release 
assay (67), the radiolabelled thymidine incorporation assay (unpublished results from our laboratory), the HTCFA and a dye exclusion assay (20).

Unfortunately, there is are a large amount of variation in the literature regarding the exact procedure of the MTT assay. The cause of this variation has to do with the fact that in order for the MTT assay to be a reproducible measure of cell survival, the parameters of the assay have to be optimized for the type of cells used and the culture conditions used to grow these cells. The parameters that had to be optimized for the drug screening experiments outlined in this thesis were the type of solvent, the concentration of the MTT solution and the length of the MTT incubation time. The original MTT protocol as described by Mosmann (107) called for the MTT-containing medium not to be removed before addition of the solvent. MTT assays performed for this thesis had the MTT supernatant removed prior to solvent addition, because the results of the two wavelength scans of cell-generated formazan dissolved in different solvents (Figures 12 and 13) indicate that greater assay sensitivity can be achieved when the MTT supernatant is removed. These wavelength scans also demonstrate that isopropanol is the most suitable solvent for determing formazan absorbance at $540 \mathrm{~nm}$. The NCI, when investigating the feasibility of the MTT assay for its large scale drug-screening program, observed that DMSO is the most suitable solvent. This discrepancy can be explained by the fact that the NCI 
cultures most of their cell lines in media supplemented with 10\% FBS (2) and, at the time of assay, they add their MTT directly to the existing drug-containing growth medium (Figure 7). Thus, when the MTT supernatant is removed, there is a relatively high concentration of residual serum clinging to the cell monolayers and the walls of the wells. High concentrations of residual serum have been shown to enhance the absorption of formazan dissolved in DMSO (2). The MTT assay protocol outlined in this thesis (Figure 11) requires that the growth medium first be removed prior to the addition of MTT dissolved in serum-free and phenol redfree $\mathrm{F} 12 / \mathrm{DME} / \mathrm{H}$. Since there is relatively little residual serum present, formazan dissolved in isopropanol illicits the highest peak in the wavelength scan.

MTT was added to the cell monolayer dissolved in fresh serum-free and phenol red-free medium rather than added directly to the existing growth medium for 2 additional reasons. The first is that a positive correlation has been established between the D-glucose concentration of the culture medium at the time of assay and the production of formazan (167). Thus, adding MTT to nutrient-depleted growth medium runs the risk of decreasing the sensitivity of the assay. The relationship between D-glucose availability and formazan production may also account for the non-linearity of the cell number vs $A_{540}$ curves, since one would expect Dglucose availability to be decreased when cell density is high. The second reason is that the $\mathrm{pH}$ indicator present in 
the normal growth medium increases absorbance background (33), and thus phenol red-free medium is used instead.

A possible explanation for the observation that the coefficient of variation increases proportionally with the MTT incubation time (Figure 16) is that, as the cells generate more and more intracellular formazan crystals, they begin to lose their attatchment to the microtiter plates. When the MTT supernatant is removed, these cells are lost. To minimize cell loss in all subsequent experiments, formalin was used to fix the cells to the tissue culture plastic.

of the the 15 compounds tested against the drugsensitive cell lines $\mathrm{MCF}-7$ and T-47D, 8 demonstrate significant activity. Agents with an $E_{50}$ value of up to 25 $\mu \mathrm{g} / \mathrm{ml}$, except for imbricatine, were selected for further testing against the ZR-75-1 and MDA-MB-231 cell lines and the drug-resistant cell lines. There was an insufficient amount of imbricatine available for further testing in these cell lines. An $\mathrm{ED}_{50}$ of $25 \mu \mathrm{g} / \mathrm{ml}$ was selected as a cutoff value because many of the compounds tested were crude extracts, and a lower cutoff point might have resulted in the exclusion of potentially toxic compounds from further testing. The cutoff value used by other researchers in the drug-screening field is typically $1 \mu \mathrm{g} / \mathrm{ml}$. In addition, glaciasterol, which exhibited $\mathrm{ED}_{50}$ values in the $25 \mu \mathrm{g} / \mathrm{ml}$ range, also exhibited low in vivo host toxicity (personal communication with Dr. R Andersen). 
The geodiamolides (a mixture of two cyclodepsipeptides that are identical except that one is brominated and the other iodinated) and jaspamide are very promising compounds, since they exhibit cytotoxicity comparable with that of Adriamycin when tested against the drug-sensitive cell lines and are several orders of magnitude more cytotoxic than Adriamycin when screened against the MDR cell lines. Jaspamide, when screened against the NCI's human tumor cell line panel, also exhibits selective cytotoxicity against renal and rectal cancer cell lines (personal communication with $\mathrm{Dr}$. R Andersen). This selective activity suggests that jaspamide may have a novel mode of action. Adriamycin was selected as a standard by which the test samples could be compared because it is commonly used, in conjunction with cyclophosphamide and 5-fluorouracil, in the treatment of breast cancer.

The observation that compounds such as the geodiamolides are much less cytotoxic against $\mathrm{MCF}-7 \mathrm{Ad}^{\mathrm{r}}$ cells than the parent line MCF-7 whereas they were more cytotoxic against $\mathrm{MDA}-\mathrm{A} 1^{\mathrm{r}}$ cells than the parent line MDA-MB231 (Tables 7 and 8) suggests either that cellular mechanisms in the $M D A-A{ }^{r}$ cells may enable the drugs to overcome the effects of Pgp overexpression or that these drugs are simply not affected by this efflux pump. The presence of Pgp in these cell lines is known since other researchers in this laboratory have demonstrated using immunohistochemical techniques that the MCF-7 $\mathrm{Ad}^{\mathrm{r}}$ and MDA- 
$\mathrm{Al}^{\mathrm{r}}$ cell lines are Pgp-positive, whereas the MCF-7 cell line is Pgp-negative. The Pgp staining status of the MDA-MB-231 is currently being determined in this laboratory.

It is observed for the Garvea extract, the geodiamolides, PNG-137A, glaciasterol and jaspamide that the $E_{50}$ values generated for either the $M C F-7$ or $M D A-M B-231$ cells were not much different than those obtained using the drug-resistant daughter lines. This suggests that either these agents, in addition to being cytotoxic, may circumvent the MDR phenotype, or they may not be affected by the presence of the Pgp pump. Glaciasterol is particularily interesting since its' molecular structure is analogous to that of steroid hormones. Steroid hormones, particularily progesterone and the antiestrogen tamoxifen, have been shown to interfere with Pgp-mediated efflux of anticancer drugs $(50,70,108)$. To gain an understanding of the relationship between these 5 samples and the Pgp pump, serial dilutions of these agents were exposed to the MCF-7 $\mathrm{Ad}^{\mathrm{r}}$ cells in the presence of Adriamycin. Adriamycin is a known substrate for the Pgp pump. The failure to observe cytotoxic synergy between the samples and Adriamycin suggests that these drugs do not interfere with Pgp function.

In retrospect, with regard to these particular experiments, it may have been a more suitable experimental design if varying concentrations of Adriamycin and the $E_{50}$ concentration of our test agent were incubated with the MDR cells rather than varying concentrations of our test agent 
and the $\mathrm{ED}_{50}$ concentration of Adriamycin. The reason for this is that one wants to see if the test agent can modulate the activity of Adriamycin (ie: decrease $E D_{50}$ ), rather than vice-versa. However, the experiments actually performed are not invalid, since ultimately the $\mathrm{ED}_{50}$ concentrations of both Adriamycin and the test agent are exposed to the same MDR cells. The in vitro tumor model used in these experiments resembles a skipper-schabel model of tumor growth much more than a Gompertzian model, since the cells are growing at a low cell density (subconfluent) and there is easy access to $\mathrm{O}_{2}$ and nutrients. Consequently one would expect Skipper's constant-cell-kill law to prevail. If the 2 agents in the test system worked independently from one another, then exposure of the MDR cells to the ED50 concentration of both agents should result in $25 \%$ of the cells surviving treatment. This observation appears to hold true for all the samples (Figures 27 - 30) tested except the geodiamolides (Figure 26). If the agents work synergistically with one another (ie: the test agent interfers with Pgp function), then one would expect $>75 \%$ cell kill. Conversely, if the 2 agents interfere with one another then decreased cell kill (<75\%) would be observed. The geodiamolides appear to fit into this category (Figure 26).

It should be stressed that although the MTT assay has been shown to be a reproducible and accurate assay for generating dose response curves, there was great difficulty 
in accurately weighing the compounds and maintaining the appropriate drug concentrations. For some of the pure samples, only a very small amount ( $1 \mathrm{mg}$ ) of drug was available for testing. To keep drug vehicle (ethanol and saline) concentrations to a minimum, the drugs had to be dissolved in a minimal volume ( $100 \mu \mathrm{I}$ ) of vehicle. Consequently it was difficult to maintain a constant drug concentration when working with such a small volume of volatile organic solvent, especially when repeated opening of the drug-containing vials was required.

Previous experiments in this laboratory have demonstrated that cells from the same tumor cultured in different media vary in their responses to chemotherapeutic agents (43). These previous experiments also demonstrated that medium supplemented with the patient's serum promotes the attachment and growth of HBEC. Since medium containing the patient's serum more closely simulates the in vivo environment than defined medium and medium supplemented with FBS, the most appropriate nutrient environment for determining the effects of therapeutic agents should include serum of the patient from whom the tumor is removed (43). A wide range of chemosensitivities for the geodiamolides is observed when tested against normal and malignant breast tissue taken from different patients, although there appears to be no significant trend indicating tumor specificity. Several notes of caution should be mentioned regarding the interpretation of these results obtained from HBEC in 
primary culture. Naturally occuring breast tumors in vivo follow Gompertzian growth kinetics (109). This is likely due to the fact that they are very heterogenous, being composed of both drug-resistant and drug-responsive cells. All the malignant tissue samples used in these experiments were from biopsies and mastectomies. Furthermore, the tissue sample received from the hospital is likely composed of normal as well as malignant cells. Another confounding factor in the interpretation of these results is that the growth media used to culture these cells also promotes the growth of fibroblasts (44). The presence of fibroblasts in the culture probably helps mirror the in vivo environment since at least some epithelial stromal interactions are maintained. However, in the in vivo environment the malignant epithelial cells are much more mitotically active than the stromal cells, whereas in the in vitro condition both populations are highly mitotic. Chemotherapeutic drugs are generally more effective on mitotic cells than on quiescent cells (163) and thus the presence of mitotically active fibroblasts could influence the interpretation of an in vitro assay. However, previous studies in this laboratory have demonstrated that the HBEC culturing methods outlined in this thesis select for $~ 85 \%$ epithelial cells at the time of cell seeding (44). It was also observed in these experiments that fibroblast overgrowth occurs $7-10$ days after seeding. The drug screening protocol outlined in this thesis requires cultures to grow for only 5 days. A defined 
medium which inhibits the growth of stromal cells could be used instead of the patient's serum for the drug sensitivity testing, but this has previously been shown to alter the response of HBEC in primary culture to cytotoxic agents (43)

The geodiamolides, jaspamide and the five crude extracts PNG-31A, Garvea, BC-3, QCI-32 and PNG-137-A warrant further investigation, since they demonstrate significant cytotoxicity in the preliminary cell-line screens. The full potential of the crude extracts will not be realized until the pure active metabolites have been isolated. The next step in the identification of these agents as cytotoxic would be additional testing against other in vitro human tumor models representing a variety of tumor types, followed by in vivo testing of the tumor types that demonstrate activity in the in vitro screens. This laboratory has a mouse colony for maintaining the transplantable Shionogi mammary carcinoma (45). In conjunction with these in vitro and in vivo screens, future experiments will also include mechanism based testing to determine modes of action of these agents.

Drug resistance and host toxicity, as outlined by the Goldie-coldman model and the Norton-Simon hypothesis, are the reasons for chemotherapy failure. As the structures of the pure metabolites illustrate, marine organisms represent a vast reservoir of new and interesting chemical families that potentially provide novel modes of action, better 
therapeutic indices and fewer side effects than chemotherapeutic agents in clinical use against currently uncurable solid tumors. 


\section{REFERENCES}

1. Albertini R.J., Castle K.L., and Borcherding W.R. (1982) T-cell cloning to detect the mutant 6-thioguanine-resistant lymphocytes present in human peripheral blood. Proc. Natl. Acad. Sci. U.S.A. 79: 6617-6621.

2. Alley M.C., Scudiero D.A., Monks A., Hursey M.L., Czerwinski M.J., Fine D.L., Abbott B.J., Mayo J.G., Shoemaker R. and Boyd M.R. (1988) Feasibility of drug screening with panels of human tumor cell lines using a microculture tetrazolium assay. Cancer Res. 48: 589-601.

3. Alley M.C., Powis G., Appel P.L., Kooistra K.L. and Lieber M.M. (1984) Activation and inactivatio of cancer chemotherapeutic agents by rat hepatocytes cocultured with human tumor cell lines. Cancer Res. 44: 549-556.

4. Baguley B.C. and Wilson W.R. (1987) Comparison of in vivo and in vitro drug sensitivities of Lewis lung carcinoma and P388 leukemia to analogues of amsacrine. Eur. J. Cancer Clin. Oncol. 23: 607-613.

5. Bak M., Efferth T., Mickisch G., Mattern J. and Volm M. (1990) Detection of drug resistance and P-glycoprotein in human renal cell carcinomas. Eur. Urol. 17: 7275.

6. Beck W.T. (1983) Vinca alkaloid-resistant phenotype in cultured human leukemic lymphoblasts. Cancer Treat. Rep. 67: 875-882.

7. Beck W.T. (1991) Do anti-P-glycoprotein antibodies have a future in the circumvention of multidrug resistance? $\mathrm{J}$. Natl. Cancer Inst. (U.S.A.) 83: 1364-1366.

8. Benson A.B., Trump D.L., Koeller J.M. and 5 others (1985) Phase I study of vinblastine and verapamil given by concurrent iv infusion. Cancer Treat. Rep. 69: 795-799.

9. Bergmann W. and Feeney R.J. (1951) Contributions to the study of marine products. The nucleosides of sponges. $J$. Org. Chem. 16: 981 .

10. Biedler J.L., Chang T., Meyers M.B., Peterson R.H.F. and Spengler B.A. (1983). Drug resistance in Chinese hamster lung and mouse tumor cells. Cancer Treat. Rep. 67: 859-867.

11. Blume E. (1989) Investigators seek to increase taxol supply J. Natl. Cancer Inst. (U.S.A.) 81: 1122-1123.

12. Borenfreund E. and Puerner J.A. (1984) Toxicity determined in vitro by morphological alterations and neutral red absorption. Tox. Lett. 24: 119-124. 
13. Borenfreund E. and Puerner J.A. (1987) Short-term quantitative in vitro cytotoxicity assay involving an s-9 activating system. Cancer Lett. 34: 243-248.

14. Boyd M.R. (1989) Status of the NCI preclinical antitumor drug discovery screen. In: Cancer: Principles and practice of oncology update (DeVita V.T., Hellman S. and Rosenberg S.A., eds), vol 3, Lippincott, Philadelphia. pp 1-12.

15. Bradley G., Naik M. and Ling V. (1989) P-Glycoprotein expression in multidrug-resistant human ovarian carcinoma cell lines. Cancer Res. 49: 2790-2796.

16. Broxterman H.J., Kuiper C.M., Schuurhuis G.J., Tsuruo T., Pinedo H.M. and Lankelma J. (1988) Increase of duanorubicin and vincristine accumulation in multidrug resistant human ovarian carcinoma cells by a monoclonal antibody reacting with P-glycoprotein. Biochem. Pharm. 37: 2389-2393.

17. Burgoyne D.L., Miao S., Pathirana C., Andersen R.J., Ayer W.A., Singer P.P., Kokke W.C.M.C. and Ross D.M. (1991) The structure and partial synthesis of imbricatine, a benzyltetrahydroisoquinoline alkaloid from the starfish Dermasterias Imbricata. Can. J. Chem. 69: 20-27.

18. Canellos G.P., De Vita V.T., Gold G.L., Chabner B.A., Schein P.S. and Young R.C. (1976) Combination chemotherapy for advanced breast cancer: respnse and effect on survival. Ann. Inter. Med. 84: 389-392.

19. Cano-Gauci D.F. and Riordan J.R. (1987) Action of calcium antagonists on multidrug resistant cells. Specific cytotoxicity independent of increased cancer drug accumulation. Biochem. Pharm. 36: 2115-2123.

20. Carmichael J., DeGraff W.G., Gazdar A.F., Minna J.D. and Mitchell J.B. (1987) Evaluation of a tetrazolium-based semiautomated colorimetric assay: Assessment of chemosensitivity testing. Cancer Res. 47: 936-942.

21. Chabner B.A. (1990) In defence of cell line screening. J. Natl. Cancer Inst. (U.S.A.) 82: 1083-1085.

22. Chen C.-J., Chin J.E., Ueda K., Clark D.P., Pastan I., Gottesman M.M. and Roninson I.B. (1986) Internal

duplication and homology with bacterial transport proteins in the mar-1 (P-glycoprotein) gene from multidrug-resistant human cells. Cell 47: 381-389.

23. Christian M.C., wittes R.E., Leyland-Jones B., McLemore T.L., Smith A.C., Grieshaber C.K., Chabner B.A. and Boyd M.R. (1989) - 4-Ipomenaol: A novel investigational new drug 
for lung cancer. J. Natl. Cancer Inst. (U.S.A.) 81: 13331143 .

24. Clark R., Lippman M.E. and Dickson R.B. (1990)

Mechanisms of hormone and cytotoxic drug interactions in the development and treatment of breast cancer. In: Molecular endocrinology and steroid hormone action (Sato G.H. and Stevens J.L., eds). Alan R. Liss Inc., New York. pp 243-278.

25. Collins K.D. and Stark G.R. (1971) Aspartate transcarbamylase: interaction with the transition state analogue $\mathrm{N}$-(phosphonacetyl)-L-aspartate. J. Biol. Chem. 246: 6599-6605.

26. Conley B.A. and Van Echo D.A. (1992) Antineoplatic drug development. In: The chemotherapy source book (Perry M.C. ed.), Williams and Wilkins, Baltimore, Maryland. pp 15-21.

27. Cooper R. (1969) Combination chemotherapy in hormone resistant breast cancer. Proc. Amer. Assoc. Cancer Res. 10: 15 .

28. Cornwell M.M., Tsuruo T., Gottesman M.M. and Pastan I. (1987) ATP-binding properties of P-glycoprotein from multidrug-resistant KB cells. FASEB J. 1: 51-54.

29. Crews P., Manes L.V. and Boehler M. (1986)

Jaspalkilnotide, a cyclodepsipeptide from the marine sponge Jaspis sp. Tetrahedron Lett. 31: 2797-2798.

30. Dalton W.S. and Grogan T.M. (1991) Does P-glycoprotein predict response to chemotherapy, and if so, is there a reliable way to detect it? J. Natl. Cancer Inst. (U.S.A.) 83: 80-81.

31. DeFazio A., Musgrove E.A., and Tattersall M.H. (1988) Flow cytometric enumeration of drug-resistant tumor cells. Cancer Res. 48: 6037-6043.

32. Dempsey J.L., Seshadri R.S., and Morley A.A. (1985) Increased mutation frequency following treatment with cancer chemotherapy. Cancer Res. 45: 2873-2877.

33. Denizot F. and Lang R. (1986) Rapid colorimetric assay for cell growth and survival. Modifications to the tetrazolium dye procedure giving improved sensitivity and reliability. J. Immun. Meth. 89: 271-277.

34. desilva E.D., Andersen R.J. and Allen T.M. (1990) Geodiamolides $C$ to $F$, new cytotoxic cyclodepsipeptides from the marine sponge Pseudaxinyssa sp. Tetrahedron Lett. 31 : 489-492.

35. Dietel M. (1991) What's new in cytostatic drug 
resistance and pathology. Path. Res. Pract. 187: 892-905.

36. Dolnick B.J., Berenson R.J., Bertino J.R., Kaufman R.J., Nunberg J.H. and Schimke R.T. (1979) Correlation of kehydrofolate reductase elevation with gene amplification in a homogeneously staining chromosomal region in L5178Y cells. J. Cell. Biol. 83: 399-402.

37. Double J.A. and Bibby M.C. (1989) Therapeutic index: A vital component in selection of anticancer agents for clinical trial. J. Natl. Cancer Inst. (U.S.A.) 81: 988-994.

38. Driscoll J.S. (1984) The preclinical new drug research program of the National Cancer Institute. Cancer Treat. Rep. 68: $63-76$.

39. Duerst R.E. and Frantz C.N. (1985) A sensitive assay of cytotxicity applicable to mixed cell populations. J. Immun. Meth. 82: 39-46.

40. Dumdei E.J., deSilva E.D., Andersen R.J., Iqbal Choudry M. and Clardy J. (1989) Chromodorolide A, a rearranged diterpene with a new carbon skeleton from the Indian Ocean nudibranch Chromodoris cavae. J. Amer. Chem. Soc. 111: 27122713 .

41. Elmore E., Kakunaga T., and Barrrett J.C. (1983)

Comparison of spontaneous mutation rates of normal and chemically transformed human skin fibroblasts. Cancer Res. 43: 1650-1655.

42. Emerman J.T., Tolcher A.W. and Rebbeck P.M. (1990) In vitro sensitivity testing of human breast cancer cells to hormones and chemotherapeutic agents. Cancer Chemother. Pharm. 26: 245-249.

43. Emerman J.T., Fiedler E.E., Tolcher A.W. and Rebbeck P.M. (1987) Effects of defined medium, fetal bovine serum, and human serum on growth and chemosensitivities of human breast cancer cells in primary culture: inference for in vitro assays. In Vitro Cell. Devel. Biol. 23: 134-140.

44. Emerman J.T. and Wilkinson D.A. (1990) Routine culturing of normal, dysplastic, and malignant human mammary epithelial cells from small tissue samples. In Vitro cell. Devel. Biol. 26: 1186-1194.

45. Emerman J.T. and Siemiatkowski J. (1984) Effects of endocrine regulation of growth of a mouse mammary tumor on tis sensitivity to chemotherapy. Cancer Res. 44: 1327-1332.

46. Fahy E. and Andersen R.J. (1987) Minor metabolites of the marine hydroid Garvea annulate. Can. J. Chem. 65: 376383 . 
47. Fairchild C.R., Ivy S.P., Kap-Shan C.S., Whang-Peng J., Rosen N., Isreal M.A., Melea P.W., Cowan C.H. and Goldsmith M.E. (1987) Isolation of amplified and overexpressed DNA sequences from Adriamycin-resistant human breast cancer cells. Cancer Res. 47:5141-5148.

48. Farber S., Diamond L.K., Mercer R.D. et al. (1948) Temporary remissions in acute leukemia in children produced by folic acid antagonist, 4-aminopteroyl-glutamic acid (aminopterin). N. Engl. J. Med. 238: 787-793.

49. Filman R.J., Brawn R.J. and Dandliker W.B. (1975)

Intracellular supravital stain delocalization as an assay for antibody-dependent complement-mediated cell damage. J. Immun. Meth. 6: 189-207.

50. Fine R.L., Sachs C.W., Albers M. and Williams A. (1991) Tamoxifen potentiates the cytotoxicity of vinblastine by increasing intracellular drug accumulation. Proc. Amer. Assoc. Cancer Res. 32: 375.

51. Finlay G.J. and Bagulaey B.C. (1984) The use of human cancer cell lines as a primary screening system for antineoplastic compounds. Eur. J. Cancer Clin. Oncol. 20: 947-954.

52. Finlay G.J., Wilson W.R. and Baguley B.C. (1986) Comparison of in vitro activity of cytotoxic drugs towards human carcinoma and leukemia cell lines. Eur. J. Cancer 22: 655-662.

53. Fisher B., Redmon C., Legault-Poisson S. et al. (1990) Postoperative chemotherapy and tamoxifen compared with tamoxifen alone in the treatment of positive-node breast cancer patients with tumors responsive to tamoxifen: results from NSABP B-16. J. Clin. Oncol. 8: 1005-1018.

54. Fojo A.T., Ueda K., Slamon D.J., Poplack D.G., Gottesman M.M. and Pastan I. (1987) Expression of a multidrugresistance gene in human tumors and tissues. Proc. Natl. Acad. Sci. U.S.A. 84: 265-269.

55. Frie E., III, and Canellos G.P. (1980) Dose: a critical factor in cancer chemotherapy. Am. J. Med. 69: 585-594.

56. Furth J., Kahn M.C. (1937) The transmission of leukemia of mice with a single cell. Am. J. Cancer. 31: 276-282.

57. Gianni A.M., Siena S., Bregni M., Tarella C., Stern A.C., Pileri A. and Bonadonna G. (1989). Granulocytemacrophage colony-stimulating factor to harvest circulating haematopoietic stem cells for autotransplantation. Lancet 2: 580-585. 
58. Goldie J.H. and Coldman A.J. (1979) A mathematical model for relating the drug sensitivity of tumors to their spontaneous mutation rates. Cancer Treat. Rep. 63: 17271733.

59. Goldstein L.J., Galski H., Fojo A., Willingham M. and 10 others (1989) Expression of a multidrug resistance gene in human cancers. J. Natl. Cancer Inst. (U.S.A.) 81: 116-124.

60. Goodman L.S., Wintrobe M.M., Dameshek W., et al. (1946) Use of methyl-bis (beta-chloroethyl) amine hydrochloride for Hodkin's disease, lymphomsarcoma, leukemia. JAMA 132: 126.

61. Gorelik E., Alley M. and Shoemaker R. (1986) A new in vivo short-term assay for evaluation of antitumor chemotherapeutic drugs. Proc. Amer. Assoc. Cancer Res. 27: 389 .

62. Grindey G.B. (1990) current status of cancer drug development: Failure or limited success? Cancer cells 2: 163-171.

63. Hamada H. and Tsuruo T. (1988) Characterization of the ATPase activity of the $\mathrm{M}_{\mathrm{r}} 170,000$ to 180,000 membrane glycoprotein (P-glycoprotein) associated with multidrug resistance in K562/ADM cells. Cancer Res. 48: 4926-4932.

64. Hamburger A.W. and S.E. Salmon (1977) Primary bioassay of human tumor stem cells. Science 197: 461-463.

65. Hegewisch-Becker S., Fliegner M., Hossfeld D. and Zander A. (1991) Clincial relevance of $\mathrm{P}-\mathrm{glycoprotein}$ expression and drug uptake. Proc. Amer. Assoc. Cancer. Res. 32: 434 .

66. Heidelberger C., Chaudhuari N.K., Danenberg P. et al. (1957) Fluorinated pyrimidines: a new class of tumor inhibitory compounds. Nature 179: 663-666.

67. Heo D.S., Park J.-G., Hata K., Day R., Herberman R.B. and Whiteside T.L. (1990) Evaluation of tetrazolium-based semiautomatic colorimetric assay for measurement of human antitumor cytotoxicity. Cancer Res. 50: 3681-3690.

68. Heuser L., Spratt J. and Polk H. (1979) Growth rates of primary breast cancer. Cancer 43: 1888-1894.

69. Hitchins R.N., Harman D.H., Davey R.A. and Bell D.R. (1988) Identification of a multidrug resistance associated antigen (P-glycoprotein) in normal human tissues. Eur. J. Cancer clin. Oncol. 24: 449-454.

70. Huang Yang C.-P., Goei DePinho S., Greenberger L.M., Arceci R.J. and Band Horwitz S. (1989) Progesterone 
interacts with P-glycoprotein in multidrug-resistant cells and in the endometrium of gravid usterus. J. Biol. Chem. $264: 782-788$.

71. Irwin L.E., Pugh R., Sadoff L., Hestorff R., Weiner J.M. and Bateman J.R. (1975) The influence on survival of continuous combination vs sequential single agent chemotherapy in disseminated breast cancer. Presented at the American College of Physicians 56th annual meeting, San Francisco.

72. Jacobson L.P., Spurr C.L., Barron E.S.Q., et al. (1946) Studies on the effect of methyl-bis (beta-chloroethyl)amine hydrochloride for neoplastic deseases and allied disorders of the hemapoitic system. JAMA 132: 263.

73. Johnson R.K. (1990) Screening methods in antineoplastic drug discovery. J. Natl Cancer Inst. (U.S.A.) 82: 1082-1083.

74. Jones C.A., Tsukamoto T., O'Brien P.C., Uhl C.B. and Alley M.C. (1985) Soft agarose culture human tumour colony forming assay for drug sensitivity testing: [ ${ }^{3} \mathrm{H}$ ]-thymidine incorporation vs colony counting. Br. J. Cancer 52: 303-310.

75. Jordan V.C. and Murphy C.S. (1990) Endocrine pharmacology of antiestrogens as antitumor agents. Endocrine Rev. 11: 578-601.

76. Juranka P.F., Zastawny R.L. and Ling V. (1989) Pglycoprotein: Multidrug-resistance and a superfamily of membrane-associated transport proteins. FASEB J. 3: 25832592 .

77. Kardinal C.G. (1992) Chemotherapy of breast cancer. In: The chemotherapy source book (Perry M.C., ed), Williams and Wilkins, Baltimore, Maryland. pp 948-988.

78. Kardinal C.G., Perry M.C., Korzun A.H., Rice M.A., Ginsberg S. and Wood W. (1988) Responses to chemotherapy of chemohormonal therapy in advanced breast cancer patients treated previously with adjuvant chemothrapy. Cancer 61: 415-419.

79. Kardinal C.G. (1979) Chemotherapy. In: Cancer of the breast, 2nd edition (Donegan W.L. and Spratt J.S., eds), W.B. Saunders, Philadelphia. pp 405-447.

80. Kaufman R.J., Brown P.C., and Schimke R.T. (1979) Amplified dihydrofolate reductase genes in unstably methotrexate-resistant cells are associated with double minute chromosomes. Proc. Natl. Acad. Sci. U.S.A. 76: 56695673 . 
81. Keith W.N., Stallard S. and Brown R. (1990) Expression of $\operatorname{mdr} 1$ and $g s t-\oplus$ in human breast tumours: Comparison to in vitro chemosensitivity. Br. J. Cancer 61: 712-716.

82. Kennedy J.M., Beveridge R.A., Rowley S.D., Gordon G.B., Abeloff M.D. and Davidson N.E. (1991) High-dose chemotherapy with reinfusion of purged autologous bone marrow following dos-intense induction as initial therapy for metastatic breast cancer. J. Natl. Cancer Inst (U.S.A.) 83: 920-926.

83. Kerkvliet G.J. (1990) Scientists search rain forests for novel chemicals. J. Natl. Cancer Inst. (U.S.A.) 82; 10001001 .

84. Kidd J.G. (1953) Regression of transplanted lymphomas induced in vivo by means of normal guinea pig serum: I. Course of transplanted cancers of various kinds in mice and rats given guinea pig serm, horse serum, or rabbit serum. $J$. Exp. Med. 98: 565-582.

85. Klohs W.D., Steinkampf R.W., Havlick M.J. et al. (1986) Resistance to anthracyclines in multidrug-resistant P388 murine leukemia cells: Reversal by calcium blockers and calmodulin antagonists. Cancer Res. 46: 4352-4356.

86. Kovach J.S., Ames M.M., Powis G. et al. (1980) Use of a liver microsome system in testing drug sensitivity of tumor cells in soft agar. Proc. Amer. Assoc. Cancer Res. 21: 257.

87. Laird A.K. (1969) Dynamics of tumor growth in tumors and normal organisms. Natl. Cancer Inst. Mono. 30: 15-28.

88. Law L.W. (1952) origin of the resistance of leukemic cells to folic acid antagonists. Nature 169: 628-629.

89. Lee W.W., Benitez A., Goodman L. and Baker B.R. (1960) Potential anticancer agents. Synthesis of the B-anomer of 9(D-arabinofuranosyl)-adenine. J. Am. Chem. Soc. 82: 2648.

90. Licht T.H., Fiebig H.H., Bross K.J., Berger D.P., Dreher C. and Shoemaker R. (1991) Induction of multidrug-resistance during antineoplastic chemotherapy. Proc. Amer. Assoc. Cancer Res. 32: 367.

91. Lillie R.D. (1977) In: H.J. Conn's biological stains, 9th ed. Williams and Wilkins, Baltimore, Maryland.

92. Ling V., Kartner N., Sudo T., Siminovicth L and Riordan J.R. (1983) Multidrug-resistance phenotype in Chinese hamster ovary cells. Cancer Treat. Rep. 67: 869-874.

93. Ling V. (1989) Does P-glycoprotein predict response to chemotherapy? J. Natl. Cancer Inst. (U.S.A.) 81: 84-85. 
94. Marsoni S. and Wittes R.E. (1984) Clinical development of anticancer agents - A National Cancer Institute Perspective. Cancer Treat. Rep. 68: 77-85.

95. Marsoni S., Hoth D., Simon R., Leyland-Jones B., De Rosa M. and Wittes R.E. (1987) Clinical drug development: An analysis of phase II trials, 1970-1985. Cancer Treat. Rep. 71: 71-80.

96. Martin W.M.C. and McNally N.J. (1980) The cytotoxic effects of Adriamycin on tumour cells in vitro and in vivo. $\mathrm{Br}$. J. Cancer 41 (suppl IV) : 306.

97. Mendelsohn M.L. (9160) The growth fraction: A new concept applied to tumors. Science 132: 1496.

98. Merry S., Flanigan P., Schlick E., Freshney R.I. and Kaye S.B. (1989) Inherent adriamycin resistance in a murine tumour line: Circumvention with verapamil and norverapamil. Br. J. Cancer 59: 895-897.

99. Miao S. (1991) Novel secondary metabolites from selected marine invertebrates. PhD Thesis, University of British Columbia.

100. Miao S., Andersen R.J. and Allen T.M. (1990) Cytotoxic metabolites from the sponge Ianthella Basta collected in Papua New Guinea. J. Naturall Prod. 53: 1441-1446.

101. Mickisch G.H., Kossig J., Keilhauer G.K., Schlick E., Tschada R.K. and Alken P.M. (1990) Effects of calcium antagonists in multidrug resistant primary human renal cell carcinomas. Cancer Res. 50: 3670-3674.

102. Mickisch G.H., Merlino G.T., Galski H., Gottesman M.M. and Pastan I. (1991) Transgenic mice that express the human multidrug-resistance gene in bone marrow enable a rapid identification of agents that reverse multidrug resistance. Proc. Natl. Acad. Sci. U.S.A. 88: 547-551.

103. Monks A., Scudiero D., Skehan P., Shoemaker R. and 10 others (1991) Feasibility of a high-flux anticancer drug screen using a diverse panel of cultured human tumor cell lines. J. Natl. Cancer Inst. 83: 757-766.

104. Moore R.E. and Scheuer P.J. (1971) Palytoxin: A new toxin from a coelenterate. Science 172: 494-498.

105. Morris S.A. and Andersen R.J. (1989) Nitrogenous metabolites fro the deep water sponge Hexadella sp. Can. J. Chem. 67: 677-681.

106. Morrison V.A. and Luikart S.D. (1992) Chemotherapy of lung cancer. In: The chemotherapy source book (Perry M.C., 
ed), Williams and Wilkins, Baltimore, Maryland. pp 932-947.

107. Mosmann T. (1983) Rapid colorimetric assay for cellular growth and survival: Application to proliferation and cytotoxicity assays. J. Immun. Meth. 65: 55-63.

108. Naito M., Yusa K. and Tsuruo T. (1989) Steroid homones inhibit binding of Vinca alkaloids to multidrug resistance related P-glycoprotein. Biochem. Biophys. Res. Comm. 158: 1066-1071.

109. Norton L. (1988) A Gompertzian model of human breast cancer. Cancer Res. 48: 7067-7071.

110. Norton L. (1992) The Norton-Simon hypothesis. In: The chemotherapy source book (Perry M.C., ed), Williams and wilkins, Baltimore. pp 36-53.

111. Norton L. and Simon R. (1986) The Norton-Simon hypothesis revisited. Cancer Treat. Rep. 70: 163-169.

112. Oliver M.H., Harrison N.K., Bishop J.E., Cole P.J. and Laurent G.J. (1989) A rapid and convenient assay for counting cells cultured in microwell plates: application for assessment of growth factors. J. Cell Science 92: 513-518.

113. Otis P.T. and Armentrout S.A. (1975) Combination chemotherapy in metastatic carcinoma of the breast: results with a three-drug combination. Cancer 36: 311-317.

114. Ovejera A.A. and Houchens D.P. (1981) Human tumor xenografts in athymic nude mice predlinical screen for anticancer agents. Semin. Oncol. 8: 386-393.

115. Ozawa S., Yasuda T. and Inaba M. (1988) Comparison of cellular basis of drug sensitivity of human colon, pancreatic, and renal carcinoma cell lines with that of leukemia cell lines. Cancer Chemother. Pharm. 22: 41-46.

116. Padmanabhan N., Howell A., Rubens R.D. (1986) Mechanism of action of adjuvant chemotherapy for breast cancer. Lancet ii: $411-414$.

117. Pathirana C. and Andersen R.J. (1986) Imbricatine, an unusual benzyltetrahydroisoquinoline alkaloid isolated from the starfish Dermasterias imbricata. J. Am. Chem. Soc. 108: $8228-8229$.

118. Paull K.D., Shoemaker R.H., Hodes L., Monks A., Scudiero D.A., Rubinstein L., Plowman J. and Boyd M.R. (1989) Display and analysis of patterns of differential activity of drugs against human tumor cell lines: Development of mean graph and COMPARE algorithm. J. Natl. Cancer Inst. (U.S.A.) 81: 1088-1092. 
119. Perry M.C., Kardinal C.G., Korzun A.H. et al. (1987) Chemohormonal theray in advanced carcinoma of the breast: Cancer and Leukemia Group B protocol 8081. J. Clin. Oncol. 5: $1534-1545$.

120. Petit G.R., Herald C.L., Doubek D.L., Herald D.L., Arnold E. and Clardy J. (1982) Isolation and structure of bryostatin 1. J. Am. Chem. Soc. 104: 6846-6848.

121. Peto R. Data presented at King's Fund Forum on

Treatment of Primary Breast Cancer. London, 1 October, 1986.

122. Phillips R.M., Bibby M.C. and Double J.A. (1990) A critical appraisal of the predictive value of in vitro chemosensitivity assays. J. Natl. Cancer Inst. (U.S.A.) 82 : 1457-1468.

123. Pika J., Tischler M. and Andersen R.J. (1992) Glaciasterols $A$ and $B, 9,11$-secosteroids from the marine sponge Aplysilla glacialis. Can. J. Chem. 70: 1506-1510.

124. Price P. and T.J. McMillan (1990) Use of the tetrazolium assay in measuring the response of human tumor cells to ionizing radiation. Cancer Res. 50: 1392-1396.

125. Ragaz J. and Ariel I.M. (1989) Diagnostic and therapeutic highlights of high risk breast cancer-Part one. Comments related to surgery, radiotherapy and hormonal therapy. In: High risk breast cancer-therapy. (Ragaz J. and Ariel I.M., eds), Springer-Verlag, Heidelberg. pp 17-39.

126. Ramachandran C., wellham L., Sridhar K.S. and Krishan A. (1991) Mdr-1 gene, P-glycoprotein, and doxorubicin cytotoxicity in human lung tumor cell lines. Proc. Amer. Assoc. Cancer Res. 32: 365.

127. Reynolds T. (1991) Tropical rain forest conservation tied to drug development. J. Natl. Cancer Inst. (U.S.A.) 83; 594-596.

128. Rhoads C.P. (1946) Nitrogen mustards in treatment of neoplastic disease. JAMA 131: 656 .

129. Richards W.L., Song M. -K., Krutzsch H., Evarts R.P., Marsden E. and Thorgeirsson S.S. (1985) Measurement of cell proliferation in microculture using Hoechst 33342 for the rapid semiautomated microfluorimetric determination of chromatin DNA. Exp. Cell. Res. 159: 235-246.

130. Rinehart K.L., Gloer J.B., Cook J.C., Mizsak S.A. and Scahill T.A. (1981) structures of the didemnins, antiviral and cytotoxic depsipeptides from a Caribbean tunicate. J. Am. Chem. Soc. 103: 1857-1859. 
131. Ro J., Sahin A., Ro J.Y., Fritsche H., Hortobagyi G. and Blick M. (1990) Immunohistochemical analysis of Pglycoprotein expression correlated with chemotherapy resistance in locally advanced breast cancer. Hum. Path. 21: 787-791.

132. Rosenberg B. (1985) Fundamental studies with cisplatin. Cancer 55: 2303-2316.

133. Ross D.D., Joneckis C.C., Wu R., Hambuerger A., Condon M., Ordonez J.V. and Sisk A. (1987) Estimation of leukemic cell kill by flow cytometric quantification of fluorescein diacetate (FDA) viable cell number. Proc. Amer. Assoc. Cancer Res. 28: 428.

134. Ruben R.L. and Neubauer R.H. (1987) Semiautomated colorimetric assay for in vitro screening of anticancer compounds. Cancer Treat. Rep. 71: 1141-1149.

135. Ruben R.L. (1988) Cell culture for testing anticancer compounds. In: Advances in cell culture, vol 6 (Maramorosch K., ed), Academic Press, Inc., New York. pp 161-197.

136. Rubinstein L.V., Shoemaker R.H., Paull K.D., simon R.M., Tosini S., Skehan P., Scudiero D.A., Monks A. and Boyd M.R. (1990) Comparison of in vitro anticancer-drug-screening data generated with a tetrazolium assay versus a protein assay against a diverse panel of human tumor cell lines. $\mathrm{J}$. Natl. Cancer Inst. (U.S.A.) 82: 1113-1118.

137. Safa A.R., Glover C.J., Sewell J.L., Meyers M.B., Biedler J.L. and Felsted R.L. (1987) Identification of the multidrug resistance-related membrane glycoprotein as an acceptor for calcium channel blockers. J. Biol. Chem. 262: 7884-7888.

138. Salmon S.E. (1989) Chemosensitivity testing: Another chapter. J. Natl. Cancer Inst. (U.S.A.) 82: 82-83.

139. Salmon S.E., Hamburger A.W., Soehnlen B., Durie B.G.M., Alberts D.S. and Moon T.E. (1978) Quantitation of differential sensitivity of human-tumor stem cells to anticancer drugs. New Engl. J. Med. 298: 1321-1327.

140. Schneider S.L., Fuqua S.A.W., Speeg C.V., Tandon A. and McGuire W. (1990) Isolation and characterization of an Adriamycin-resistant breast tumor cell line. In Vitro cell. \& Devel. Biol. 26: 621-628.

141. Scudiero D., Shoemaker R., Paull K., Alley M., Monks A., Fine D. and Boyd M. (1987) A new tetrazolium reagent for a simplified growth and drug sensitivity assay of human tumor cell lines. Proc. Amer. Assoc. Cancer Res. 28: 421. 
142. Selby P., Buick R.N. and Tannock I. (1983) A critical appraisal of the "human tumor stem-cell assay". New Engl. J. Med. 308: 129-134.

143. Seshadri R., Kutlaca R.J., Trainor K., Matthews C. and Morley A.A. (1987) Mutation rates of normal and malignant human lymphocytes. Cancer Res. 47: 407-409.

144. Shieh C.Y., Fojo A.T. and Bates S.E. (1989) Expression of a multidrug resistance gene (mar-1/Pgp) in human breast carcinoma. Proc. Amer. Assoc. Cancer Res. 30: 521.

145. Shoemaker R.H., Wolpert-DeFilippes M.K., Kern D.H., Lieber M.M., Makuch R.W., Melnick N.R., Miller W.T., Salmon S.E., Simon R.M., Venditti J.M. and Vom Hoff D.D. (1985) Application of a human tumor colony-forming assay to new drug screening. Cancer Res. 45: 2145-2153.

146. Shoemaker R.H. (1986) New approaches to antitumor drug screening: The human tumor colony forming assay. Cancer Treat. Rep. 70: 9-12.

147. Shopsis C. and Eng B. (1985) Rapid cytotoxicity testing using a semi-automated protein determination on cultured cells. Tox. Lett. 26: 1-8.

148. Sikic B.I. (1991) Anticancer drug discovery. J. Natl. Cancer Inst. (U.S.A.) 83: 738-742.

149. Skehan P., storeng R., Scudiero D., Monks A., McMahon J., Vistica D., Warren J.T., Bokesch H., Kenney S. and Boyd M.R. (1990) New colorimetric assay for anticancer-drug screening. J. Natl. Cancer Inst. (U.S.A.) 82: 1107-1112.

150. Skipper H.E., Schabel F.M., Jr, and Wilcox W.S. (1964) Experimental evaluation of potential anticancer agents. XIII. On the criteria and kinetics associated with "curability" of experimental leukemia. Cancer Chemother. Rep. 35: 1-111.

151. Skipper H.E. (1979) Historic milestones in cancer biology: A few that are important in cancer treatment. Semin. Oncol. 6: 506-514.

152. Skipper H.E. (1986) Laboratory models: the historical perspective. Cancer Treat. Rep. 70: 3-7.

153. Slater T.F., Sawyer B. and Strauli U.D. (1963) Studies on succinate-tetrazolium reductase systems. III. Points of coupling of four different tetrazolium salts. Biochem. Biophys. Acta. 77: 383-393.

154. Smigel K. (1991) Scientists fing better ways to find 
better drugs. J. Natl. Cancer Inst. (U.S.A.) 83: 1370-1372.

155. Smith I.E. (1989) Adjuvant chemotherapy in early breast cancer. Update 15 February: 359-365.

156. Staquet M.J., Byar D.P., Green S.B. and Rozencweig M. (1983) Clinical predictivity of transplantabe tumor systems in the selection of new drugs for solid tumors: Rationale for a three-stage strategy. Cancer Treat. Rep. 67: 753-765.

157. Suffness M. and Thompson J.E. (1988) National Cancer Institute's role in the discovery of new antineoplastic agents. In: Biomedical importance of marine organisms (Fautin D.G., ed), California Academy of Sciences, San Francisco. pp 151-157.

158. Tannock I.F. (1968) The relationship between proliferation and the vascular system in a transplanted mouse mammary tumor. Br. J. Cancer 22: 258-273.

159. Tsuruo T., Iida H., Nojiri M., Tsukagoshi S. and Sakurai Y. (1983) Circumvention of vincristine and Adriamycin resistance in vitro and in vivo by calcium influx blockers. Cancer Res. 43: 2905-2910.

160. Tsuruo T., Iida H., Tsukagoshi S. et al. (1982) Increased accumulation of vincristine and Adriamycin in drug-resistant P388 tumor cells following incubation with calcium antagonists and calmodulin inhibitors. Cancer Res. $42: 4730-4733$.

161. Twentyman P.R., Walls G.A. and Wright K.A. (1984) The response of tumour cells to radiation and cytotoxic drugs-a comparison of clonogenic and isotope uptake assays. $\mathrm{Br} . \mathrm{J}$. Cancer 50: 625-631.

162. Valagussa P., Tancini G. and Bonadonna G. (1986) Salvage treatment of pateints suffering relapse after adjuvant CMF chemotherapy. Cancer 58: 1411-1417.

163. Valeriote F. and Vanputten L. (1975) Proliferationdependent cytotxicity of anticancer agents: A review. Cancer Res. 35: 2619-2630.

164. Van der Bliek A.M., Baas F., Van der Velde-Koerts T., Biedler J.L., Meyers M.B., Ozols R.F., Hamilton T.C., Joenje H. and Borst P. (1988) Genes amplified and overexpressed in human multidrug-resistant cell lines. Cancer Res. 48: 59275932 .

165. Venditti J.M. (1983) The National Cancer Institute antitumor drug discovery program, current and future perspectives: A commentary. Cancer Treat. Rep. 67: 767-772. 
166. Verrelle P., Meissonnier F., Fonck Y., Feillel V., Dionet C., Kwiatkowski F., Plagne R. and Chassagne J. (1991) clinical relevance of immunohistochemical detection of multidrug resistance P-glycoprotein in breast carcinoma. $\mathrm{J}$. Natl. Cancer Inst. (U.S.A.) 83: 111-116.

167. Vistica D.T., Skehan P., Scudiero D., Monks A., Pittman A. and Boyd M.R. (1991) Tetrazolium-based assays of cellular viability: A critical examination of selected parameters affecting formazan production. Cancer Res. 51: 2515-2520.

168. Volkers N. (1992) Diving for drugs: Scientists search the sea. J. Natl. Cancer Inst. (U.S.A.) 84: 1062-1063.

169. Von Hoff D.D., Sandbach J.F., Clark G.M., Turner J.N., Forseth B.F., Piccart M.J., Colombo N. and Muggia F.M. (1990) Selection of cancer chemotherapy for a patient by an in vitro assay versus a clinician. J. Natl. Cancer Inst. (U.S.A.) 82: 110-124.

170. Von Hoff D.D. (1990) He's not going to talk about in vitro predictive assays again, is he? J. Natl. Cancer Inst. (U.S.A.) 82: 96-101.

171. Watson J.V. (1976) The cell proliferation kinetics of the EMT6/M/AC mouse tumours at four volumes during unperturbed growth in vivo. Cell Tissue Kinetics 9: 147-156.

172. Wiltrout R.H., Talmadge J.E. and Herberman R.B. (1987) Role of NK cells in prevention and treatment of metastases by biological response modifiers. In: Immune response to metastases, Vol II (Herberman R.B., Wiltrout R.H. and Gorelik E. eds.), CRC Press, Bocca Raton, Florida. pp 26-41.

173. Wooley P.V. and Tew K.D. (1988) Mechanisms of drug resistance in neoplastic cells. Academic Press, San Diego, California. pp 1-390.

174. Yarbro J.W. (1992) The scientific basis of cancer chemotherapy. In: The chemotherapy source book (Perry M.C., ed.), Williams and Wilkins, Baltimore. pp 7 .

175. Yoshinari T., Iwasawa Y., Miura K., Takahashi I.S., Fukuroda T., Suzuki K. and Okura A. (1989) Reversal of multidrug resistance by new dihydropyridines with lower calcium antagonistic activity. Cancer Chemother. Pharm. 24: 367-370.

176. Yusa K. and Tsuruo T. (1989) Reversal mechanism of multidrug resistance by verapamil: Direct binding of verapamil to $\mathrm{P}-\mathrm{glycoprotein}$ on specific sites and transport of veramail outward across the plasma membrane of K562/ADM cells. Cancer Res. 49: 5002-5006. 
APPENDICES

APPENDIX 1: Growth Medium for MCF-7, T-47D and ZR-75-1 Cell Iines for Routine Passaging

$\begin{array}{ll}\text { F12/DME } & (1: 1) \\ \text { Hepes buffer } & 10 \mathrm{mM} \\ \text { FBS } & 5 \% \\ \text { Insulin } & 5 \mu \mathrm{g} / \mathrm{ml}\end{array}$

APPENDIX 2: Growth Medium for the MDA-MB-231 Cell Line for Routine Passaging

$\begin{array}{ll}\text { F12/DME } & (1: 1) \\ \text { Hepes buffer } & 10 \mathrm{mM} \\ \text { FBS } & 10 \%\end{array}$

APPENDIX 3: Growth Medium for the MCF-7 Ad cell Line for Routine Passaging

$\begin{array}{ll}\text { F12/DME } & (1: 1) \\ \text { Hepes buffer } & 10 \mathrm{mM} \\ \text { FBS } & 5 \% \\ \text { Insulin } & 5 \mu \mathrm{g} / \mathrm{ml} \\ \text { Adriamycin } & 0.5 \mu \mathrm{g} / \mathrm{ml}\end{array}$

\section{APPENDIX 4: Growth Medium for the MDA-A1 Cell Line for Routine Passaging}

$\begin{array}{ll}\text { F12/DME } & (1: 1) \\ \text { Hepes buffer } & 10 \mathrm{mM} \\ \text { FBS } & 10 \% \\ \text { Adriamycin } & 1 \mu \mathrm{g} / \mathrm{ml}\end{array}$

\section{APPENDIX 5: Preparation of Saline-Trypsin-Versene}

$\begin{array}{ll}\mathrm{NaHCO}_{3} & 0.35 \mathrm{~g} \\ \mathrm{NaCl} & 8.0 \mathrm{~g} \\ \mathrm{KCl} & 0.4 \mathrm{~g} \\ \text { Glucose } & 0.35 \mathrm{~g} \\ \text { EDTA } & 0.25 \mathrm{~g} \\ \text { Trypsin (Gibco) } & 0.5 \mathrm{~g} \\ \text { Distilled water } & 1000 \mathrm{ml}\end{array}$

The first 5 ingredients were weighed out and placed in a large Erlenmeyer flask. Nine hundred and fifty $\mathrm{ml}$ of 
distilled water was added and the solution was stirred until the ingredients were dissolved. Following this, the trypsin was added and stirred until dissolved (_ 1h). The pH was adjusted to 7.4 by the addition of either $\mathrm{NaOH}$ or $\mathrm{HCl}$, and then the remaining distilled water was added. Under aeseptic conditions, the solution was filter sterilized using a Millipore peristaltic pump. The sterilized solution was then stored as $10 \mathrm{ml}$ aliquots in $17 \times 100 \mathrm{~mm}$ propylene plastic test tubes in a $-20^{\circ} \mathrm{C}$ freezer.

\section{APPENDIX 6: Preparation of Calcium and Magnesium-Free PBS}

$\begin{array}{ll}\mathrm{NaCl} & 0.8 \mathrm{~g} \\ \mathrm{KCl} & 0.03 \mathrm{~g} \\ \mathrm{Na}_{2} \mathrm{HPO}_{4} \cdot 7 \mathrm{H}_{2} \mathrm{O} & 0.0138 \mathrm{~g} \\ \mathrm{KH}_{2} \mathrm{PO}_{4} & 0.02 \mathrm{~g} \\ \mathrm{Glucose} & 0.2 \mathrm{~g} \\ \text { EDTA } & 0.038 \mathrm{~g} \\ \begin{array}{l}\text { Deionized } \\ \text { distilled water }\end{array} & 100 \mathrm{ml}\end{array}$

All the above ingredients are mixed into the deionized distilled water until dissolved. The solution is then filter sterilized using a Millipore peristaltic pump. The final solution is stored in the refrigerator at $5^{\circ} \mathrm{C}$.

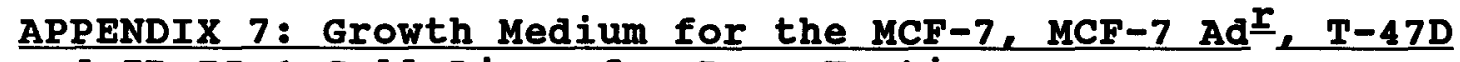
and ZR-75-1 Cell Lines for Drug Testing

F12/DME

$(1: 1)$

Hepes buffer $\quad 10 \mathrm{mM}$

FBS $5 \%$

Insulin $\quad 5 \mu \mathrm{g} / \mathrm{ml}$

APPENDIX 8: Growth Medium for the MDA-MB-231 and MDA-A1 Cell Lines for Drug Testing

F12/DME

Hepes buffer $10 \mathrm{mM}$

FBS $10 \%$

APPENDIX 9: Transport Medium

$\begin{array}{ll}\text { F12/DME } & (1: 1) \\ \text { Hepes buffer } & 10 \mathrm{mM} \\ \text { Bovine serum } & 5 \% \\ \text { Insulin } & 5 \mu \mathrm{g} / \mathrm{ml}\end{array}$




\section{APPENDIX 10: Freezing Medium}

$\begin{array}{ll}\text { DME } & 50 \% \\ \text { Bovine serum } & 44 \% \\ \text { Dimethylsulfoxide } & 6 \%\end{array}$

\section{APPENDIX 11: Dissociation Medium}

$\begin{array}{ll}\text { F12/DME } & (1: 1), 18 \mathrm{ml} / \mathrm{sample} \\ \text { Hepes buffer } & 10 \mathrm{mM} \\ \text { BSA } & 0.4 \mathrm{~g} / \mathrm{sample} \\ \text { Insulin } & 5 \mu \mathrm{g} / \mathrm{ml} \\ \text { Collagenase } & 300 \mathrm{U} / \mathrm{ml} \\ \text { Hyaluronidase } & 100 \mathrm{U} / \mathrm{ml}\end{array}$

APPENDIX 12: Growth Medium for Human Breast Epithelial Celis (Normal and Malignant) in Primary Culture

$\begin{array}{ll}\text { F12/DME } & (1: 1) \\ \text { Hepes buffer } & 10 \mathrm{mM} \\ \text { Insulin } & 5 \mu \mathrm{g} / \mathrm{ml} \\ \text { Patients' serum } & 5 \%\end{array}$

\section{APPENDIX 13: Preparation of Human Serum Samples}

Serum samples were collected in the mornings from patients who had fasted over the previous 8-12 h. Blood was received in nonheparinized tubes, incubated for $30 \mathrm{~min}$ at $37^{\circ} \mathrm{C}$, centrifuged at $100 \mathrm{x} \mathrm{g}$ and the serum was collected. If not used immediately, the serum was stored at $-20^{\circ} \mathrm{C}$.

\section{APPENDIX 14: Preparation of Rat Tail collagen}

The collagen solution was prepared by placing rat tails in 95\% ethanol for $15 \mathrm{~min}$. The tendons were dissected out, weighed and then submersed in sterile deionized water while under UV radiation in a laminar flow hood. The fibers were then submersed in a $0.01 \mathrm{~N}$ acetic acid solution and stirred for $48 \mathrm{~h}$ at $4^{\circ} \mathrm{C}$. Subsequently they were left in the acid solution at $4^{\circ} \mathrm{C}$ for $24 \mathrm{~h}$ with no stirring. The solution was then transferred into $50 \mathrm{ml}$ centrifuge tubes and centrifuged in a Sorvall unltracentrifuge for $30 \mathrm{~min}$ at $10000 \mathrm{x} \mathrm{g}$. The supernatant consisted of the collagen solution and was bottled and stored at $4^{\circ} \mathrm{C}$. 